UNIVERSIDADE DE SÃO PAULO

INSTITUTO DE ASTRONOMIA, GEOFÍSICA E CIÊNCIAS ATMOSFÉRICAS

DEPARTAMENTO DE GEOFÍSICA

Estudo Paleomagnético do Complexo Máfico- ultramáfico Rincón del Tigre - Sudeste da Bolívia, Cráton Amazônico

Oscar Andrés Lazcano Patroni

Orientador: Prof. Dr. Manoel Souza D’Agrella Filho 
Oscar Andrés Lazcano Patroni

\section{Estudo Paleomagnético do Complexo Máfico- ultramáfico Rincón del Tigre - Sudeste da Bolívia, Cráton Amazônico}

Dissertação de Mestrado apresentada ao Instituto de Astronomia, Geofísica e Ciências Atmosféricas da Universidade de São Paulo (IAG-USP), para a obtenção do título de Mestre em Geofísica.

Orientador: Prof. Dr. Manoel Souza D’Agrella Filho 
Dedicado aos meus pais e irmãos. 


\section{Agradecimentos}

Ao meu orientador Prof. Dr. Manoel Souza D’Agrella Filho pela paciência, dedicação e orientação cuidadosa, realizando várias vezes revisões de textos e, analises de dados, até em dias de final de semana e ocupando o período de férias, tudo para que este trabalho fosse concluído da melhor forma possível.

Ao Dr. Franklin Bispo dos Santos pelas sugestões, correções e paciência nas inúmeras dúvidas paleomagnéticas que foram geradas desde a preparação das amostras até a escrita deste trabalho.

Ao Professor Amarildo Salina Ruíz da Universidade Federal de Mato Grosso e ao Professor Ramiro Matos Salinas da Universidad Mayor de San Andrés (La Paz, Bolívia) na realização do trabalho de campo realizado no Complexo Rincón del Tigre, tendo em vistaas duras condições que tivemos que passar.

A fundação de Amparo à Pesquisa do Estado de São Paulo (FAPESP) pelo financiamento da Pesquisa (processo FAPESP 2011/50887-6) e a CAPES pela bolsa de mestrado.

Ao GEOCIAM (Instituto Nacional de Ciência e Tecnologia de Geociências da Amazônia).

Aos professores do Departamento de Geofísica do IAG/USP, pelas contribuições valiosas na minha formação acadêmica.

A Daniele Brandt amiga e técnica do Laboratório de Paleomagnetismo do IAG-USP nas inúmeras dúvidas geradas durante todo o estudo paleomagnético realizado.

Ao Dr. Vinícius Tieppo Meira na colaboração da análise petrográfica.

Aos meus amigos queridos Pablo Ibieta J., Jahiro Miranda C., Alessandra Brognára, Renata Constantino. Jorge Tapias S., Antonio C. Siqueira Neto, Cyntia Okida Minei, Petre Candelero Griscenco e Paul Antonio Yves. A presença de cada um de vocês marcou uma etapa memorável na minha vida.

A Ingrid Moerschberger Nedel pela ajuda dos termos, traduções e definições geológicas necessárias para a escrita deste trabalho. 
Ao pessoal do Departamento de Geofísica que realizou um trabalho impecável, Maria Perpetua "Teca", Virginia Teixeira e Eliza Ribeiro.

Finalmente, a minha família; meu pai Oscar, a minha mãe Rosemary e irmãos Saulo e Cecilia por toda a confiança, apoio, carinho e paciência em cada uma das minhas escolhas feitas até o lugar onde me encontro. A minha tia Patty pela acolhida em São Paulo. Sem o estimulo afetuoso de cada uma de suas palavras e atos eu não teria conseguido concluir esta Dissertação de Mestrado 


\section{Resumo}

Estudo Paleomagnético do Complexo Máfico- ultramáfico Rincón del Tigre - Sudeste da Bolívia, Cráton Amazônico.

Oscar Andrés Lazcano Patroni

Universidade de São Paulo

Orientador: Professor Dr. Manoel Souza D’Agrella Filho

Modelos de reconstruções paleogeográficas envolvendo o Cráton Amazônico para 1100 Ma são motivos de controvérsia devido à carência de dados paleomagnéticos de qualidade para esta unidade geotectônica. Com intuito de contribuir para o esclarecimento da participação do Cráton Amazônico na evolução do ciclo continental, este trabalho apresenta o estudo paleomagnético realizado para o Complexo Máficoultramáfico Rincón del Tigre localizado na região sudeste da Bolívia, sudoeste do Cráton Amazônico. Uma recente datação U-Pb em badeleítas forneceu idade de 1110,4 $\pm 1,8 \mathrm{Ma}$ para esta unidade. Para o estudo paleomagnético, 101 amostras cilíndricas orientadas foram coletadas de 15 sítios de composição litológica variada, compreendendo ultramáficas, ortopiroxenitos adcumuláticos, gabro noritos e serpentinitos. Um total de 359 espécimes cilíndricos de rocha de $2.2 \mathrm{~cm}$ de altura por $2.5 \mathrm{~cm}$ de diâmetro foi preparado para os tratamentos por campos magnéticos alternados (AF) e térmicos, assim como, para medidas de anisotropia de susceptibilidade magnética (ASM). As mesmas amostras foram preparadas para os experimentos de mineralogia magnética: curvas termomagnéticas, curvas de histerese e curvas de magnetização remanente isotérmica (MRI).

Os resultados obtidos a partir da análise de anisotropias de suscetibilidade magnética (ASM) indicam, para boa parte das amostras analisadas, trama magnética aproximadamente horizontal coerente com a colocação de sills e lineação magnética para NW/SE, a qual indica que estas rochas sofreram influência da tectônica de deformação de direção NE-SW que as afetou durante a orogênese Sunsás. O estudo da mineralogia magnética indica magnetita como principal portador magnético presente nas rochas analisadas. Os tratamentos por campos alternados e térmico foram eficientes para separar as componentes de magnetização através da análise vetorial, sendo que direções coerentes foram obtidas para boa parte dos espécimes analisados para cada sítio. Todavia, a mesma coerência não é observada para as direções médias por sítio. 
Assim, correções tectônicas foram efetuadas e para um grupo de sítios obteve-se um teste de dobra positivo, com direção média $\mathrm{Dm}=327,9^{\circ}, \mathrm{Im}=53,5^{\circ}\left(\alpha_{95}=13,1^{\circ}, \mathrm{K}=22,6\right.$, $\mathrm{N}=7$ ), a qual forneceu o polo paleomagnético situado em $271,7^{\circ} \mathrm{E}, 28,6^{\circ} \mathrm{N}\left(\mathrm{A}_{95}=17,6^{\circ}\right)$.

Supondo uma trama magnética horizontal $\left(\mathrm{k}_{3}=90^{\circ}\right)$ para os sills acamadados que constituem o Complexo Rincón del Tigre, a direção média (declinação e inclinação) do eixo k3 para cada sítio foi utilizada para corrigir as direções de magnetização para a situação de trama horizontal. Após a correção de ASM, outro grupo de sítios apresentou direções consistentes, cuja direção média $\mathrm{Dm}=118,6^{\circ}, \mathrm{Im}=20,7^{\circ}\left(\alpha_{95}=16,5^{\circ}, \mathrm{K}=12,2\right.$, $\mathrm{N}=8$ ) forneceu o polo paleomagnético situado em $28,5^{\circ} \mathrm{E}, 30,0^{\circ} \mathrm{S}\left(\mathrm{A}_{95}=12,8\right)$. Os parâmetros estatísticos foram também significativamente melhorados após a correção de ASM.

Com base nos dois polos determinados para o Complexo Rincón del Tigre e polos selecionados para o Cráton Amazônico e Laurentia são propostas paleogeografias para $1265 \mathrm{Ma}, 1200 \mathrm{Ma}, 1150 \mathrm{Ma}, 1100 \mathrm{Ma}$ e $1000 \mathrm{Ma}$ que apoiam o modelo que propõe a ruptura do supercontinente Columbia, por volta de $1270 \mathrm{Ma}$ atrás, e o posterior movimento de rotação horária do Cráton Amazônico/Oeste-África e da Báltica até estes blocos cratônicos colidirem novamente há 1000 Ma atrás com a Laurentia, ao longo do cinturão Grenville, para formar o supercontinente Rodínia. 


\section{Abstract \\ Paleomagnetic Study of the Rincón del Tigre Mafic- ultramafic Complex - Southeastern Bolivian, Amazonian Craton \\ Oscar Andrés Lazcano Patroni \\ University of São Paulo}

Advisor: Prof. Dr. Manoel Souza D’Agrella Filho

Paleogeographic reconstructions at $1100 \mathrm{Ma}$ involving the Amazonian Craton are controversial due to the absence of key paleomagnetic poles for this geotectonic unit. Trying to elucidate the participation of the Amazonian Craton in the continental cycle, this work present a paleomagnetic study of the Rincón del Tigre mafic-ultramafic complex from southeast Bolivia, southwestern Amazonian Craton. A recent U-Pb dating on baddeleyites of a rock from this complex yielded an age of $1110.4 \pm 1.8 \mathrm{Ma}$ for this unit. For the paleomagnetic study, 101 cylindrical cores were sampled from 15 sites with variable lothologies, comprising ultramafics, adacumulatic orthopyroxenites, gabbro norites and serpentinites. A total of 359 cylindrical specimens $(2.5 \mathrm{~cm}$ diameter $\mathrm{x} 2.2 \mathrm{~cm}$ height) were prepared for the $\mathrm{AF}$ and thermal treatments, and for the anisotropy of magnetic susceptibility (AMS) measurements. The same samples were prepared for magnetic experiments: thermomagnetic curves, hysteresis curves and isothermal remanent magnetization (IRM) curves.

The ASM results indicate nearly horizontal magnetic fabric for many of the analyzed sites, which agrees with that originated by sill's emplacement, and a NW/SE magnetic lineation, which suggests that these rocks were tectonically affected by the Sunsás orogen.

The magnetic mineralogy studies indicate magnetite as the main magnetic carrier in the rocks. The AF and thermal treatments were effective in isolating magnetic components through vector analysis, and coherent magnetic directions were disclosed for much of the specimens from each site. However, the same consistency was not observed for the between-site directions. Tectonic corrections were applied for the site mean directions, which yielded a positive fold test for a group of sites: mean direction $\mathrm{Dm}=327.9^{\circ}$, 
$\operatorname{Im}=53.5^{\circ}\left(\alpha_{95}=13.1^{\circ}, \mathrm{K}=22.6, \mathrm{~N}=7\right)$, which yielded the paleomagnetic pole at $271.7^{\circ} \mathrm{E}$, $28.6^{\circ} \mathrm{N}\left(\mathrm{A}_{95}=17.6^{\circ}\right)$.

Supposing an horizontal magnetic fabric $\left(\mathrm{k}_{3}=90^{\circ}\right)$ for the layered sills that originally formed the Rincón del Tigre Complex, the mean direction (declination and inclination) of the $\mathrm{k}_{3}$ axis calculated for each site, was used to correct site mean magnetization directions for the situation of horizontal magnetic fabric. After ASM correction, another group of sites yielded consistent directions, whose mean direction $\mathrm{Dm}=118.6^{\circ}$, $\mathrm{Im}=20.7^{\circ}\left(\alpha_{95}=16.5^{\circ}, \mathrm{K}=12.2, \mathrm{~N}=8\right)$ yielded the paleomagnetic pole at $28.5^{\circ} \mathrm{E}, 30.0^{\circ} \mathrm{S}$ $\left(\mathrm{A}_{95}=12.8\right)$. Statistical parameters were also greatly improved after ASM corrections.

Paleogeographies at $1265 \mathrm{Ma}, 1200 \mathrm{Ma}, 1150 \mathrm{Ma}, 1100 \mathrm{Ma}$ and $1000 \mathrm{Ma}$ were constructed based on the Rincón del Tigre poles and other selected poles from the Amazonian Craton and Laurentia, which support the model where soon after Columbia rupture at around $1270 \mathrm{Ma}$, the Amazonian Craton/West Africa and Baltica executed clockwise rotations until they collide again at 1000 Ma with Laurentia, along the Grenvillian belt, forming Rodinia supercontinent. 


\section{Lista de Figuras}

2.1 Estrutura da América do Sul com ênfase no Cráton Amazônico e suas províncias tectônicas. Cráton São Francisco, Cráton São Luís e fragmentos tectônicos Luiz Alves, asím como o Neoproterozoico Brasiliano-Pan Africano são mostrados na parte oriental da figura. Províncias geocronológicas: ACAmazônia Central; MI- Marini-Itacaiúnas; VT- Ventuari-Tapajós; RNJ- Rio Negro-Juruena; RSI- Rondoniano-San Ignacio[extraído de Cordani et al., 2008].

2.2 Estrutura crustal geológica-tectônica do sudoeste do Cráton Amazônico mostrando a zona de estudo: Complexo Rincón del Tigre RT. As frentes tectônicas que delineiam o limite norte entre o cinturão colisional (província Sunsás-Aguapeí) Sunsás com a província Rondoniano-San Ignacio (Complexo Granitóide Pensamiento - PGC) também são mostrados. Unidades geológicas atribuídas à província Sunsás-Aguapeí: As sequências metasedimentares Vibosí e Sunsás, o cinturão supracrustal Nova Brasilândia e o aulacógeno Aguapeí; Comberturas de plataforma (por exemplo, Huanchaca, Aguapeí, Pacaás Novos); Suites graníticas: $\mathrm{scl}=$ Santa Clara $(1,08-1,07 \mathrm{Ga}) ; \mathrm{sg}=$ granitos Sunsás $(1,13-1,00 \mathrm{Ga})$; rp = Rio Pardo $(1,05 \mathrm{Ga})$; rtp = Província Rondônia Tin $(0,99-0,97 \mathrm{Ga})$; rp = Rio Pardo $(1,05 \mathrm{Ga})$. Provínciast tectônicas (inserção): $\mathrm{CA}=$ Amazônia Central (> 2,6 Ga); $\mathrm{MI}=$ MaroniItaicaiúnas (2,25-2,05 Ga); VT = Ventuarí-Tapajós (2,00-1,81 Ga), RNJ = Rio Negro-Juruena (1,80-1,60 Ga), RSI = Rondoniano-San Ignacio (1,56-1,30 Ga), SA = Sunsás-Aguapeí (1,20-0,97 Ga). (Modificado de Teixeira et al, 2015).

2.3 Mapa geológico da área de estudo do Complexo Rincón del Tigre (modificado de Teixeira et al., 2015). Os sítios de amostragem são mostrados na figura através de círculos cheios

3.1 Esquema de amostragem paleomagnética. Diversos sítios de amostragem são coletados dentro uma unidade rochosa; várias amostras são coletadas de cada sítio; espécimes são preparados para serem medidos no laboratório a partir das amostras [Extraído de Paleomagnetism: Magnetic Domains to Geologic Terranes; R. Butler, 1992]

3.2 Esquema de amostragem paleomagnética. Diversos sítios de amostragem são coletados dentro de uma unidade [Eric Font, tese de doutorado 2005]

3.3 Anisotropia de susceptibilidade magnética representada por um elipsoide triaxial com os eixos $\mathrm{k} 1 \geq \mathrm{k} 2 \geq \mathrm{k} 3$ [Extraído de The Earth's Magnetism; R. Lanza and A. Meloni, 2006]

3.4 Parâmetro de forma $T$. Parâmetro de forma $T$ em função da lineação magnética $(\mathrm{L})$ e foliação magnética $(\mathrm{F})$. As setas indicam o incremento no grau de anisotropia (P) [Extraído de The Earth's Magnetism; R. Lanza and A. Meloni, 2006]

3.5 Projeção de igual área das direções principais de susceptibilidade em vários tipos de trama magnética. Os símbolos representam os seguintes eixos: quadrado $=\mathrm{k} 1$; triângulo $=\mathrm{k} 2$; ponto $=\mathrm{k} 3$; círculo máximo $=$ foliação magnética; (a) eixos k3 bem agrupados, foliação bem desenvolvida: a fábrica é planar; (b) eixos k1 bem agrupados, lineação bem desenvolvida: a trama é linear; (c) todos os eixos bem agrupados, tanto foliação quanto lineação bem desenvolvidas. [Extraído de The Earth's Magnetism; R. Lanza and A. Meloni, 2006]

3.6 Esquema do processo de aplicação do campo magnético alternado. A intensidade do campo magnético aplicado aumenta linearmente com o tempo até atingir um patamar de curta duração (Hpeak)(seção marrom da figura). 
Após a estabilidade na intensidade máxima, o valor do campo começa a decair linearmente até atingir o valor nulo. [Extraído de The Earth's Magnetism; R. Lanza and A. Meloni, 2006]

3.7 (a) Representação do vetor na esfera de raio unitário e sua projeção no plano equatorial, (b) projeção estereográfica (plano equatorial da esfera) [Extraído de Bispo-Santos (2012).

3.8 Diagrama vetorial de Zijderveld para analisar desmagnetização AF ou térmica. (a) Diagrama mostrando as projeções da ponta do vetor magnetização em três planos ortogonais após cada etapa de desmagnetização (planos horizontal, vertical N-S e vertical E-W). (b) Etapas de desmagnetização obtidas por desmagnetização térmica para uma amostra de calcário da região de Gubbio, Itália. As componentes de magnetização sem sobreposição no espectro de temperatura de bloqueio mostram-se como segmentos lineares. [Extraído de Fundamentals of Geophysics; W. Lowrie, 2007]

3.9 Espectros de coercividades e/ou temperaturas de bloqueio de duas componentes de magnetização e representação estereográfica e diagramas de Zijderveld para as seguintes situações: (a) espectro não superposto (comportamento ideal de Zijderveld), (b) superposição parcial, e (c) superposição total (comportamento não ideal). Em (a) e (b), ambas as direções podem ser determinadas; em (c), nenhuma pode ser determinada. [Extraído de On the use of Zijderveld vector diagrams in multicomponent paleomagnetic studies; D. Dunlop, 1979]

3.10 Comportamento de curvas termomagnéticas. (a) A curva termomagnética descreve duas trajetórias, uma no aquecimento e outra no resfriamento. Este comportamento caracteriza uma curva irreversível. A curva mostra a presença de titanomagnetita pouco oxidada com temperatura de Curie próxima de 220 ${ }^{\circ} \mathrm{C}$. (b) Para o segundo caso, a curva representa o comportamento reversível. A curva termomagnética é característica de titanomagnetita pobre em titânio e rica em ferro. A temperatura de Curie está em torno de $570{ }^{\circ} \mathrm{C}$. [Modificado de Carvallo et al, 2004]

3.11 Histerese Magnética. Os domínios magnéticos têm comportamento concordante com o campo magnético $\mathrm{H}$, inicialmente crescendo nos domínios em que a magnetização tem a direção mais próxima de $\mathrm{H}$ e logo depois rotacionando no sentido do campo aplicado. [Modificado de R. Lanza and Meloni, 2006]

3.12 Ciclo de Histerese Magnética. Ciclo de histerese magnética para um mineral ferromagnético arbitrário. [Modificado de Fundamentals of Geophysics; W. Lowrie, 2007]

3.13 (a) Diagrama de Day et al. (1977) modificado por D. Dunlop (2002) evidenciando os diferentes domínios magnéticos presentes nas rochas: SD domínio simples; PSD - pseudo-domínio simples; MD - multi-domínios; curvas SD-MD indicam misturas de grãos SD e MD com diferentes porcentagens (indicadas na figura) de grãos MD; curvas SP-SD indicam misturas de grãos SD e SP com diferentes porcentagens (indicadas na figura) de grãos SP de $10 \mathrm{~nm}, 15 \mathrm{~nm}, 20 \mathrm{~nm}, 25 \mathrm{~nm}$ e $30 \mathrm{~nm}$, respectivamente.

3.14 Ciclos de histerese magnética com comportamentos diferentes: (a) diamagnético, (a) paramagnético, (c) superparamagnético (e.g., vidro submarino basáltico), (d) uniaxial, monodomínio, (e) magnetocristalino, domínio simples, (f) pseudo-domínio simples. [Extraído de Essentials of Rock and Paleomagnetism ; L. Tauxe, 2008].

3.15 Exemplos de curvas de MRI obtidas para amostras de calcário do Cretácio (a) e do Jurássico (b). Em (a) a rocha apresenta magnetita e hematita e em (b) a rocha apresenta pirrotita e hematita [extraído de Lowrie, 1997].

3.16 (a) Representação de cinco direções de magnetização como vetores 
unitários. (b) A direção do vetor médio é a direção do vetor resultante R. (c) Estereograma mostrando diferentes distribuições de direções paleomagnéticas: quanto maior o agrupamento das direções, maior o valor do parâmetro de precisão k [Modificado de Fundamentals of Geophysics; W. Lowrie, 2007].

3.17 Representação de dipolo geocêntrico e axial. O momento de dipolo $\mathrm{M}$ achase localizado no centro da Terra e alinhado com o eixo de rotação; $\lambda$ é a latitude; rT é o rádio da Terra; as direções do campo magnético produzido na superfície estão mostrados esquematicamente: $\mathrm{H}$ representa o campo produzido pelo dipolo, I (inclinação) é mostrada para uma localização; N é o polo norte geográfico. [Modificado de Paleomagnetism: Magnetic Domains to Geologic Terranes; R. Butler, 1992]

3.18 Localização do polo paleomagnético a partir da direção média do campo geomagnético registrado pelas rochas. A localização média dos sítios amostrados é representada por $\mathrm{S}(\lambda \mathrm{s}, \varphi s)$; direção média do campo geomagnético Dm, Im; M é o dipolo geocêntrico que pode ser responsável pela direção do campo geomagnético observado; $\mathrm{P}$ é a localização do polo paleomagnético com coordenadas $(\lambda \mathrm{p}, \varphi \mathrm{p}) ; \mathrm{p}$ é a colatitude magnética; $\mathrm{O}$ Polo Norte é o norte geográfico; $\beta$ é a diferença angular entre os meridianos que passam pelo polo magnético (P) e pelo sítio (S). [Extraído de Paleomagnetism: Magnetic Domains to Geologic Terranes; R. Butler, 1992]

3.19 Elipse de confiança em torno do polo: p é a colatitude magnética; dp é o semi-eixo da elipse de confiança ao longo do círculo máximo que passa pelo sítio amostrado e pelo polo; dm é o semi-eixo da elipse de confiança perpendicular ao círculo máximo descrito acima. [Extraido de Paleomagnetism: Magnetic Domains to Geologic Terranes; R. Butler, 1992].

3.20 Representação esquemática da técnica paleomagnética para realizar reconstruções paleogeográficas. A e B são blocos continentais hipotéticos plotados a partir dos respectivos dados de paleolatitude e paleoorientação, com base nos respectivos polos paleomagnéticos. As posições de a a d indicam possíveis posições do continente B no hemisfério norte; de modo análogo, as posições de e a $\mathrm{h}$ indicam possíveis posições do continente $\mathrm{B}$ no hemisfério sul. Estas ambigüidades nas localizações dos blocos continentais resultam das indefinições na paleolongitude e na polaridade do pólo, a qual é desconhecida para épocas mais antigas. [Extraído de Pesonen et al., 2003]

3.21 Exemplo de construção de uma curva de deriva polar aparente para um bloco continental. (a) com polos médios calculados para intervalos de tempo préestabelecidos. (b) para polos paleomangnéticos de alta confiabilidade (polos de referência). [Modificado de L. Tauxe, 2008]

4.1 (a) Grau de anisotropia $(\mathrm{P})$ contra suscetibilidade média $(\mathrm{Km})$ por amostra; (b) parâmetro de Jelinek (T) contra grau de anisotropia (P) por amostra.

4.2 Estereogramas mostrando as direções dos eixos de suscetibilidade magnética (máxima (k1), intermediária (k2) e mínima (k3)) para cada sítio analisado, relacionado a sua posição geográfica indicado no mapa geológico.

4.3 (a) Curvas de desmagnetização por campos magnéticos alternados para amostras diferentes apresentam diferentes comportamentos na coercividade. (b) Curvas de intensidade de desmagnetização térmica.

4.4 Curvas termomagnéticas (susceptibilidade (SI) contra temperatura $\mathrm{T}\left[{ }^{\circ} \mathrm{C}\right]$ ) para amostras de rochas máficas do Complexo Rincón del Tigre. As setas com direção à direita e à esquerda indicam o processo de aquecimento e resfriamento, respectivamente.

4.5 Curvas de histerese para distintas amostras analisadas do Complexo Rincón del Tigre. Os resultados obtidos para as amostras apresentam cintura fina e saturação em torno de $300 \mathrm{mT}$. 
4.6 Curva de histerese para a amostra OL15C. A pequena quantidade de mineral ferromagnético é mascarada pela maior presença de minerais paramagnéticos presentes na amostra.

4.7 Diagrama de Day (Day et al., 1977, modificado por Dunlop, 2002a) indicando a estrutura de domínios magnéticos das amostras analisadas do Complexo Rincón del Tigre. A Figura mostra as curvas teóricas propostas por Dunlop (2002a) que indicam misturas de grãos de domínio simples com diferentes porcentagens de grãos multi-domínios (curvas SD-MD) e de misturas de grãos de domínio simples com diferentes porcentagens de grão superparamagnéticos com tamanhos de $10 \mathrm{~nm}$ (curva SP-SD). Os círculos indicam amostras analisadas.

4.8 Exemplos de curvas de aquisição da magnetização remanente isotérmica (MRI) obtidas para rochas do Complexo Rincón del Tigre.

4.9 Projeção estereográfica das direções médias por sítio. Símbolos cheios (vazios) representam direções com inclinação positiva (negativa).

4.10 Exemplos de desmagnetização de amostras que apresentaram direções Leste (oeste) com inclinações baixas. São mostradas para cada amostra, da esquerda para a direita, a projeção estereográfica, a curva de intensidade normalizada (M/Mmax versus campo alternado ou temperatura) e as projeções ortogonais (Zijderveld).

4.11 Exemplos de desmagnetização de amostras que apresentaram direções norte (sul) com inclinações positivas (negativas. São mostradas para cada amostra, da esquerda para a direita, a projeção estereográfica, a curva de intensidade normalizada (M/Mmax versus campo alternado ou temperatura) e as projeções ortogonais (Zijderveld).

5.1 Direções médias por sítio: (a) sem correção tectônica; (b) com correção tectônica. Símbolos cheios (vazios) representam direções com inclinação positiva (negativa).

5.2 Direções médias dos sítios OL3, OL4, OL7, OL8, OL9, OL11, OL12: (a) sem correção tectônica, (b) invertendo as direções com inclinações negativas - 0 símbolo + indica a direção média com o respectivo círculo de confiança $\left(\alpha 95=17,2^{\circ}\right)$, (c) após correção tectônica, (d) invertendo as direções com inclinações negativas - o símbolo + indica a direção média com o respectivo círculo de confiança $\left(\alpha 95=13,1^{\circ}\right)$.

5.3 Direções médias por sítio: (a) sem correção de ASM; (b) com correção de ASM. Símbolos cheios (vazios) representam direções com inclinação positiva (negativa).

5.4 Direções médias dos sítios OL1, OL3, OL4, OL10, OL11, OL13, OL14, OL15: (a) sem correção de ASM, (b) invertendo as direções com inclinações negativas - o símbolo + indica a direção média com o respectivo círculo de confiança $\left(\alpha 95=17,2^{\circ}\right)$, (c) após correção tectônica, (d) invertendo as direções com inclinações negativas - o símbolo + indica a direção média com o respectivo círculo de confiança $\left(\alpha 95=13,1^{\circ}\right)$.

5.5 Configuração do núcleo do Columbia proposto por Bispo-Santos et al. (2014a). Cinturões orogênicos Paleoproterozoicos e áreas Arqueanas (cor cinza): Laurentia ( $\mathrm{S}$ - Slave; C - Churchill; SU - Superior; N - Nain, NQ New Quebec; T - Tornget; W - Wopmay; P - Penokean; K - Kefilidian; NA - Nagssugtoqidian; FR - Foxe-Rinklan), Báltica (KO - Kola; KA - Karelia, LK - Lapland-Kola; SD - Svecofennian Domain; G - Gothian Province), Amazonia (CA - Amazonia Central, MI - Maroni-Itacaiunas; VT - VentuariTapajos; RNJ - Rio Negro-Juruena, GU - lineamento Guri) e Cráton Oeste África (LS - Leo Shield, KD - Domínio Kenemanan; RB - Requibat Shield, SSA - lineamento Sassandra) e Cráton Norte da China (YB - bloco Yinshan; OB - bloco Ordos; WB - bloco West; EB - bloco East, NH - cinturão North Hebei/Khondolite; TNC - cinturão Trans-North China; JLJ - cinturão Jiao- 
Liao-Ji).

5.6 Interação dinâmica entre o Cráton Amazônico a e a Laurentia ente 1200 e 980

Ma com base em dados paleomagnéticos (modificado de Elming et al. 2009).

Posição do Cráton Amazônico relativo à Laurentia (América do Norte na posição atual) são mostrados para $1200 \mathrm{Ma}$ (baseado no polo Nova Floresta Tohver et al. 2002), para $1150 \mathrm{Ma}$ (baseado no polo Formação Fortuna D'Agrella-Filho et al. 2008) e para $980 \mathrm{Ma}$ (baseado no polo Salto do Céu (sills da região de Rio Branco - Elming et al. 2009).

5.7 Modelo proposto por Evans (2013) para a ruptura do Columbia e aglutinação do Rodinia envolvendo a Laurentia, a Baltica e o Cráton Amazônico. Após a ruptura do Columbia, a Baltica e o Cráton Amazônico executam um movimento de rotação horária até colidirem novamente com a Laurentia.

5.8 Reconstruções paleogeográficas para a Laurentia, Baltica e Cráton Amazônico/Oeste-África em 1265 Ma, 1200 Ma, 1150 Ma, 1100 Ma e 1000 Ma. As quatro primeiras reconstruções foram feitas utilizando os polos da Tabela 5.1. A reconstrução há 1000 Ma foi feita utilizando os polos de rotação apresentadas em Li et al. (2008). Utilizou-se o polo de Rincón del Tigre obtido após correção de ASM para posicionar o Cráton Amazônico/Oeste-África em 1100 Ma.

5.9 Reconstruções paleogeográficas para a Laurentia, Baltica e Cráton Amazônico/Oeste-África em $1150 \mathrm{Ma}, 1100 \mathrm{Ma}$ e $1000 \mathrm{Ma}$. As duas primeiras reconstruções foram feitas utilizando os polos da Tabela 5.1. A reconstrução há 1000 Ma foi feita utilizando os polos rotação apresentadas em Li et al. (2008). Utilizou-se o polo de Rincón del Tigre obtido após correção tectônica para posicionar o Cráton Amazônico/Oeste-África há 1100 Ma. 


\section{Lista de Tabelas}

Tabela 2.1 Número do sítio, localização, identificação e litologia da amostragem 29 paleomagnética para o Complexo Rincón del Tigre.

Tabela 4.1 Parâmetros obtidos de curvas de histerese 83

Tabela 4.2 Dados paleomagnéticos de Rincón del Tigre 87

Tabela 5.1 Uso da correção tectônica para corrigir direções. 92

Tabela 5.2 Uso da ASM para corrigir direções, assumindo uma trama original 97 horizontal $\left(\mathrm{k}_{3}=90^{\circ}\right)$.

Tabela 5.3 Polos paleomagnéticos selecionados para o Cráton Amazônico e Laurentia 104 no intervalo entre 1270 e 1100 Ma. 


\section{Conteúdo}

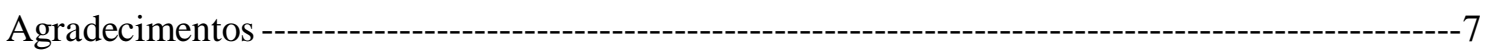

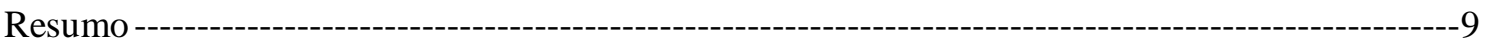

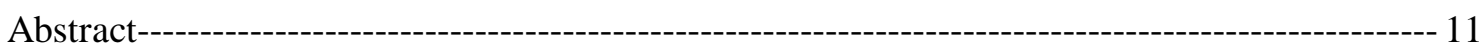

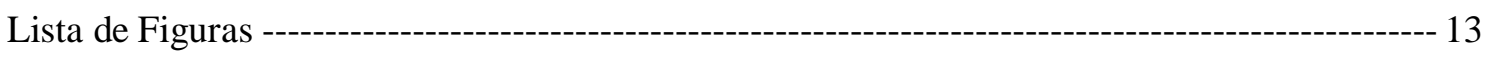

Lista de Tabelas ----- 19

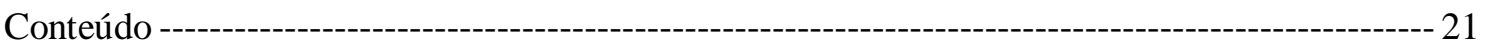

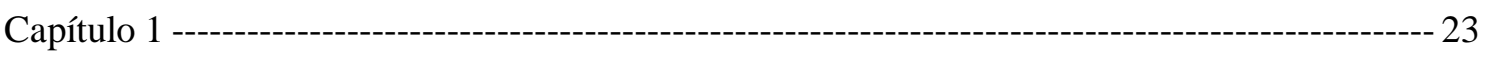

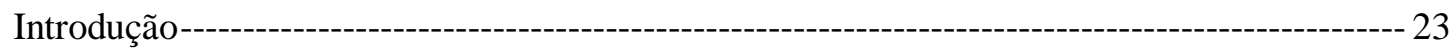

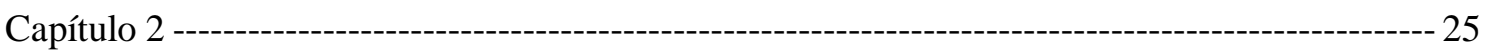

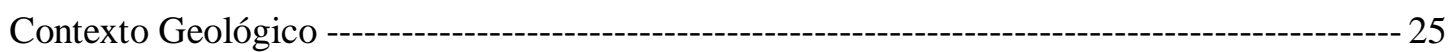

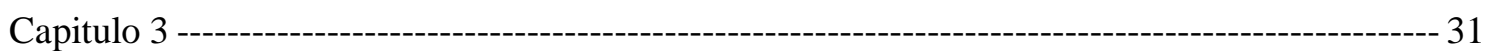

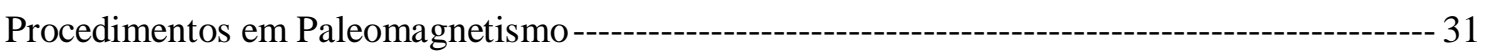

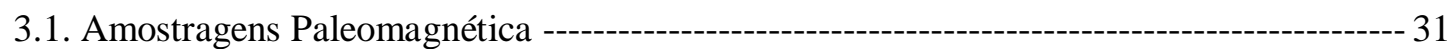

3.2 Anisotropias de Susceptibilidade Magnética (ASM) --- 36

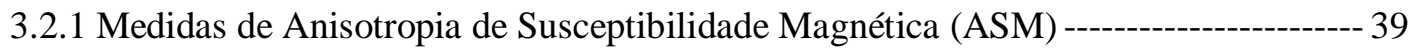

3.4 Magnetização Remanente nas Rochas ---_--- 42

3.4.1. Magnetização Termo-remanente (MTR) ----------------------------------------- 42

3.4.2 Magnetização Remanente Química (MRQ) ------- 44

3.4.3. Magnetização Remanente Viscosa (MRV) ----- 44

3.5 Processos de Desmagnetização --- 45

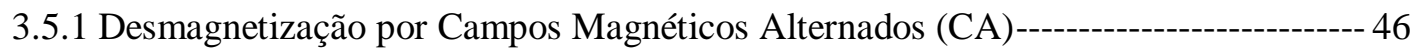

3.5.2 Desmagnetização Térmica ------- 48

3.6 Análise das Componentes de Magnetização ------------------------------------------- 49

3.7 Estudo da Mineralogia Magnética----_- 53

3.7.1 Identificação dos Minerais "Ferromagnéticos" --- 53

3.7.1.1 Curvas Termomagnéticas ------------------------------------------------- 53

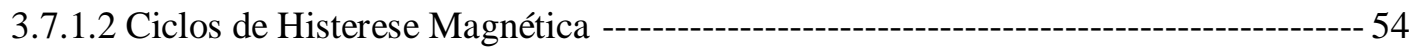

3.7.1.3. Curvas de Magnetização Remanente Isotérmica(MRI) -------------------------- 60

3.8. Análise Estatística de Direções Paleomagnéticas ----------------------------------------- 61

3.9. Modelo de Dipolo Geocêntrico Axial ---

3.10. Polo Paleomagnético ------------------------ 66

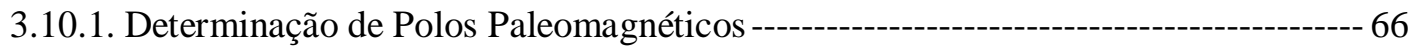

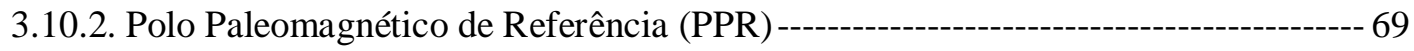

3.10.3. Testes de campo.--- 72 


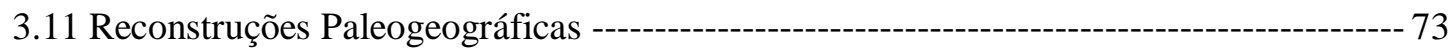

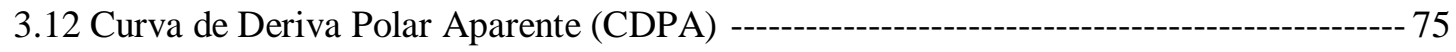

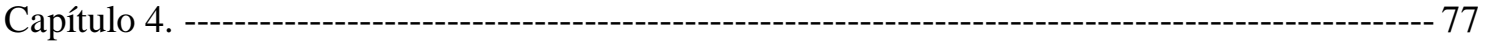

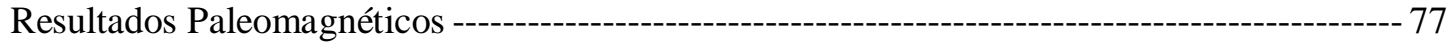

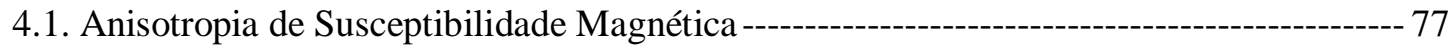

4.2. Mineralogia Magnética ---------------------------------------------------------- 79

4.2.1. Tratamentos por Campos Alternados (CA) e Térmicos--------------------------------- 79

4.2.2. Curvas Termomagnéticas --- 80

4.2.3. Curvas de Histerese Magnética ---------------------------------------------------- 82

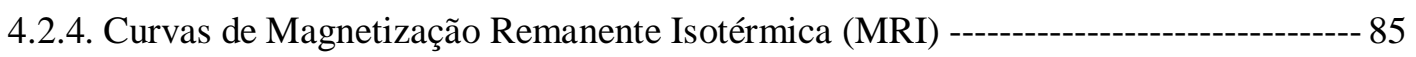

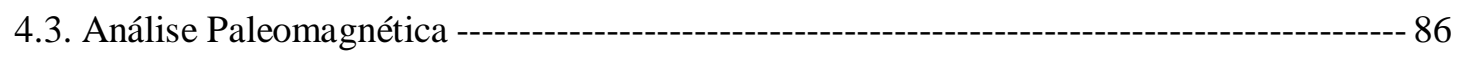

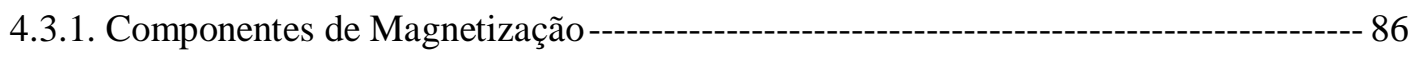

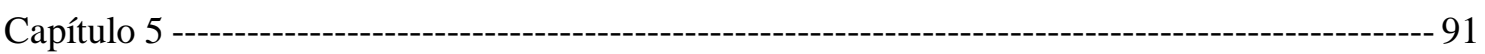

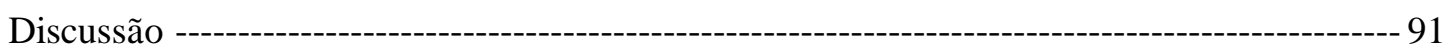

5.1. Paleogeografia do Cráton Amazônico no Columbia. --

5.2. Paleogeografia do Cráton Amazônico - do Columbia ao Rodinia.----------------------101

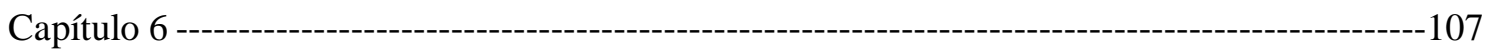

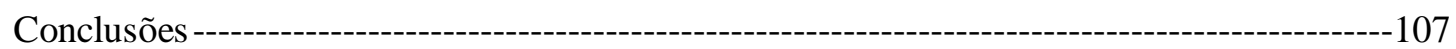

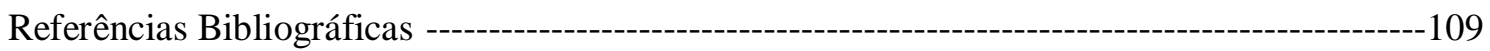




\section{Capítulo 1}

\section{Introdução}

As reconstruções paleogeográficas são essenciais para a compreensão do ciclo continental no passado geológico. O Cráton Amazônico representa uma das maiores áreas cratônicas do planeta e teve participação importante na formação do supercontinente Meso-Neoproterozoico Rodinia. Segundo modelos geológicos, durante a formação do Rodinia, o Cráton Amazônico colidiu com a Laurentia ao longo dos cinturões Sunsás e Grenville, respectivamente. Basicamente, dois modelos de colisão distintos têm sido propostos (Evans, 2013): o primeiro sugere uma colisão obliqua do Cráton Amazônico ao longo do cinturão Lhano (no Texas), há 1.200 Ma atrás, seguido de movimento transcorrente até a sua posição final na região do Labrador, há cerca de 1.070-1.000 Ma, quando colide com o continente Báltico (Tohver et al., 2004a, Elming et al., 2009, Ibanez-Mejia et al., 2011). Um segundo modelo propõe uma colisão frontal do Cráton Amazônico ao longo do cinturão Grenville (região do Labrador) (Li et al., 2008, Evans, 2013). Segundo este modelo (Evans, 2013), após a ruptura do núcleo do supercontinente Columbia (formado por Laurentia, Báltica, Cráton Amazônico/Oeste África) há aproximadamente 1.270 Ma, o bloco Amazônia/Oeste-África executou movimento de rotação no sentido horário até o choque final com a Laurentia, há cerca

de 1.000 Ma. Deste modo, a obtenção de pólos paleomagnéticos bem datados para o Cráton Amazônico para o intervalo entre 1.200 e 1.000 Ma torna-se crucial para definir qual foi a cinemática desta unidade cratônica durante esta época importante da história da Terra. Rochas máficas e ultramáficas aflorantes no leste-sudeste da Bolívia (parte ocidental/meridional do Cráton Amazônico), formam o Complexo Ígneo Rincón del Tigre. Estas rochas foram recentemente datadas pelo método U-Pb (Badeleíta) em $1.110,4 \pm 1,8 \mathrm{Ma}$ (Teixeira et al., 2015) o que as tornam um alvo importante para o estudo paleomagnético visando a elucidação da evolução geodinâmica deste cráton na formação do supercontinente Rodinia. 


\section{Capítulo 2}

\section{Contexto Geológico}

O Cráton Amazônico é uma das maiores áreas cratônicas do mundo, com cerca de $4.300 .000 \mathrm{~km}^{2}$ (Figura 2.1). Ele está exposto em duas grandes áreas, as quais formam o Escudo das Guianas ao norte e o Escudo do Brasil Central (também conhecido como Escudo Guaporé) ao sul, interposta pela Bacia Amazônica (Lacerda Filho et al., 2004; Schobbenhaus et al., 1984, 2004; Santos et al., 2000). O Escudo das Guianas consiste em dois núcleos Arqueanos (Província Amazônia Central: > 2600 Ma, AC in Figura 2.1), cuja colisão originou a Província Paleoproterozóica Maroni-Itacaiúnas (Tassinari \& Macambira, 1999, 2004; Tassinari et al., 2000). A parte sudoeste deste núcleo Arqueano foi acrescida por arcos magmáticos juvenis relacionados a processos de subducção, os quais formaram as Províncias Ventuari-Tapajós (1980-1810 Ma) e Rio Negro Juruena (1780-1600 Ma) (Tassinari et al., 2000; Pinho et al., 2003; Schobbenhaus and BritoNeves, 2003; Cordani \& Teixeira, 2007).

Durante o Mesoproterozóico, arcos magmáticos relacionados a processos de subducção foram desenvolvidos entre 1600 Ma e 1300 Ma (e.g., Terreno Jauru no Estado do Mato Grosso), os quais originaram a Província Rondoniano-San Ignacio, até a colisão final do Terreno Paraguá, há cerca de 1320 Ma atrás (Bettencourt et al., 2010). Este modelo colisional foi recentemente estendido para o noroeste do estado de Rondônia, com o reconhecimento do ofiolito Trincheira (Rizzotto \& Hartmann, 2012, Rizzotto et al., 2013). Estes autores interpretam estas rochas como representando o registro de crosta oceânica associada à colisão do Terreno Paraguá com o proto-Cráton Amazônico ao longo do Cinturão Alto Guaporé, durante o Mesoproterozóico. Neste cenário, o Cinturão Nova Brasilândia (CNB) (de direção E-W e de idade 1100-1000 Ma) localizado a norte do Terreno Paraguá, o qual foi previamente interpretado por Tohver et al., (2004a) como decorrente da colisão entre o Terreno Paraguá (o qual se estenderia para a área do Estado do Mato Grosso (Brasil), ao sul do CNB, segundo estes autores) e o proto-Cráton Amazônico (a norte do CNB), no final do Mesoproterozóico, muito provavelmente, representa reativações intracratônicas que ocorreram durante $o$ desenvolvimento do Cinturão Sunsás (1200-950 Ma), localizado na borda sudoeste do Cráton Amazônico, já em domínio Boliviano (Litherland et al., 1989, Teixeira et al., 2010, Cordani et al., 2010, Boger et al., 2005, Santos et al., 2008). Pólos paleomagnéticos similares obtidos para o enxame de diques Novos Guarita e para a 
Intrusiva Indiavaí, com idades de aproximadamente 1420 Ma, cujas áreas estão situadas em lados opostos ao CNB, corroboram esta interpretação (D’Agrella-Filho et al., 2012). A área a ser investigada encontra-se em território Boliviano. Do ponto de vista tectônico, ela está inserida no Terreno Paraguá (como definido por Litherlandet al., 1986), no limite da fronte tectônica Rio Negro-Santa Catalina que separa este terreno do cinturão Sunsás (Figura 2). Ao norte deste limite, encontramos o Complexo Granítico Pensamiento, formado por granitos sin- a pós-tectônicos, com idades entre 1390 e 1310 Ma (Litherlandet al., 1989, Boger et al., 2005).

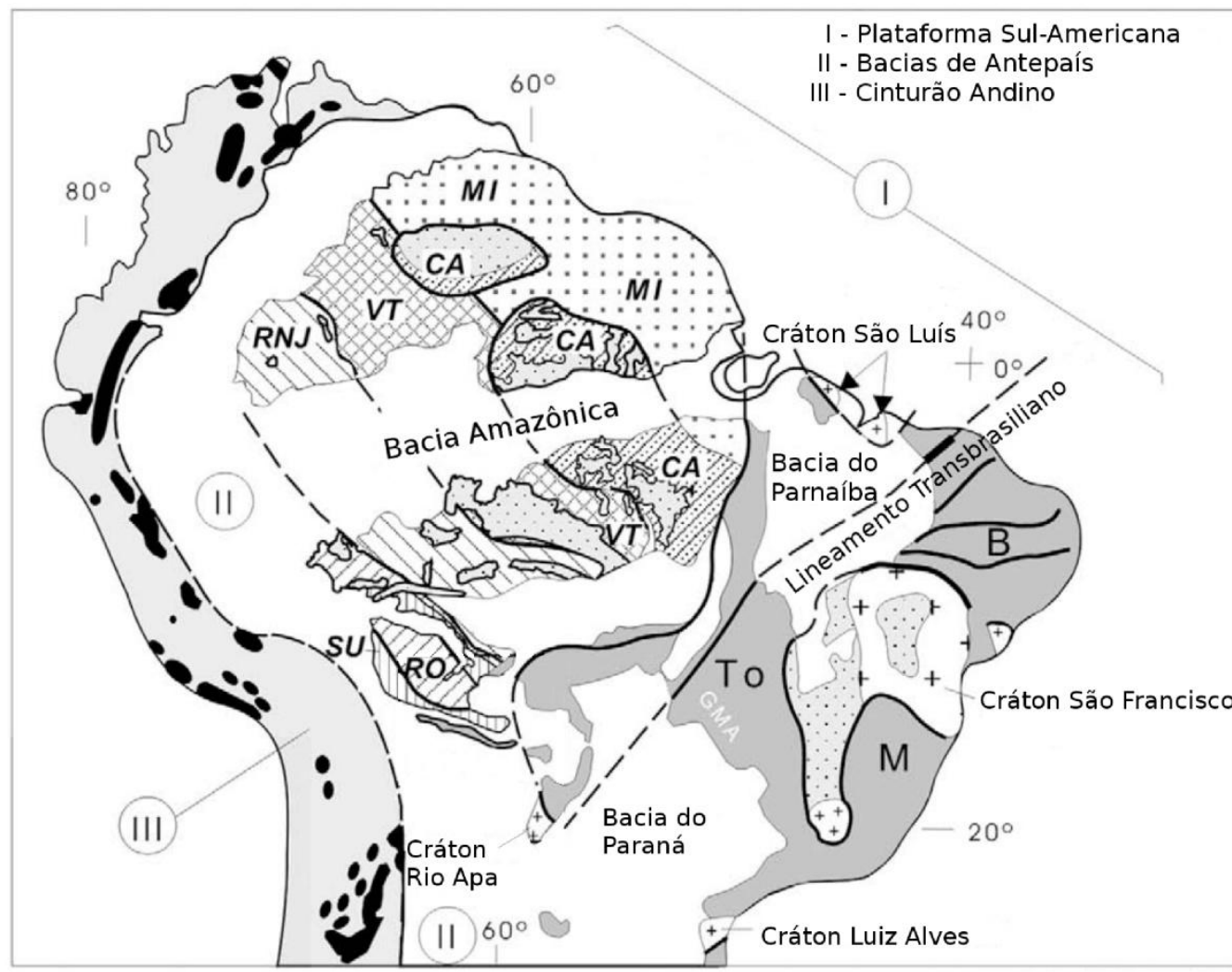

\section{Cráton Amazônico}

CA Provincia Amazônia CA\% Central

MI:
Provincia Maroni-
Itacaiúnas
Vrovincia Ventuari-
Tapajós

\section{Coberturas} sedimentares

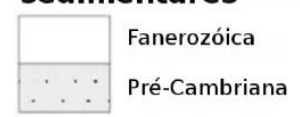

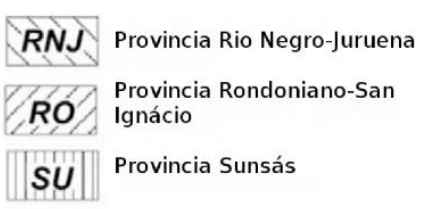

Provincias Neoproterozoicas

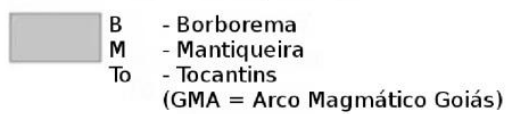
(GMA = Arco Magmático Goiás)
Massas cratônicas menores

Cráton São Luís

$+$ Cráton São Francisco Cráton Luiz Alves Cráton Rio Apa

\section{Faixa Andina}

- Afloramentos Pré-

Figura 2.1. Estrutura tectônica da América do Sul com ênfase no Cráton Amazônico e suas províncias tectônicas. Os Crátons São Francisco, São Luís e Luiz Alves, assim como o Neoproterozoico BrasilianoPan Africano são mostrados na parte oriental da figura [extraído de Cordani et al., 2009]. 


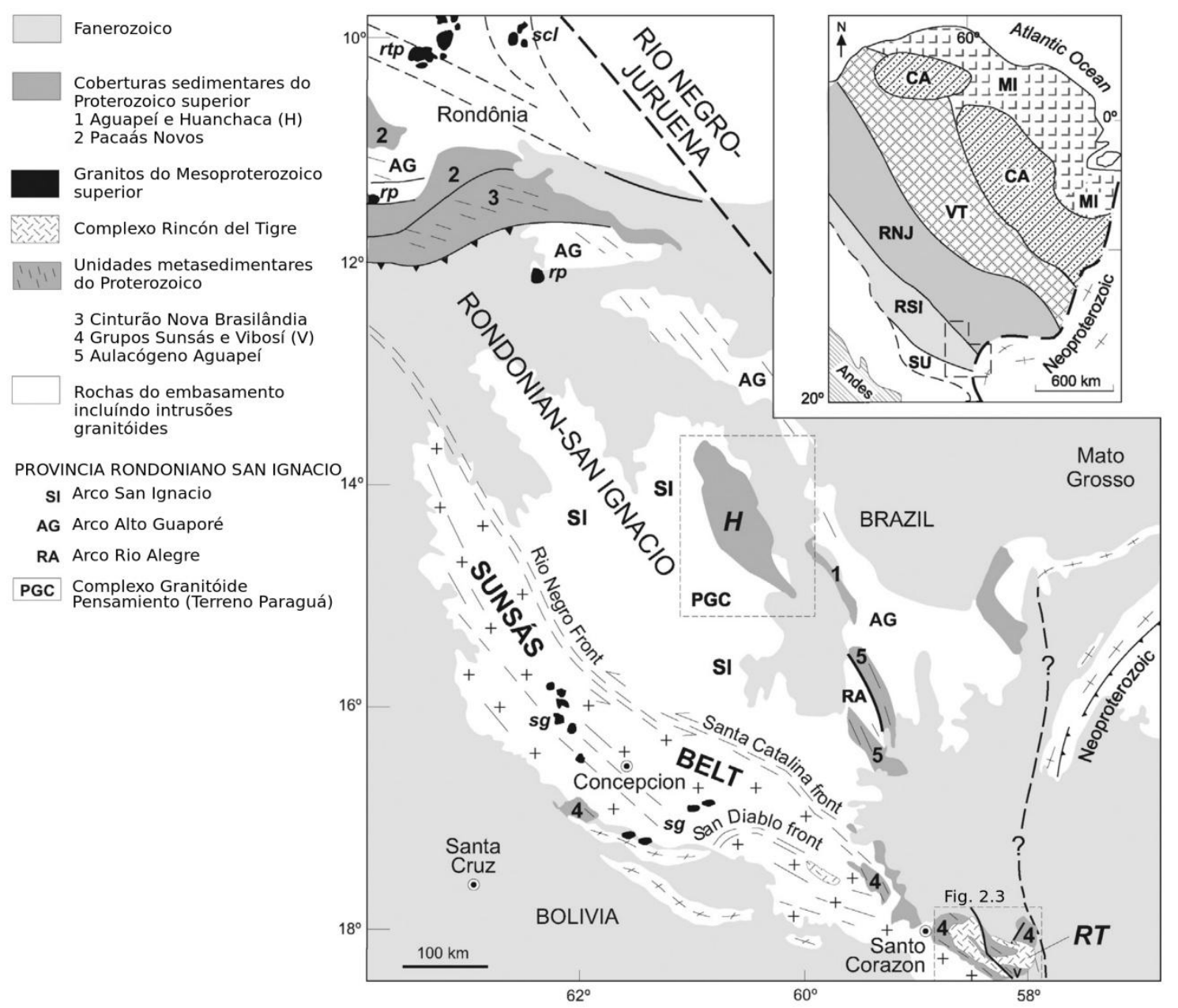

Figura 2.2. Estrutura crustal geológica-tectônica do sudoeste do Cráton Amazônico mostrando a zona de estudo: Complexo Rincón del Tigre RT. As frontes tectônicas que delineiam o limite norte entre o cinturão colisional (província Sunsás-Aguapeí) Sunsás com a província Rondoniano-San Ignacio (Complexo Granitóide Pensamiento - PGC) também são mostradas. Unidades geológicas atribuídas à província Sunsás-Aguapeí: Sequências meta-sedimentares Vibosí e Sunsás; cinturão supracrustal Nova Brasilândia; aulacógeno Aguapeí; Comberturas de plataforma (e.g., Huanchaca, Aguapeí, Pacaás Novos); Suites graníticas: $\mathrm{scl}=$ Santa Clara (1,08-1,07 Ga); sg = granitos Sunsás (1,13-1,00 Ga); rp = Rio Pardo $(1,05 \mathrm{Ga}) ;$ rtp = Província Estanífera de Rondônia (0,99-0,97 Ga); rp = Rio Pardo (1,05 Ga). Inserção: Províncias tectônicas CA = Amazônia Central (> 2,6 Ga); MI = Maroni-Itaicaiúnas (2,25-2,05 Ga); VT = Ventuarí-Tapajós (2,00-1,81 Ga), RNJ = Rio Negro-Juruena (1,80-1,60 Ga), RSI = Rondoniano-San Ignacio (1,56-1,30 Ga), SA = Sunsás-Aguapeí (1,20-0,97 Ga). (Modificado de Teixeira et al, 2015).

O embasamento do Precambriano da Bolívia, segundo Litherland et al. (1989), é composto por rochas granulíticas (charnoquitos, enderbitos e quartzo-feldspatos), as quais formam o Complexo granulítico Lomas Maneches e gnaisses do Complexo Chiquitania. Estes autores consideram estas rochas como pertencentes ao evento Transamazônico com base em uma isócrona $\mathrm{Rb}-\mathrm{Sr}$ obtida em rochas do Complexo Lomas Maneches, que forneceu uma idade de 1961 Ma. Entretanto, novas 
determinações geocronológicas U-Pb indicam idades entre 1880 Ma e 1660 Ma para estas rochas do embasamento (Bogeret al., 2005, Santos et al., 2008). Muitos zircões metamórficos extraídos de rochas pertencentes aos granulitos Lomas Maneches e gnaisses Chiquitania, forneceram idades entre 1340 Ma e 1320 Ma (Boger et al., 2005, Santos et al., 2008), mostrando que elas foram metamorfizadas durante a Orogênese San Ignacio, muito provavelmente, em decorrência da colisão do Terreno Paraguá com o proto-Cráton Amazônico (Bettencourt et al., 2010, Rizzotto e Hartmann, 2012). Ao sul da fronte Rio Negro-Santa Catalina, as rochas do embasamento sofreram influência da Orogênese Sunsás (1300-950 Ma), a qual aumenta para a direção oeste da Bolívia (região de San Javier e San Ramon, vide Figura 2 de Boger et al., 2005). Este evento inclui a erosão de rochas pertencentes a ciclos mais antigos, com a formação e subsequente deformação dos Grupos Sunsás e Vibosi (Litherlandet al., 1989). De acordo com Boger et al. (2005), o evento de deformação em decorrência da Orogênese Sunsás ocorreu entre 1110 e 1070 Ma, tendo em vista a idade de $1076 \pm 18$ Ma obtida para o granito Taperas, de origem pós-tectônica, e de idades de intrusivas sin-tectônicas (1100 Ma) obtidas para a região de Nova Brasilândia (Rizzotto, 1999, Luft et al., 2000).

O estágio orogênico da Orogênese Sunsás foi acompanhado por intrusões máficas, as quais podem ser correlacionáveis à Suíte Intrusiva Huanchaca, composta por sills máficos que afloram na Serra Ricardo Franco/Huanchaca, próximo à divisa Brasil/Bolívia, e que forneceram idades platôs ${ }^{40} \mathrm{Ar}-{ }^{39} \mathrm{Ar}$ em anfibólio e plagioclásio de $1040 \pm 40$ Ma e $948 \pm 5$ Ma, respectivamente (Lima et al., 2012).

Na região mais a leste da Bolívia (Figura 2.3), encontramos rochas pertencentes ao Complexo Ígneo Rincón del Tigre, datado pelo método U-Pb (badeleíta) em 1110,4 $\pm 1,8$ Ma por Teixeira et al. (2015). O complexo Rincón del Tigre é formado por rochas máficas-ultramáficas intrusivas, dispostas em sills acamadados, com uma espessura de aproximadamente 4,5 km (Prendergast, 2000, Teixeira et al., 2015). Além disso, o complexo é composto por rochas ultrabásicas como dunitos serpentinizados, harzburgitos, bronzonitos olivina, picritos bronzonito, rochas máficas tais como noritos, gabros e adicionalmente granófiros.

Segundo Prendergast (2000), as melhores exposições estão nas proximidades de Potosi, La Cal e San Fernandito e apresentam relações intrusivas com rochas sedimentares 
pertencentes aos Grupos Sunsás e Vibosi, as quais fazem parte do cinturão Sunsás, caracterizado por um cinturão colisional de direção NW/SE (1.200-1.000 Ma).

Por causa dessa boa exposição realizamos a amostragem paleomagnética nas vizinhanças do vilarejo Rincón del Tigre e nos entornos das estâncias Palmeras, Cabeceras, Santa Isabel, Los Puquios, Mangales e San Fernandito entre outros. Durante a amostragem foram coletados 101 cilindros orientados de quinze sítios (Figura 2.3). A localização dos sítios e as litologias para algumas amostras estão mostradas na tabela 2.1 .

Tabela 2.1. Número do sítio, localização, identificação e litologia da amostragem paleomagnética para o Complexo Rincón del Tigre.

\begin{tabular}{|c|c|c|c|}
\hline Sítios & Localização & Amostras & Litologia \\
\hline 1 & $18^{\circ} \mathrm{S} 13^{\prime} 57^{\prime \prime} / 58^{\circ} \mathrm{W} 13^{\prime} 27^{\prime \prime}$ & OL1A-OL1F & Gabro norito \\
\hline 2 & $18^{\circ} \mathrm{S} 12^{\prime} 20^{\prime \prime} / 58^{\circ} \mathrm{W} 09^{\prime} 43^{\prime \prime}$ & OL2A-OL2G & Ultramáfica harzburgítica \\
\hline 3 & $18^{\circ} \mathrm{S} 12^{\prime} 20^{\prime \prime} / 58^{\circ} \mathrm{W} 09^{\prime} 43^{\prime \prime}$ & OL3A-OL3H & Ultramáfica harzburgítica. \\
\hline 4 & $18^{\circ} \mathrm{S} 12^{\prime} 40^{\prime \prime} / 58^{\circ} \mathrm{W} 10^{\prime} 07^{\prime}$ & OL4A-OLG4 & Serpentinito \\
\hline 5 & $18^{\circ} \mathrm{S} 12^{\prime} 41^{\prime \prime} / 58^{\circ} \mathrm{W} 10^{\prime} 08^{\prime \prime}$ & OL5A-OL5F & Serpentinito \\
\hline 6 & $18^{\circ} \mathrm{S} 12^{\prime} 41^{\prime \prime} / 58^{\circ} \mathrm{W} 10^{\prime} 08^{\prime \prime}$ & OL6A-OL6G & Serpentinito \\
\hline 7 & $18^{\circ} \mathrm{S} 12^{\prime} 19^{\prime \prime} / 58^{\circ} \mathrm{W} 09^{\prime} 43^{\prime \prime}$ & OL7A-OL7F & Adcumulato harzburgítico \\
\hline 8 & $18^{\circ} \mathrm{S} 12^{\prime} 19^{\prime \prime} / 58^{\circ} \mathrm{W} 09^{\prime} 42^{\prime \prime}$ & OL8A-OL8F & Adcumulato harzburgítico \\
\hline 9 & $18^{\circ} \mathrm{S} 12^{\prime} 18^{\prime \prime} / 58^{\circ} \mathrm{W} 09^{\prime} 42^{\prime \prime}$ & OL9A-OL9F & Adcumulato \\
& & & harzburgítico/lherzolítico \\
\hline 10 & $18^{\circ} \mathrm{S} 11^{\prime} 16^{\prime \prime} / 58^{\circ} \mathrm{W} 11^{\prime} 13^{\prime \prime}$ & OL10A-OL10H & Adcumulato harzburgítico \\
\hline 11 & $18^{\circ} \mathrm{S} 10^{\prime} 56^{\prime \prime} / 58^{\circ} \mathrm{W} 18^{\prime} 50^{\prime \prime}$ & OL11A-OL11G & Adcumulato harzburgítico \\
\hline 12 & $18^{\circ} \mathrm{S} 11^{\prime} 29^{\prime \prime} / 58^{\circ} \mathrm{W} 21^{\prime} 44^{\prime \prime}$ & OL12A-OL12F & Gabro norito \\
\hline 13 & $18^{\circ} \mathrm{S} 03^{\prime} 25^{\prime \prime} / 58^{\circ} \mathrm{W} 26^{\prime} 35^{\prime \prime}$ & OL13A-OL13E & Adcumulato hazrburgítico \\
\hline 14 & $17^{\circ} \mathrm{S} 58^{\prime} 25^{\prime \prime} / 58^{\circ} \mathrm{W} 28^{\prime} 58^{\prime \prime}$ & OL14A-OL14J & Serpentinito \\
\hline 15 & $17^{\circ} \mathrm{S} 58^{\prime} 25^{\prime \prime} / 58^{\circ} \mathrm{W} 28^{\prime} 58^{\prime \prime}$ & OL15A-OL15F & Ortopiroxenito adcumulático \\
\hline
\end{tabular}




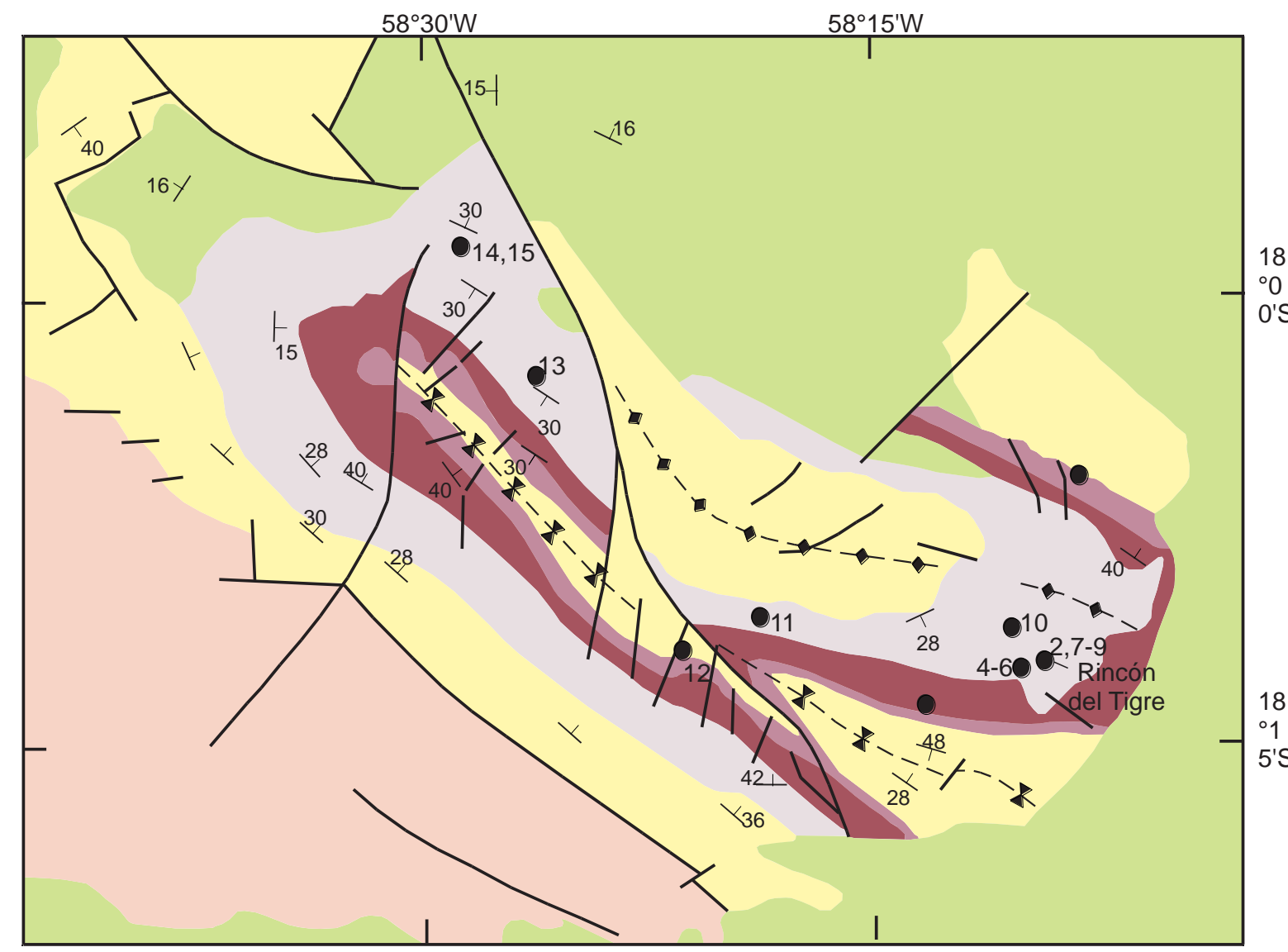

Rochas Pós-Sunsas

\section{Grupos Sunsas (S) Vibosi (V)}

...... Quartzito

18

Complexo Rincón del Tigre

O'S Unidade félsica (granófiro)

Unidade máfica

Unidade ultramáfica

Embasamento (gnaisse e granito)

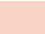

$7 \quad$ Falha

16 Direção e inclinação das rochas

18 - Traço axial anticlinal

5 's

* Traço axial sinclinal

(Sinclinal Santa Isabel)

- Sítio de amostragem

Figura 2.3. Mapa geológico da área de estudo do Complexo Rincón del Tigre (modificado de Teixeira et al., 2015). Os sítios de amostragem são mostrados na figura através de círculos cheios. 


\section{Capitulo 3}

\section{Procedimentos em Paleomagnetismo}

No paleomagnetismo consideramos que as amostras coletadas de uma formação geológica registram, na média, o campo de um dipolo geocêntrico e axial (DGA). Partindo desse pressuposto, determinamos a posição do polo paleomagnético que representa uma formação geológica de determinada idade e, através dele, a paleolatitude e a paleodireção do bloco tectônico em que a unidade geológica está inserida. A seguir, será descrita a metodologia relacionada à análise paleomagnética.

\subsection{Amostragens Paleomagnética}

O objetivo principal da pesquisa paleomagnética é a obtenção do registro das configurações antigas do campo magnético terrestre. Variações na direção e na intensidade do campo magnético terrestre durante o tempo geológico constituem a variação secular geomagnética. A coleta de amostras paleomagnéticas representa a obtenção de um conjunto de testemunhos que registraram a direção do campo magnético terrestre no momento de formação da rocha. Assim, para o estudo paleomagnético é imperativo realizar coletas de vários sítios de amostragem de uma formação geológica, cujas direções de magnetização registrem a variação secular do campo geomagnético e representem, na média, o campo de dipolo geocêntrico axial. Além disso, várias amostras de cada sítio são amostradas com o objetivo de aumentar a confiabilidade estatística, tendo em vista os erros inerentes aos procedimentos de amostragem e de laboratório.

Em paleomagnetismo existe uma hierarquia no procedimento de amostragem, a qual está representada na Figura 3.1 (Butler, 1992). Parte-se de uma formação geológica que pode ser representada por uma sequência sedimentar de diferentes camadas, por um grande corpo intrusivo, por derrames de lavas formando camadas, por rochas intrusivas formando um enxame de diques, ou mesmo por sills acamadados de um complexo ígneo, sendo este último o caso deste estudo. Um sítio paleomagnético pode ser representado por um nível sedimentar no caso de um perfil sedimentar (Figura 3.1) ou por um afloramento que represente um 
derrame de lavas, um dique ou um sill, no caso das rochas ígneas. É recomendável amostrar uma variedade de afloramentos amplamente espalhados (várias centenas de quilômetros) para evitar que os resultados sejam dependentes de uma única localidade específica. Além disso, como já evidenciado acima, é necessário efetuar a coleta de amostras em diversos sítios da mesma unidade rochosa para obter uma amostragem adequada do campo geomagnético no tempo.

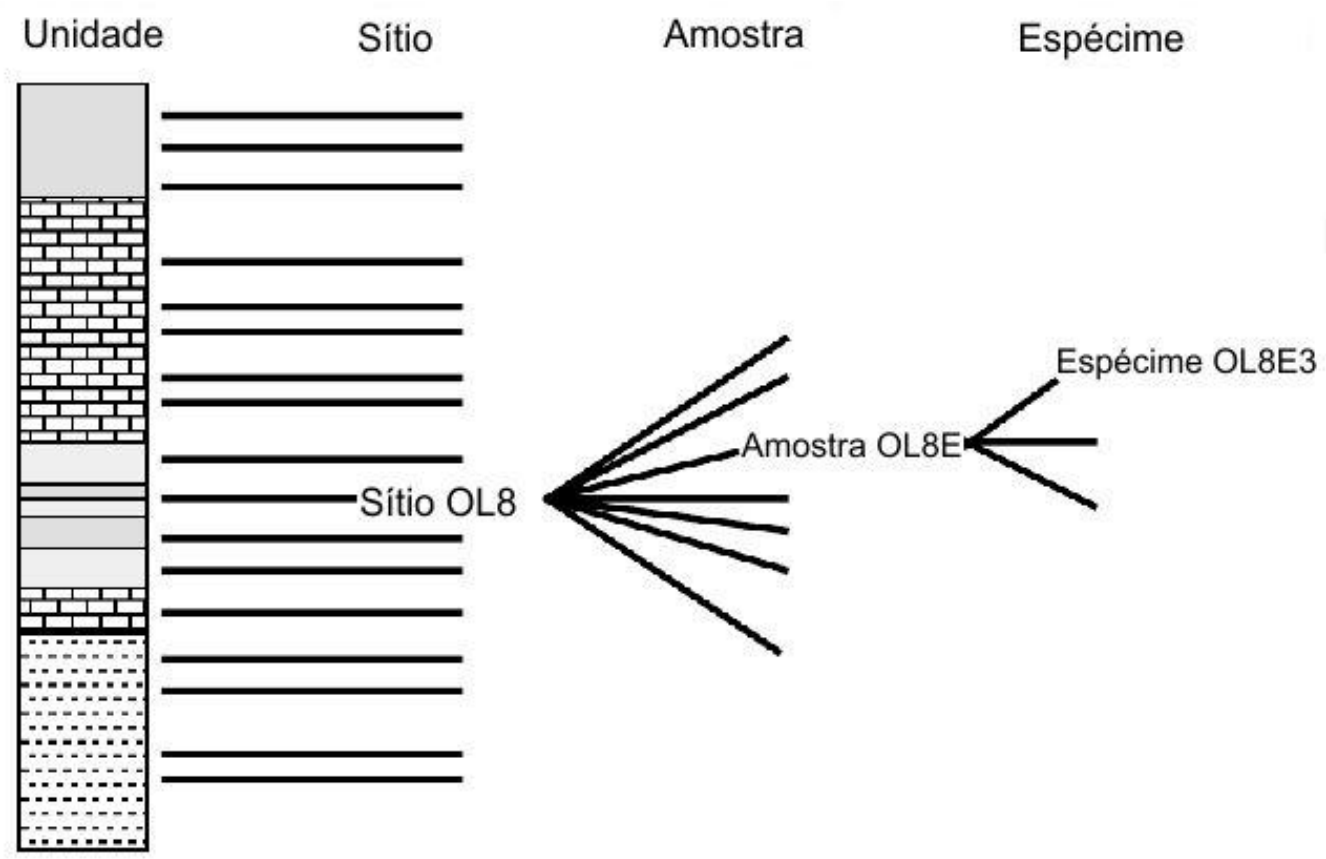

Figura 3.1 Esquema de amostragem paleomagnética. Diversos sítios de amostragem são coletados dentro uma unidade rochosa; várias amostras são coletadas de cada sítio; espécimes são preparados para serem medidos no laboratório a partir das amostras [Extraído de Paleomagnetism: Magnetic Domains to Geologic Terranes; R. Butler, 1992]

Dois métodos de amostragem são frequentemente empregados no paleomagnetismo: coleta de blocos orientados e coleta de cilindros orientados: Na coleta de blocos orientados, deve-se escolher uma face plana (a melhor possível) da amostra e fazer um traço horizontal com a ajuda de um dispositivo contendo níveis de bolha. Esta marca de referência é orientada da esquerda para a direita, usando como referência a pessoa que está coletando a amostra. Mede-se, então, o ângulo que esta marca faz com o norte magnético, utilizando-se uma bússola magnética. Posteriormente, este ângulo é corrigido em relação ao norte geográfico, 
utilizando-se a declinação magnética local, a qual pode ser determinada pelo "International Geomagnetic Reference Field” IGRF (Tauxe, 2002). Este ângulo é normalmente denominado de "STRIKE". Além disso, mede-se o ângulo de inclinação da face da amostra em relação à horizontal, através de um inclinômetro, o qual é denominado de "DIP". Após esta marcação, o bloco de rocha é retirado do afloramento.

A amostragem de cilindros orientados é efetuada empregando-se uma perfuratriz portátil adaptada, movida à gasolina (misturada com óleo de motor dois tempos), a qual possui uma broca diamantada com corpo não magnético (Figura 3.2). Para evitar aquecimento, a broca e a rocha são resfriadas por meio de água bombeada por um segundo operador. Usualmente, os testemunhos amostrados têm dimensões de 2,5 cm de diâmetro e o comprimento (de 6 a 12 cm) depende geralmente da dureza da rocha e da habilidade do operador da perfuratriz. Para a orientação do cilindro utiliza-se um dispositivo contendo níveis de bolha que auxiliam na determinação da horizontal local. Este dispositivo é composto por um tubo cilíndrico de alumínio vazado de diâmetro levemente maior que o da amostra, o qual é introduzido no furo para fazer a orientação. O tubo apresenta uma fenda longitudinal que coincide com o zero da bússola magnética, a qual é inserida na parte superior do dispositivo. Assim, após a colocação da bússola na horizontal, faz-se uma marca de referência na amostra utilizando a fenda do tubo e mede-se o ângulo que a marca faz com o norte magnético. Posteriormente, do mesmo modo que na amostragem de bloco orientado, este ângulo é corrigido em relação ao norte geográfico, utilizando-se a declinação magnética local, fornecendo o STRIKE. O dispositivo contém um inclinômetro que mede o ângulo entre a vertical local e a direção do eixo do cilindro amostrado (DIP). Nas amostragens paleomagnéticas (tanto de blocos de mão quanto de cilindros) é também comum o uso de uma bússola solar para a orientação das amostras. Os dispositivos utilizados para a coleta de blocos de mão e cilindros orientados estão adaptados com um goniômetro, com variação angular entre zero (o qual coincide com a direção da marca de referência da amostra) e $360^{\circ} \mathrm{C}$. Na região central do goniômetro uma haste de latão ou alumínio é colocada na posição vertical através de níveis de bolha. Assim, pode-se medir o ângulo que a sombra da haste faz com a marca de referência. Ao mesmo tempo, anotam-se as coordenadas geográficas (latitude e longitude) do local de amostragem e a data e horário em que a orientação está sendo efetuada. Com estes dados é possível determinar o azimute do Sol (ângulo entre a sombra do Sol e o norte geográfico). Como 
temos o ângulo que a sombra do Sol faz com a marca da amostra fica fácil determinar o ângulo que a marca de referência faz com o norte geográfico. Para rochas sedimentares, a determinação do STRIKE através das bússolas solar e magnética coincidem, normalmente, dentro do erro de um grau, se as leituras forem feitas com cuidado. No caso de rochas ígneas, entretanto, diferenças de vários graus (muitas vezes acima de $30^{\circ}$ ) podem ser observadas. Isto decorre, normalmente, devido à intensidade de magnetização muito forte que algumas rochas ígneas (principalmente máficas, tais como, basaltos e gabros) possuem, as quais defletem a agulha da bússola. Nestes casos, o uso da bússola solar é crucial na orientação das amostras.
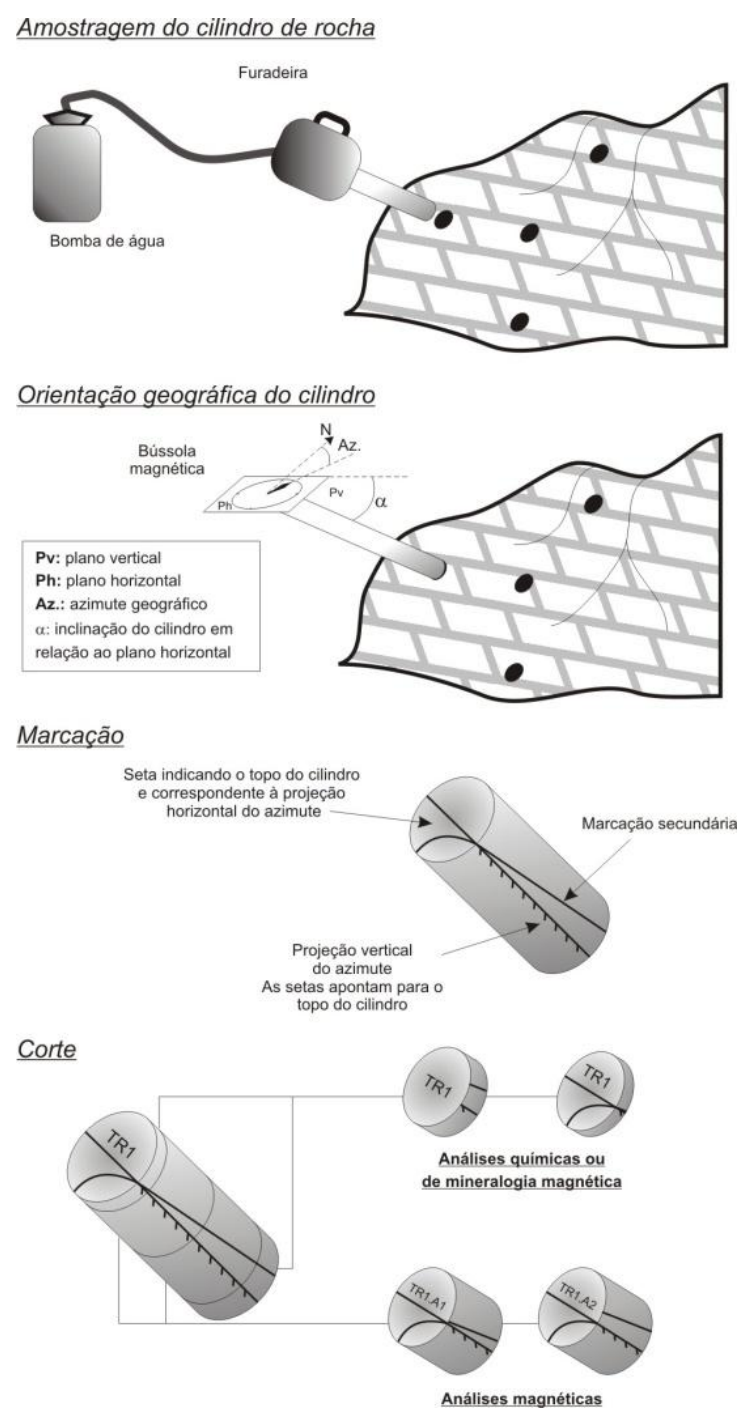

Figura 3.2. Esquema de amostragem paleomagnética. Diversos sítios de amostragem são coletados dentro de uma unidade [Eric Font, tese de doutorado 2005] 
A escolha do tipo de amostragem (blocos de mão ou cilindro) depende das condições de cada afloramento e do tipo de rocha que se pretende amostrar. Entre as vantagens de se utilizar blocos orientados estão a possibilidade de coletar amostras onde o uso da perfuratriz é limitado pela logística (transporte braçal de perfuratriz, combustível, água, etc.,) ou pela dureza ou friabilidade excessiva da rocha. Entre as desvantagens presentes destacamos a maior imprecisão na orientação das amostras, quando comparada à coleta de cilindros; a dificuldade em se achar rochas frescas ao longo de fraturas que possibilitem a remoção dos blocos a serem amostrados; a limitação, na maioria das vezes, do número de amostras (três a quatro blocos) coletadas por sítio; e a necessidade de se transportar vários blocos, os quais terão que ser re-orientados no laboratório para a extração de cilindros. Atualmente, sempre que possível, dá-se preferência à coleta de cilindros orientados. Além de diminuir os erros associados ao procedimento de orientação, podemos coletar testemunhos das partes mais frescas do afloramento, além de aumentar a precisão da estatística no cálculo de direções médias (vide Estatística). Além disso, a quantidade de amostras de rocha a ser transportada será bem menor. Assim, este procedimento foi adotado neste trabalho.

Existem recomendações importantes na amostragem paleomagnética para garantir a menor quantidade de erros possíveis que podem afetar os resultados em todos os níveis de analise. De inicio, as rochas do afloramento não devem apresentar alterações devido ao intemperismo; isto quer dizer que a coleta deve ser feita em rochas, as mais frescas possíveis. Outra recomendação crucial é que a rocha a ser amostrada esteja 'in situ' (McElhinny, 1973). Esta situação nem sempre é fácil de ser confirmada, principalmente, quando o afloramento é constituído por blocos de rocha isolados (tipo matacões).

Durante a coleta de amostras, anotam-se em uma caderneta de campo, as coordenadas geográficas de cada sítio, obtidas por meio de um GPS, as leituras das bússolas solar e magnética, as quais definem o STRIKE, além da hora local e do DIP associados a cada cilindro coletado. A identificação das amostras é feita de maneira específica: uma sigla identifica a coleção da formação estudada (AZ, PY, SD, etc.), a qual é seguida de um numero que identifica o sítio de amostragem $(1,2,3, \ldots)$ e mais uma letra $(A, B, C, \ldots)$ que identifica o cilindro perfurado em cada sítio, finalizando assim os procedimentos no campo para a coleta 
de amostras. No laboratório, os cilindros são remarcados, mantendo-se as marcas de referência realizadas no campo e, em seguida, cortados em espécimes de 2,2 cm de altura. Cada espécime cortado do cilindro (já identificado no campo pela sigla de identificação da formação estudada, pelo número do sítio $(1,2,3, \ldots)$ a que ele pertence e pela letra $(\mathrm{A}, \mathrm{B}$, $\mathrm{C}, \ldots)$ que o identifica no sítio) recebe um número final $(1,2,3, .$.$) que o identifica dentro do$ cilindro.

\subsection{Anisotropias de Susceptibilidade Magnética (ASM)}

A anisotropia de susceptibilidade magnética (ASM) é uma propriedade física das rochas que contêm minerais ferromagnéticos, paramagnéticos e/ou diamagnéticos. Assim, todos os minerais presentes em uma amostra contribuem para a ASM, pois a susceptibilidade magnética e, como consequência, a anisotropia, representa a somatória das susceptibilidades magnéticas de cada um dos grãos que formam a amostra. A trama magnética reflete a orientação preferencial de todos aqueles minerais que contribuem para a susceptibilidade magnética, de modo que ela fica registrada nas rochas como variações direcionais da suscetibilidade magnética, as quais produzem a ASM.

A susceptibilidade magnética $K$ é expressa pela equação $\mathbf{M}=K \mathbf{H}$, onde $\mathbf{M}$ e $\mathbf{H}$ são a magnetização induzida e o campo indutor aplicado a um material, respectivamente. A susceptibilidade varia em função da temperatura e da intensidade do campo $\mathrm{H}$ aplicado na amostra. Na pratica, entretanto, assume-se que a susceptibilidade é sempre medida à temperatura ambiente $\left(\approx 20^{\circ} \mathrm{C}\right)$ e considera-se que $\mathrm{M}$ varia linearmente com $\mathrm{H}$ para campos menores que $1 \mathrm{mT}$ (Tarling e Hrouda, 1993).

Matematicamente, a ASM é definida como um tensor simétrico de segunda ordem $\left(\mathrm{k}_{\mathbf{i j}}\right)$ no qual a magnitude e orientação das suas principais direções $\left(\mathrm{k}_{1}, \mathrm{k}_{2}, \mathrm{k}_{3}\right.$ onde $\left.\mathrm{k}_{1} \geq \mathrm{k}_{2} \geq \mathrm{k}_{3}\right)$ dependem de vários fatores como a mineralogia, forma, tamanho, distribuição e concentração dos grãos que compõem a rocha (Tarling e Hrouda, 1993). A forma deste tensor depende da 
trama mineral magnética na rocha e reflete a orientação estatística preferencial dos grãos e redes cristalinas de todas as suas fases minerais (Hrouda, 1973).

Como mencionado no parágrafo anterior, a ASM pode ser representada por um tensor de segunda ordem, o qual pode ser representado da seguinte forma:

$$
\begin{aligned}
& \mathrm{J}_{1}=\mathrm{k}_{11} \mathrm{H}_{1} \\
& \mathrm{~J}_{2}=\mathrm{k}_{22} \mathrm{H}_{2} \\
& \mathrm{~J}_{3}=\mathrm{k}_{33} \mathrm{H}_{3},
\end{aligned}
$$

se um sistema de coordenadas cartesianas adequado (em que os termos fora da diagonal da matriz 3x3 definida pelo tensor são cancelados mutuamente) for escolhido (Lanza e Meloni, 2006). Assim, os autovalores $\mathrm{k}_{1}\left(\mathrm{k}_{11}\right), \mathrm{k}_{2}\left(\mathrm{k}_{22}\right)$ e $\mathrm{k}_{3}\left(\mathrm{k}_{33}\right)$ do tensor são normalmente chamados de eixos principais de suscetibilidade máxima, intermediária e mínima, respectivamente.

Entretanto, para os estudos geológicos e geofísicos, a ASM pode ser mais bem compreendida visualmente em termos de um elipsoide (Figura 3.3), em que a maior intensidade de suscetibilidade é representada ao longo do eixo $\left(\mathrm{k}_{1}\right)$ maior do elipsóide e a intensidade mais fraca define o eixo $\left(\mathrm{k}_{3}\right)$ menor do elipsoide (Nye, 1957; 1985). Assim, graficamente, a ASM pode ser expressa mediante um elipsoide cujos eixos definem as direções de susceptibilidade máxima (eixo k1), intermediária (eixo k2) e mínima (eixo k3). 


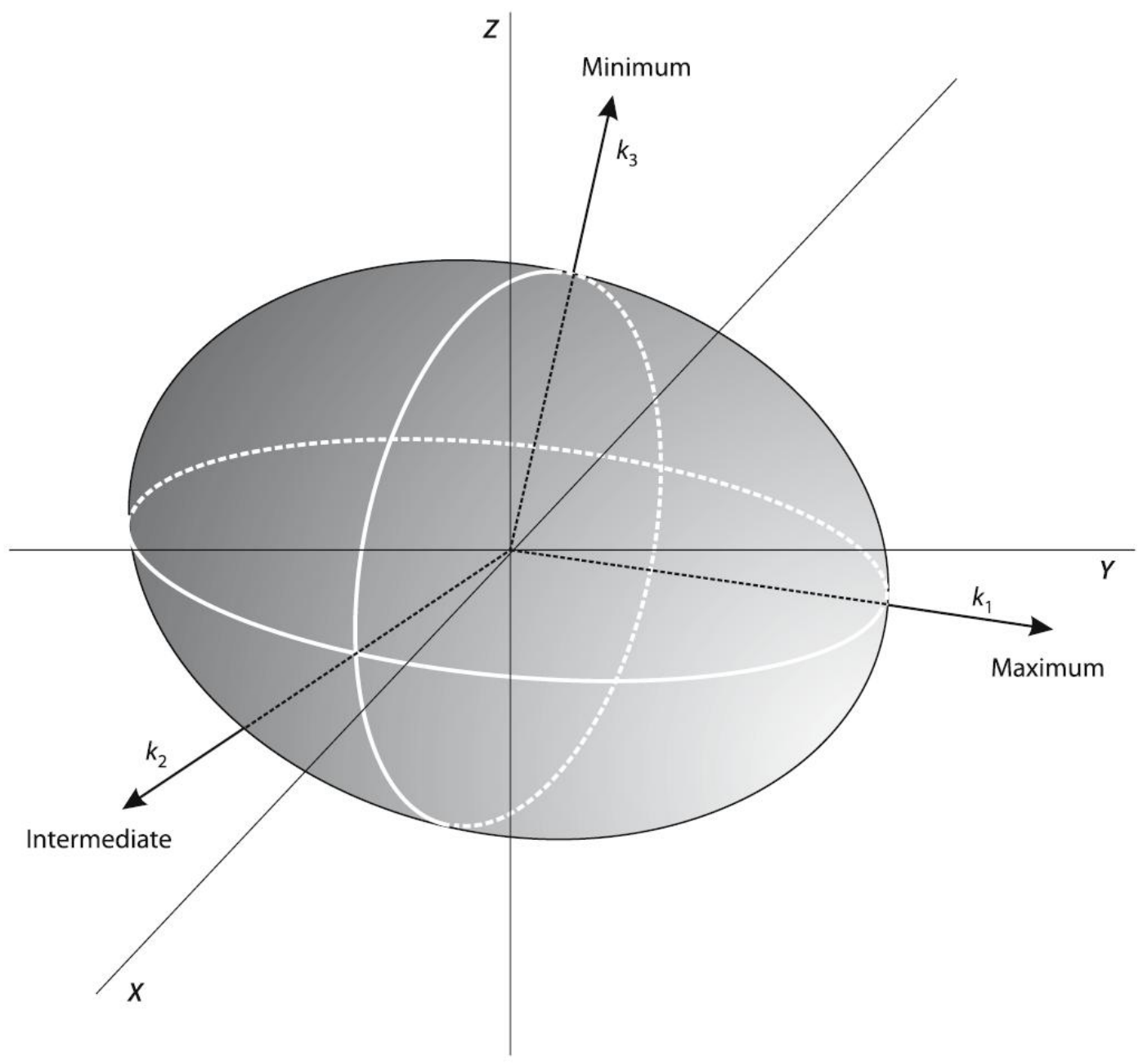

Figura 3.3: Anisotropia de susceptibilidade magnética representada por um elipsoide tri-axial com os eixos $\mathrm{k}_{1} \geq \mathrm{k}_{2} \geq \mathrm{k}_{3}$ [Extraído de The Earth's Magnetism; R. Lanza and A. Meloni, 2006]

Alguns parâmetros podem ser calculados através dos eixos $\mathrm{k}_{1}$, $\mathrm{k}_{2}$ e $\mathrm{k}_{3}$, os quais definem a forma do elipsoide. Os mais usados (Hrouda, 1982, Borradaile, 1988, Lanza e Meloni, 2006) são: o grau de anisotropia $(\mathrm{P})$, definido pela razão entre os eixos máximo e mínimo de susceptibilidade magnética:

$$
P=\frac{k_{1}}{k_{3}}
$$

a lineação magnética (L), definida pela razão entre os eixos máximo e intermediário 


$$
L=\frac{k_{1}}{k_{2}}
$$

a foliação magnética $(\mathrm{F})$, definida pela razão entre os eixos intermediário e mínimo

$$
F=\frac{k_{2}}{k_{3}}
$$

e o parâmetro de Jelinek,

$$
T=\left[\frac{2 \ln \left(\frac{k_{2}}{k_{3}}\right)}{\ln \left(\frac{k_{1}}{k_{3}}\right)}\right]-1
$$

o qual define a forma do elipsóide, se prolata $(-1 \leq \mathrm{T}<0)$ ou oblata $(0<\mathrm{T} \leq 1)$ (Jelinek,1981). A Figura 3.3 mostra o parâmetro de forma (T) em função da lineação magnética (L) e foliação magnética $(\mathrm{F})$.

\subsubsection{Medidas de Anisotropia de Susceptibilidade Magnética (ASM)}

No laboratório, as medições de anisotropia de susceptibilidade magnética das rochas são efetuadas usando o instrumento MFK1-FA, construído pela AGICO (Advanced Geoscience Instruments Company). O Kappabridge MFK1-FA é provavelmente um dos instrumentos comerciais disponíveis mais sensíveis para medir susceptibilidade e anisotropia de suscetibilidade magnética. Este aparelho permite obter o tensor de ASM através de quatro medidas.

"A obtenção do tensor da ASM de uma determinada amostra, neste equipamento, demanda quatro medições. As três primeiras delas são realizadas a partir da rotação da amostra em torno de três eixos distintos perpendiculares entre si no interior de uma bobina (indutora) percorrida por uma corrente elétrica fraca, responsável pela geração de um campo magnético também fraco em seu interior. Este campo induz em sua direção diferentes magnetizações na amostra, enquanto a mesma gira. Estas diferentes magnetizações da amostra geram, então, correntes elétricas de intensidades distintas na bobina vizinha (receptora). Um computador 
ligado ao aparelho, por fim, calcula, a partir das intensidades destas correntes elétricas, as suscetibilidades magnéticas da amostra nestas diferentes direções. A quarta medição determina sua suscetibilidade volumétrica. Todas estas medições fornecem o conjunto dos dados que levarão à composição dos tensores da suscetibilidade magnética e da anisotropia de suscetibilidade pelo programa de medidas instalado no computador."

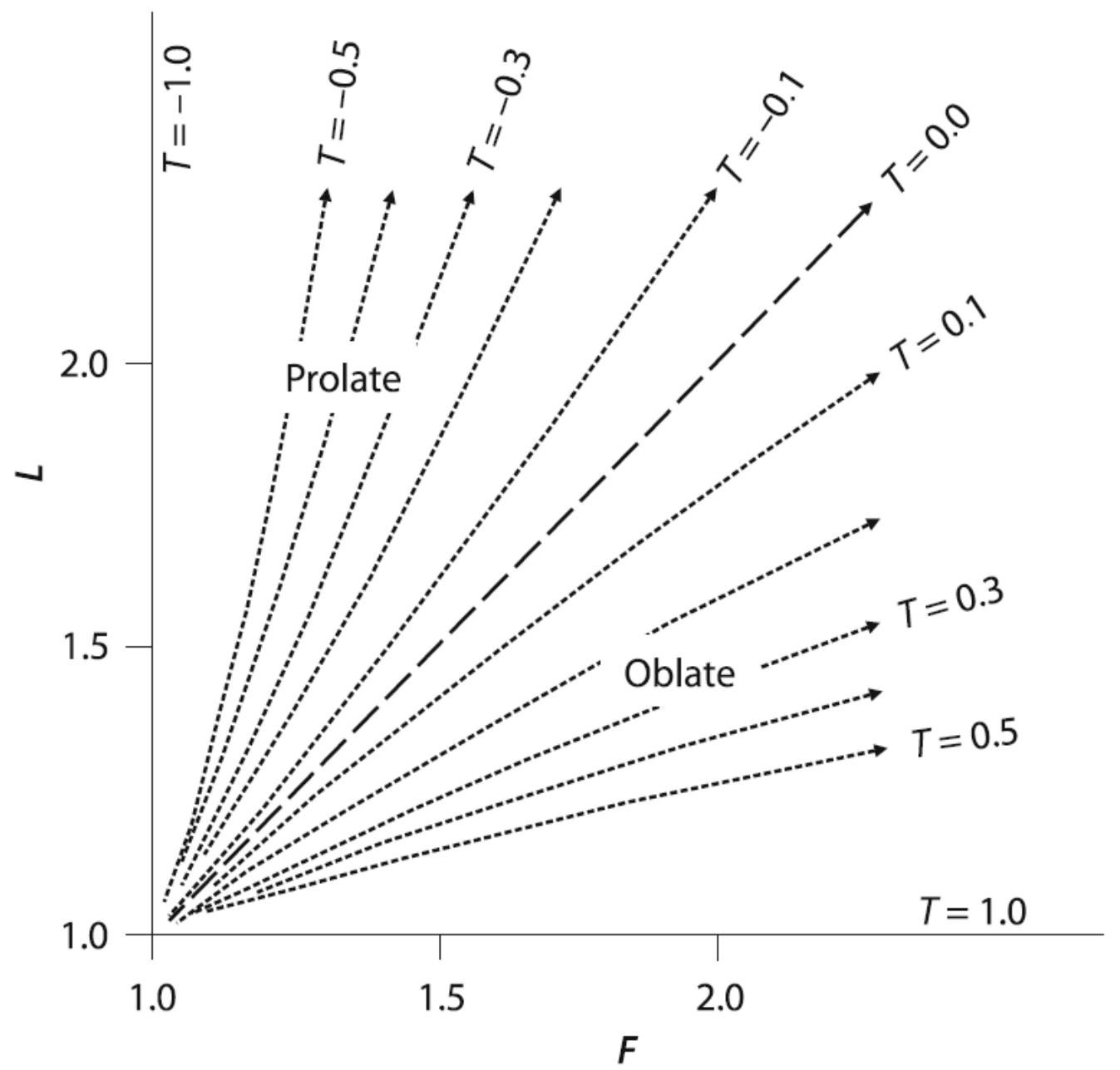

Figura 3.4 Parâmetro de forma T. Parâmetro de forma $T$ em função da lineação magnética (L) e foliação magnética (F). As setas indicam o incremento no grau de anisotropia (P) [Extraído de The Earth's Magnetism; R. Lanza and A. Meloni, 2006]

Estes valores de susceptibilidade magnética e de anisotropia permitem obter a orientação e magnitude dos três eixos principais do elipsoide de susceptibilidade magnética $\left(\mathrm{k}_{1}>\mathrm{k}_{2}>\right.$ 
k3). O eixo k1 é um parâmetro utilizado para classificar a lineação magnética e o pólo da foliação magnética (plano k1-k2) é atribuído ao eixo k3.

Os dados direcionais da ASM são representados por meio de projeções estereográficas, como acontece em geologia estrutural. A projeção é feita no hemisfério inferior da esfera. Convencionou-se representar as direções principais $\mathrm{k}_{1}, \mathrm{k}_{2}$ e $\mathrm{k}_{3}$ por quadrados, triângulos e círculos, respectivamente. Considerando um grupo de espécimes de um mesmo afloramento, se a fábrica da rocha é foliada, os eixos $\mathrm{k}_{3}$ medidos para o grupo de espécimes ficarão agrupados, enquanto $\mathrm{k}_{1}$ e $\mathrm{k}_{2}$ estarão mais ou menos dispersos ao longo de uma faixa, definindo o plano de foliação magnética (Figura 3.5a); se a lineação prevalece, os eixos $\mathrm{k}_{1}$ ficam agrupados (Figura 3.5b) e não há foliação coerente; se ambas, lineações e foliações são bem desenvolvidas, cada uma das três direções forma um conjunto bastante bem definido (Figura 3.5c). A análise estatística dos dados de ASM é algo complexa devido ao fato que a susceptibilidade é um tensor: as direções principais não são vetores e a distribuição não é Fisheriana. Vários métodos de análise têm sido propostos: o método mais simples calcula os termos do tensor médio $\mathrm{K}_{\mathbf{i j}}$ como a somatória dos correspondentes $\mathrm{N}$ termos $\mathrm{k}_{\mathrm{ij}}$ dos tensores individuais normalizados.

$$
K_{i j}=\sum \frac{k_{i j}}{N}
$$
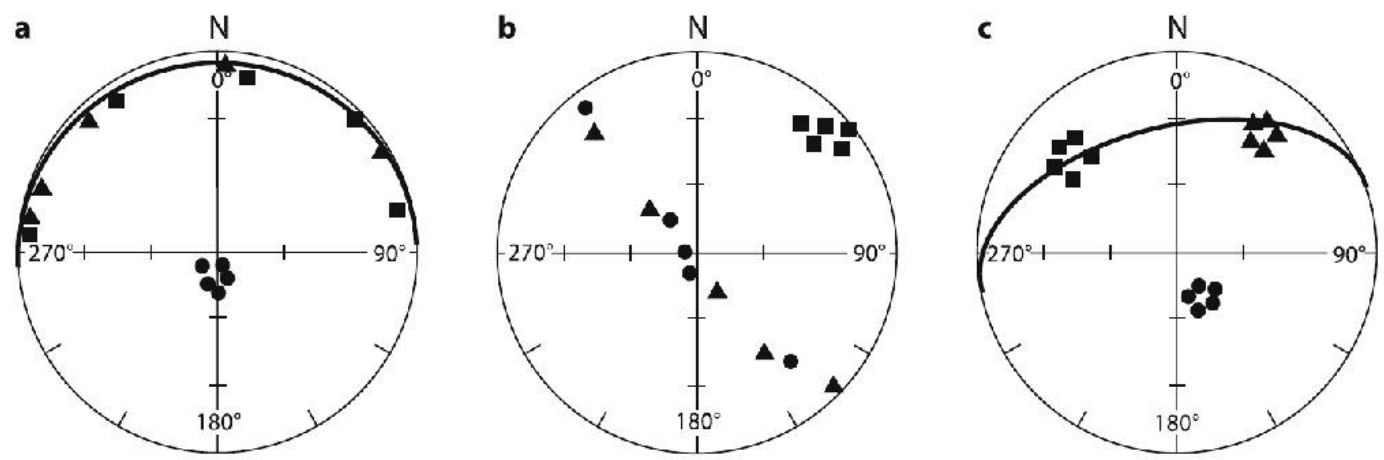

Figura 3.5. Projeção de igual área das direções principais de susceptibilidade em vários tipos de trama magnética. Os símbolos representam os seguintes eixos: quadrado $=\mathrm{k}_{1}$; triângulo $=\mathrm{k}_{2}$; ponto $=\mathrm{k}_{3}$; círculo máximo = foliação magnética; (a) eixos $\mathrm{k}_{3}$ bem agrupados, foliação bem desenvolvida: a fábrica é planar; (b) eixos $\mathrm{k}_{1}$ bem agrupados, lineação bem desenvolvida: a trama é linear; (c) todos os eixos bem agrupados, tanto foliação quanto lineação bem desenvolvidas. [Extraído de The Earth's Magnetism; R. Lanza and A. Meloni, 2006] 


\subsection{Magnetização Remanente nas Rochas}

As rochas apresentam um campo magnético, mesmo na ausência de um campo aplicado. Este campo decorre das propriedades magnéticas de alguns minerais capazes de portar magnetização, a qual é chamada de magnetização remanente ou espontânea. O fenômeno que explica esta propriedade é conhecido como ferromagnetismo. A Magnetização Remanente Natural $(\mathrm{MRN})$ é a magnetização remanente que está presente na rocha, sem prévio tratamento de laboratório. As rochas adquirem a magnetização através de distintos processos geológicos sob a influência do campo geomagnético. No momento de formação da rocha ela adquire uma magnetização que registra o campo geomagnético atuante, a qual é conhecida como magnetização remanente primária (MRP). Processos físicos e químicos posteriores à formação da rocha podem ocorrer e a rocha pode adquirir novas magnetizações, as quais são chamadas de magnetizações remanentes secundárias (MRS). A magnetização remanente total da rocha (MRN) pode ser composta, portanto, por uma ou mais componentes de magnetização, dependendo dos eventos geológicos aos quais ela foi submetida.

$$
\mathrm{MRN}=\mathrm{MRP}+\mathrm{MRSs}
$$

Existem duas formas básicas de magnetização remanente primária: (i) magnetização termoremanente, adquirida durante o resfriamento da rocha a partir de altas temperaturas; e (ii) magnetização remanente detrítica ou deposicional (MRD), adquirida durante a sedimentação de grãos contendo minerais ferromagnéticos detriticos. A MRS pode ser resultado de alterações químicas que afetam os minerais ferromagnéticos pré-existentes (alterações intempéricas) ou pelo crescimento de novos minerais ferromagnéticos decorrentes, por exemplo, da circulação de fluidos ricos em ferro, após a formação da racha. Esta magnetização é conhecida como magnetização remanente química (MRQ). Uma MRS pode também se originar do impacto de raios, originando uma magnetização remanente isotérmica (MRI) ou mesmo, pela exposição da rocha ao campo geomagnético, ao longo do tempo geológico, o que irá produzir uma magnetização remanente viscosa (MRV).

\subsubsection{Magnetização Termo-remanente (MTR)}

A magnetização termo-remanente (MTR) é adquirida por rochas metamórficas de alto grau 
ou por rochas ígneas quando se resfriam a partir de temperaturas acima da temperatura de Curie dos minerais ferromagnéticos presentes na rocha, na presença do campo geomagnético. A MTR representa o processo mais comum pelo qual as rochas ígneas adquirem a magnetização.

A medida que a rocha esfria e a temperatura dos grãos ferrimagnéticos passa pela temperatura de Curie $\left(\mathrm{T}_{\mathrm{C}}\right)$ destes minerais, eles adquirem magnetização espontânea. Em grãos de domínio simples (SD), o tempo de relaxação $(\tau)$ é regido pela equação (3.5) (Lowrie, 1997), a qual descreve uma variação exponencial de $\tau$ com o volume do grão (V) e com a temperatura $(T) . \mathrm{VM}_{\mathrm{s}} \mathrm{B}_{\mathrm{c}} / 2$ representa a energia de anisotropia magnética, onde Ms e Bc são, respectivamente, a magnetização espontânea e a coercividade do grão ferrimagnético. kT representa a energia térmica, onde k é a constante de Boltzmann.

$$
\tau=\left(\frac{1}{v_{0}}\right) \exp \left(\frac{V M_{s} B_{c}}{2 k T}\right)
$$

$v_{\mathrm{o}}$ é uma constante relacionada à frequência de vibração da rede cristalina (Lowrie, 1997)

A altas temperaturas (próximas de $\mathrm{T}_{\mathrm{C}}$ ) a energia térmica $\mathrm{kT}$ é maior que a energia magnética e a magnetização é instável. Nestas temperaturas, embora os momentos magnéticos atômicos individuais sejam forçados pelo campo molecular a se comportar como unidades coerentes, os grãos magnéticos apresentam comportamento superparamagnético. À medida que a rocha esfria a magnetização espontânea e a energia de anisotropia magnética do grão aumenta. Eventualmente, a temperatura passa abaixo de um valor em que a energia térmica, que gera o efeito de aleatorizar os momentos magnéticos dos grãos, torna-se menor do que a energia de anisotropia magnética e, com isso, a magnetização espontânea é "bloqueada" ao longo de um eixo fácil (easy axis) de magnetização do grão. A temperatura em que isto ocorre é chamada de Temperatura de Bloqueio $\left(\mathrm{T}_{\mathrm{B}}\right)$. Na ausência de um campo magnético externo os momentos magnéticos dos grãos são orientados aleatoriamente (assumindo que os eixos fáceis estão distribuídos aleatoriamente). Se os grãos magnéticos se esfriam até uma temperatura inferior à temperatura de bloqueio na presença de um campo magnético, os momentos magnéticos dos grãos são "bloqueados" ao longo do eixo fácil, na direção mais próxima do campo aplicado naquele instante. $\mathrm{O}$ alinhamento dos momentos magnéticos dos 
grãos com o campo não é perfeito nem completo; representa uma preferência estatística. Em um conjunto de grãos aleatórios a maioria dos grãos tem o momento magnético alinhado perto da direção do campo. O grau de alinhamento depende da intensidade do campo.

\subsubsection{Magnetização Remanente Química (MRQ)}

A magnetização remanente química (MRQ) é usualmente uma forma secundária de magnetização remanente nas rochas. Normalmente, ela é formada quando os grãos ferromagnéticos formam-se abaixo da temperatura de Curie. O processo pode ser a nucleação e crescimento de uma nova fase ferromagnética, tal como a formação de cimento de hematita em um sedimento, ou a alteração de uma fase ferromagnetica pré-existente, tal como a oxidação de magnetita para hematita. Devido ao fato que o tempo de relaxação $\tau$ (equação 3.7) de um grão também depende do seu volume, o modo de aquisição da MRQ é semelhante ao do MTR. Os minerais magnéticos podem ser submetidos a processos diagenéticos ou de oxidação devido ao intemperismo, os quais geralmente acontecem na superfície e ao longo de fissuras dos grãos. $\mathrm{O}$ crescimento de um novo mineral (ou a alteração de um já existente) envolve mudanças no volume $(\mathrm{V})$, na magnetização espontânea $\left(\mathrm{M}_{\mathrm{S}}\right)$ e na coercividade $\left(\mathrm{B}_{\mathrm{C}}\right)$ dos grãos magnéticos. Assim, a alteração química afeta o tempo de relaxação dos grãos, segundo a equação (3.5). Os grãos eventualmente crescem acima de um volume crítico, no qual a magnetização do grão fica bloqueada. A nova magnetização remanente química é adquirida na direção do campo magnético externo (natural) atuante durante a alteração química, por isso, é normalmente uma componente remanente secundária. A MRQ tem propriedades magnéticas similares à MTR. Um exemplo comum é a formação de hematita durante a diagênese ou intemperismo. A hematita originada neste processo é uma portadora típica de magnetização remanente química secundária.

\subsubsection{Magnetização Remanente Viscosa (MRV)}

A dependência do tempo de relaxação com o volume mostra também que, mesmo à temperatura ambiente, grãos magnéticos com volumes muito pequenos $(<0,02 \mu \mathrm{m})$ apresentam tempos de relaxação também muito baixos (< $100 \mathrm{~s})$, fazendo com que estes grãos percam rapidamente suas magnetizações. Por este motivo, estes grãos são chamados de 
superparamagnéticos. A teoria propõe que para um conjunto de grãos magnéticos SD de mesmo tamanho e forma, a magnetização $M_{r}(0)$ adquirida no tempo $t=0$, decairá com o tempo $t$ de acordo com a expressão 3.6.

$$
M_{r}(t)=M_{r}(0) \exp \left(-\frac{t}{\tau}\right)
$$

Esta expressão mostra que a estabilidade da magnetização, além de depender exponencialmente do tempo de relaxação, varia também exponencialmente com o tempo decorrido. Assim, grãos com tempos de relaxação menores são mais suscetíveis a perder sua magnetização com o tempo. Na ausência de campo magnético externo, a tendência do conjunto de grãos é a de sua magnetização $M_{r}(0)$ decair exponencialmente com o tempo até zero, tempo este que dependerá do tempo de relação associado aos grãos. Entretanto, na presença de um campo magnético externo, as magnetizações dos grãos tendem, viscosamente, a se reorientar na direção do campo atuante. Na presença do campo geomagnético, a magnetização resultante é chamada de magnetização remanente viscosa (MRV) e apresenta a direção do campo geomagnético atual.

A magnetização adquirida por uma rocha, seja ela uma MTR, uma MRD ou uma MRQ, pode apresentar como portadores magnéticos grãos de tamanhos variados e, assim, com tempos de relaxação variando desde segundos até bilhões de anos. Deste modo, toda rocha pode conter magnetização viscosa, o que muitas vezes mascara a magnetização adquirida durante a sua formação. Todavia, devido a sua natureza de afetar grãos com tempos de relaxação menores, veremos que a MRV pode ser facilmente removida através dos processos de desmagnetização descritos a seguir.

\subsection{Processos de Desmagnetização}

A magnetização remanente natural (MRN) de uma rocha pode conter várias componentes, as quais decorrem da sua historia geológica, isto é, dos eventos geológicos que a afetaram desde a sua formação. $\mathrm{O}$ estudo da $\mathrm{MRN}$ é efetuado mediante etapas sucessivas de desmagnetização, visando a remoção progressiva das componentes de magnetização adquiridas pela rocha. $\mathrm{O}$ principal objetivo neste processo é identificar a componente final 
(com maiores coercividades ou temperaturas de bloqueio), a qual representa a magnetização remanente característica (MRC) comum a um grupo de amostras analisadas. Além de proporcionar informações sobre as componentes de magnetização, os processos de desmagnetização podem fornecer evidências sobre os minerais magnéticos portadores da MRC.

As desmagnetizações por campos magnéticos alternados (AF, do inglês alternating field) e por temperaturas (desmagnetização térmica) representam procedimentos comuns de laboratório, nas pesquisas paleomagnéticas, os quais visam a separação de componentes de magnetização presentes na rocha. A magnetização remanente resultante após cada etapa de desmagnetização é medida através de um magnetômetro. Geralmente, grupos pilotos de amostras são primeiramente submetidos à desmagnetização por campos magnéticos alternados e posteriormente a desmagnetização térmica. Com isto, pode-se ter uma ideia do comportamento magnético das amostras, caracterizando os intervalos de coercividades ou temperaturas de bloqueio associados a cada componente de magnetização isolada e, assim, escolher o procedimento mais adequado a ser empregado às outras amostras (Butler, 1992).

\subsubsection{Desmagnetização por Campos Magnéticos Alternados (CA)}

O processo de desmagnetização por Campos Alternados ou AF resume-se em aplicar na rocha, em ambiente de campo nulo, um campo magnético alternado com valor de pico $\mathrm{H}$ que diminui linearmente com o tempo até atingir o valor zero, como mostrado na Figura 3.6. Deste modo, os grãos magnéticos com coercividades $\left(\mathrm{H}_{\mathrm{c}}\right)$ menores ou iguais a $\mathrm{H}$ são sucessivamente reorientados na direção do campo magnético alternado aplicado, fazendo com que a magnetização total associada a estes grãos seja nula. Assim, os grãos magnéticos que foram desmagnetizados não contribuem mais para a medida do campo magnético resultante da amostra (Tarling, 1983). Para a análise da remanência magnética das rochas, dois tipos de desmagnetizadores por campos alternados são normalmente utilizados: o de eixo fixo e o de eixo rotativo. No primeiro tipo, a amostra é desmagnetizada ao longo de três eixos ortogonais fixos na amostra. No segundo caso, a amostra gira em torno de dois eixos durante a desmagnetização de forma que o campo alternado é aplicado em todas as direções da amostra. Este procedimento garante uma maior eficiência na desmagnetização das 
amostras. Por outro lado, aparelhos deste tipo atingem campos de, no máximo, 100 mT (e.g., desmagnetizador por campos alternados da Molspin). Já os desmagnetizadores de eixo fixo atingem campos bem maiores, de até 200 mT, como e o caso do desmagnetizador SI4 da Saphire Instruments".

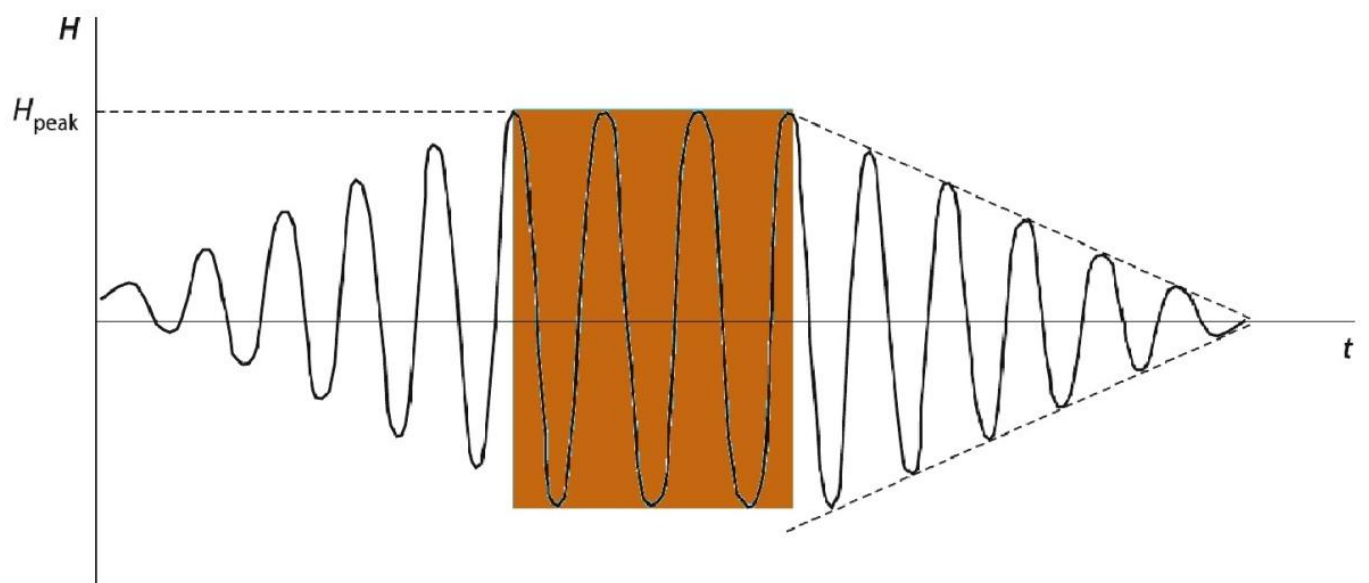

Figura 3.6: Esquema do processo de aplicação do campo magnético alternado. A intensidade do campo magnético aplicado aumenta linearmente com o tempo até atingir um patamar de curta duração $\left(\mathrm{H}_{\text {peak }}\right)$ (seção marrom da figura). Após a estabilidade na intensidade máxima, o valor do campo começa a decair linearmente até atingir o valor nulo. [Extraído de The Earth's Magnetism; R. Lanza and A. Meloni, 2006]

Campos magnéticos alternados crescentes são sucessivamente aplicados na rocha visando eliminar componentes com coercividades sucessivamente maiores. Normalmente, para uma amostra piloto, utiliza-se passos de $2,5 \mathrm{mT}$ ate atingir o campo de $15 \mathrm{mT}$ e passos de $5 \mathrm{mT}$ (ou $10 \mathrm{mT}$ ) ate alcançar o limite máximo do aparelho (100 mT). Após cada etapa de desmagnetização é medida a direção e magnitude da magnetização da amostra. Este detalhamento permite investigar o espectro de coercividades associado às componentes de magnetização da rocha. A eficiência do processo de desmagnetização por campos alternados na separação de componentes é limitada, pois depende diretamente dos minerais magnéticos que ela contém e de suas propriedades (espectro de coercividades e estabilidade magnética). O processo é geralmente eficiente para rochas contendo titanomagnetitas como principal portador magnético. Para rochas contendo minerais magnéticos com coercividades muito altas (e.g., hematita, goetita, pirrotita), o tratamento térmico mostra-se, geralmente, mais eficiente. Outra característica da desmagnetização CA é que o processo não altera quimicamente os minerais magnéticos do material, mas afeta apenas a direção e a intensidade da magnetização remanente. 


\subsubsection{Desmagnetização Térmica}

O processo de desmagnetização térmica consiste em aquecer a rocha até certa temperatura, em ambiente de campo nulo. Dessa maneira, todos os grãos com temperaturas de bloqueio menores ou iguais a essa temperatura serão termicamente afetados gerando momentos magnéticos orientados aleatoriamente e, assim, produzindo uma magnetização resultante nula. Quando a rocha e resfriada à temperatura ambiente, somente a componente da MRN que não foi afetada permanece. O procedimento de aquecimento, resfriamento e medida é repetido para etapas crescentes de temperatura até atingir a temperatura de Curie $\left(\mathrm{T}_{\mathrm{c}}\right)$ dos minerais magnéticos presentes na rocha. Este processo de aquecimento-resfriamento separa componentes de magnetização com diferentes temperaturas de bloqueio.

Um processo de desmagnetização térmica detalhado consiste em aquecer os espécimes a 100 ${ }^{\circ} \mathrm{C}$ e gradualmente realizar incrementos de $50{ }^{\circ} \mathrm{C}$ ate atingir $500{ }^{\circ} \mathrm{C}$ e, posteriormente, com incrementos de $20{ }^{\circ} \mathrm{C}$ até atingir $600{ }^{\circ} \mathrm{C}$ ou $700{ }^{\circ} \mathrm{C}$, dependendo dos minerais presentes na rocha. Este procedimento detalhado permite investigar o espectro de temperaturas de bloqueio associado às componentes de magnetização das rochas, possibilitando identificar os portadores magnéticos da amostra (D'Agrella-Filho,1984; McElhinny, 1973). O procedimento descrito é adequado para analisar rochas que contêm magnetita e hematita como portadores magnéticos. Entretanto, para rochas que possuam minerais com temperaturas de Curie menores (e.g., goetita $\left(\mathrm{T}_{\mathrm{c}}=120^{\circ} \mathrm{C}\right)$, pirrotita $\left(\mathrm{T}_{\mathrm{c}}=320^{\circ} \mathrm{C}\right)$ ) é importante que incrementos de temperaturas menores $\left(20^{\circ} \mathrm{C}\right.$, por exemplo) sejam também aplicados para temperaturas $100{ }^{\circ} \mathrm{C}$ abaixo das respectivas temperaturas de Curie destes minerais.

Simultaneamente ao processo de desmagnetização térmica é medida a susceptibilidade magnética das amostras com o objetivo de verificar possíveis transformações químicas dos minerais magnéticos na rocha. Desse modo, qualquer variação na susceptibilidade magnética demonstra uma mudança da composição química dos minerais que formam a rocha (D'Agrella-Filho, 1984). 


\subsection{Análise das Componentes de Magnetização}

A composição magnética total de uma amostra de rocha pode ser estudada por meio de desmagnetizações progressivas. Consequentemente, estas desmagnetizações progressivas representam, entre outros, os métodos mais importantes utilizados para a análise paleomagnética. Para podermos analisar e interpretar a informação obtida através das desmagnetizações progressivas para um conjunto de amostras, as direções medidas são representadas em projeções estereográficas (Figura 3.7) ou em projeções ortogonais (projeções de Zijderveld) (Figura 3.8). Na projeção estereográfica, as direções de magnetização são representadas por vetores unitários sobre uma esfera de raio unitário. $\mathrm{O}$ vetor é projetado no plano equatorial da esfera, unindo a ponta do vetor ao polo sul da esfera, no caso de inclinações negativas, ou ao pólo norte da esfera para inclinações positivas (Figura 3.7a). A declinação do vetor varia de 0 a $360^{\circ}$ e a inclinação varia de $0^{\circ}$ (na borda do círculo) até $90^{\circ}$ (no centro do círculo) (Figura 3.7b). Por convenção, inclinações positivas são representadas por símbolos cheios e inclinações negativas por símbolos vazios. (Figura 3.6). Como somente a direção de magnetização pode ser observada nesta projeção, a intensidade de magnetização (geralmente normalizada pela intensidade da NRM) é representada por um gráfico em função do campo alternado ou da temperatura. Este gráfico fornece o espectro de coercividades ou de temperaturas de bloqueio dos minerais magnéticos presentes nas rochas.

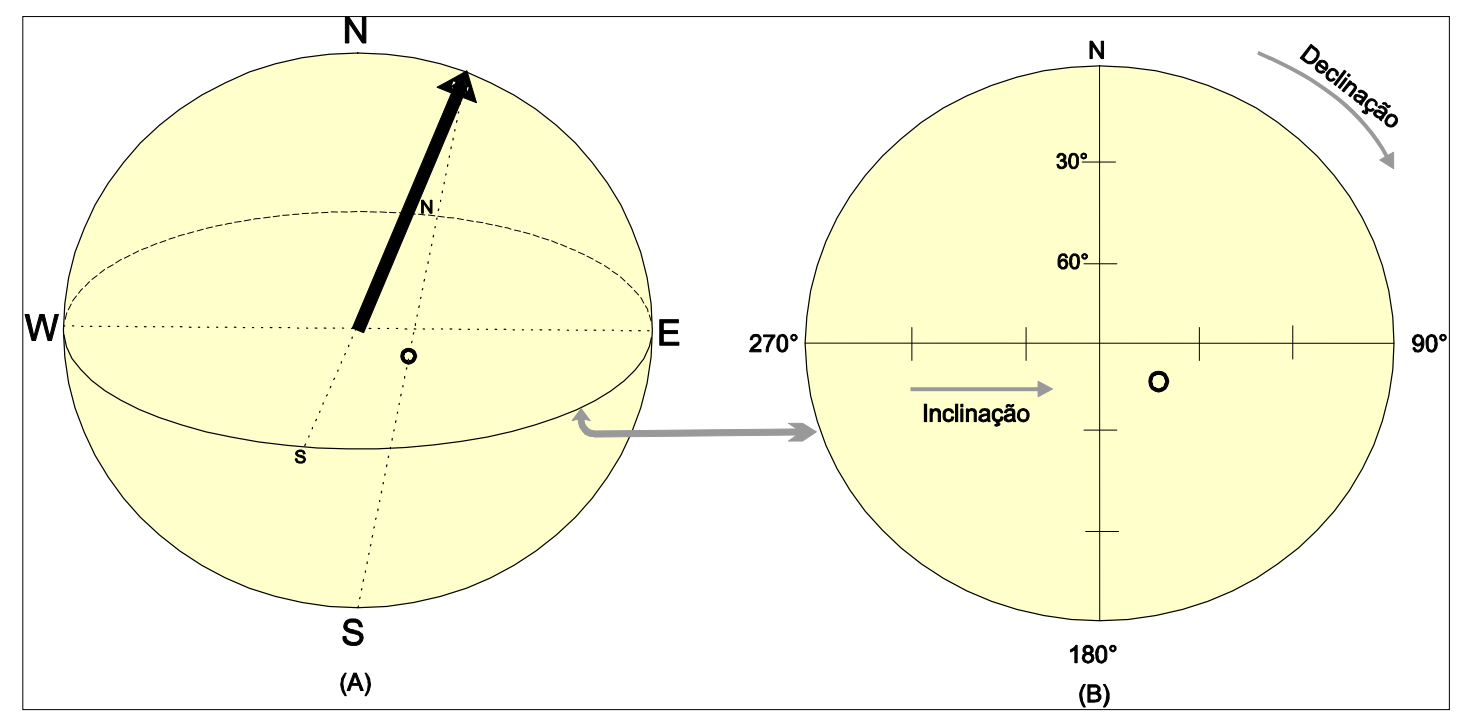

Figura 3.7. (a) Representação do vetor na esfera de raio unitário e sua projeção no plano equatorial, (b) projeção estereográfica (plano equatorial da esfera) [Extraído de Bispo-Santos (2012)]. 
A projeção ortogonal é um método mais eficiente para determinar a composição vetorial das magnetizações adquiridas pela rocha, o qual foi desenvolvido por Zijderveld, em 1967. Nesta projeção, a ponta do vetor resultante, é projetada nos planos vertical e horizontal do sistema de referência ortogonal. O plano horizontal é então rebatido para o plano vertical ao longo do eixo N-S ou, mais comumente, ao longo do eixo E-W, sendo assim, possível representar as duas projeções no mesmo plano (Figura 3.8). Por convenção, símbolos cheios (vazios) no diagrama de Zijderveld representam projeções no plano horizontal (vertical).
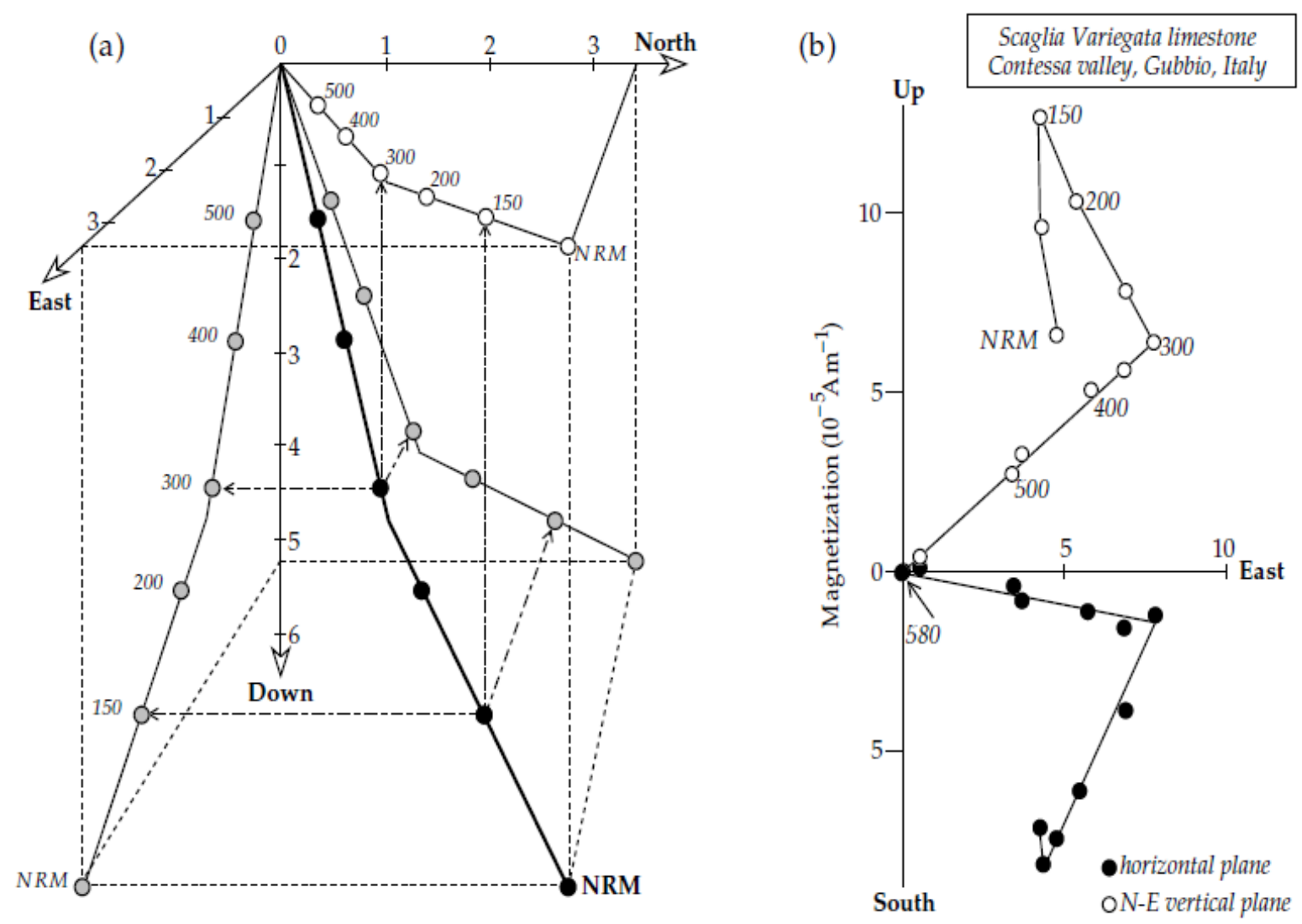

Figura 3.8: Diagrama vetorial de Zijderveld para analisar desmagnetização AF ou térmica. (a) Diagrama mostrando as projeções da ponta do vetor magnetização em três planos ortogonais após cada etapa de desmagnetização (planos horizontal, vertical N-S e vertical E-W). (b) Etapas de desmagnetização obtidas por desmagnetização térmica para uma amostra de calcário da região de Gubbio, Itália. As componentes de magnetização sem sobreposição no espectro de temperatura de bloqueio mostram-se como segmentos lineares. [Extraído de Fundamentals of Geophysics; W. Lowrie, 2007]

As componentes da MRN que têm diferentes espectros de temperatura de bloqueio ou coercividades apresentam-se como linhas retas no diagrama do vetor de desmagnetização. $\mathrm{O}$ 
exemplo da Figura $3.8 \mathrm{~b}$ apresenta três segmentos lineares que representam diferentes componentes da MRN com diferentes direções obtidas durante o tratamento térmico realizado para um calcário da região de Gubbio, Itália. A componente removida abaixo dos $150{ }^{\circ} \mathrm{C}$ tem direção norte com inclinação positiva. A componente mencionada é provavelmente um registro adquirido do campo atual. O intervalo entre $150{ }^{\circ} \mathrm{C}$ e $300{ }^{\circ} \mathrm{C}$ pode representar um registro do campo geomagnético mais antigo (remagnetização); a componente apresenta direção sul/sudoeste, com inclinação negativa. $\mathrm{O}$ intervalo entre 300 ${ }^{\circ} \mathrm{C}$ e $580{ }^{\circ} \mathrm{C}$ define uma direção leste/sudeste, também com inclinação negativa. Observa-se que os pontos caminham para o centro do sistema ortogonal indicando que, muito provavelmente, esta é a última componente (com maiores temperaturas de bloqueio) presente nesta amostra.

Em casos onde mais de uma componente de magnetização estão presentes, pode acontecer de os espectros de coercividades ou temperaturas de bloqueio se sobreporem parcialmente. A Figura 3.9 mostra três situações possíveis de amostras com duas componentes de magnetização com espectros de coercividades ou de temperaturas de bloqueio diferentes. $\mathrm{Na}$ Figura 3.9a, as duas componentes apresentam espectros distintos. Neste caso, as duas componentes são bem definidas nas projeções ortogonais. Na Figura 3.9b, as duas componentes apresentam espectros que se superpõem parcialmente. Neste caso, o diagrama vetorial apresenta uma trajetória em curva durante as etapas de desmagnetização onde há superposição. Note, entretanto, que ainda é possível definir as duas direções nos intervalos onde não há superposição. Na Figura 3.9c, as duas componentes apresentam espectros que se superpõem totalmente. Neste caso, não é possível determinar as duas componentes pelo método de projeções ortogonais. 

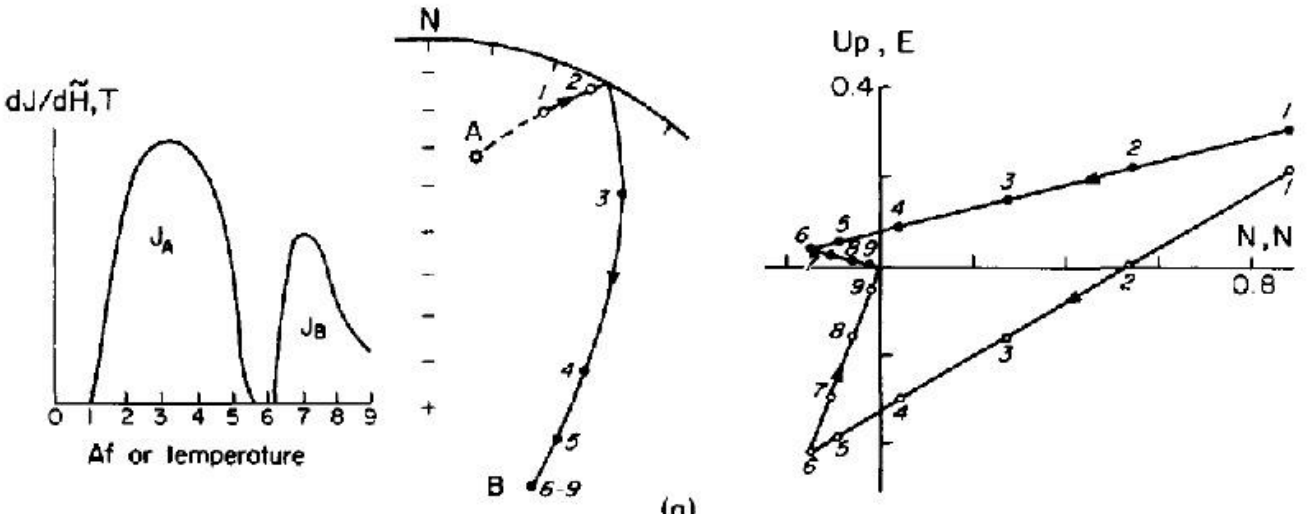

(a)

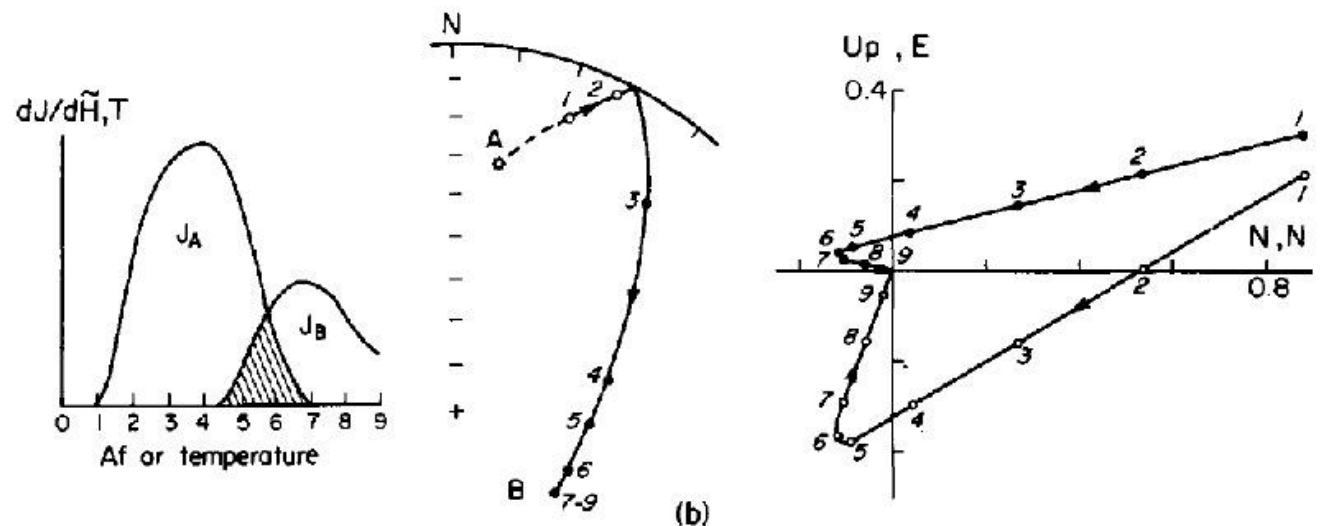

(b)
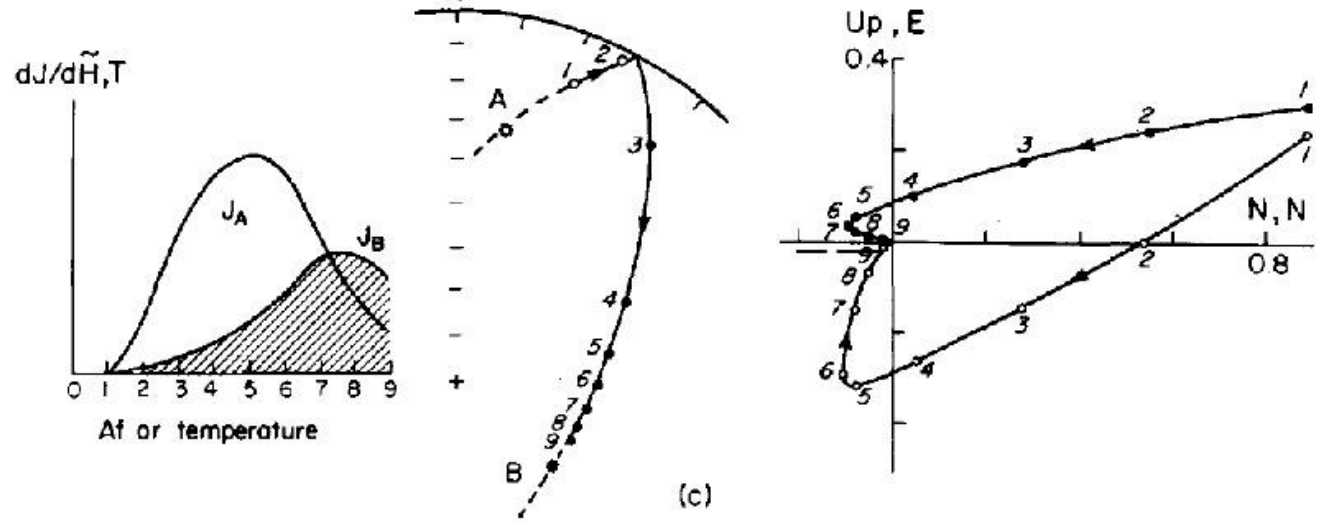

Figura 3.9. Espectros de coercividades e/ou temperaturas de bloqueio de duas componentes de magnetização e representação estereográfica e diagramas de Zijderveld para as seguintes situações: (a) espectro não superposto (comportamento ideal de Zijderveld), (b) superposição parcial, e (c) superposição total (comportamento não ideal). Em (a) e (b), ambas as direções podem ser determinadas; em (c), nenhuma pode ser determinada. [Extraído de On the use of Zijderveld vector diagrams in multicomponent paleomagnetic studies; D. Dunlop, 1979]

Utilizando o método de Zijderveld, Kirschvink (1980) aplicou a técnica de análise dos componentes principais (ACP) para estimar a colinearidade e coplanariedade dos pontos ao longo da trajetória de desmagnetização da amostra. A direção de magnetização é 
determinada pelo ajuste por mínimos quadrados. Determina-se a reta que melhor se ajusta aos pontos sucessivos, cuja precisão é estimada pelo desvio angular máximo (mean angular deviation - MAD).

Embora não exista uma regra geral, quando analisamos as direções através da análise dos componentes principais, descartamos o ajuste do componente principal que produz um MAD $\geq 8,0$. Todavia, na literatura costuma-se considerar um $\mathrm{MAD} \leq 10,0$ como sendo aceitável para os resultados paleomagnéticos (Tauxe, 2002, 2009).

\subsection{Estudo da Mineralogia Magnética}

A fim de compreender o significado geológico das magnetizações isoladas nos tratamentos por campos alternados e térmico é indispensável identificar os minerais portadores destas magnetizações e quais são as suas principais propriedades magnéticas. Existem métodos de análise mineralógica, tais como, difração de raios-X, microscopia de luz refletida e microsonda, que podem ser usados para o estudo dos minerais magnéticos presentes na rocha. Estes métodos são úteis para identificar os minerais magnéticos em boa parte das rochas. Entretanto, em alguns casos, o uso destas técnicas são dificultadas pela baixa concentração de minerais ferromagnéticos e/ou pelas suas pequenas dimensões, menores a $1 \mu \mathrm{m}$. Assim, métodos que usam experimentos magnéticos são importantes para investigar as propriedades magnéticas das rochas, procurando identificar e caracterizar os seus minerais portadores, além de avaliar a origem e a estabilidade das componentes da magnetização remanente. A metodologia empregada envolve a observação de alguma propriedade magnética, característica do mineral (ou minerais) magnético presente na rocha em estudo, seja pela aplicação de campos magnéticos (curvas de histerese ou curvas de magnetização remanente isotérmica - MRI) ou temperaturas (curvas termomagnéticas).

\subsubsection{Identificação dos Minerais "Ferromagnéticos"}

\subsubsection{Curvas Termomagnéticas}

As curvas termomagnéticas de altas temperaturas são utilizadas para determinar a temperatura de Curie e de Néel de cada fase magnética da rocha mediante a análise da susceptibilidade magnética em função da temperatura. Já as curvas de baixas temperaturas, obtidas através de resfriamento em nitrogênio líquido e posterior aquecimento gradual até 
atingir a temperatura ambiente (variação de $-200^{\circ} \mathrm{C}$ até a temperatura ambiente) identificam transições magnéticas associadas aos minerais presentes na rocha (e.g., transição de Verwey que ocorre a $120 \mathrm{~K}$, a qual é característica da presença de magnetita, Dunlop e Özdemir, 1997). Durante o aquecimento podem ocorrer mudanças na estrutura cristalina além de reações químicas que alteram os minerais originais da rocha. Para evitar estas transformações mineralógicas, os experimentos são, preferencialmente, realizados em atmosfera controlada, utilizando argônio, a qual limita as reações de oxidação que podem acontecer nos minerais magnéticos.

As curvas termomagnéticas são classificadas como reversíveis e irreversíveis. No caso em que as curvas de aquecimento e resfriamento são diferentes, dizemos que ela é irreversível (Figura 3.10a). Este fato decorre de transformações mineralógicas que formam novos minerais com susceptibilidades magnéticas distintas. As curvas reversíveis descrevem o mesmo comportamento da susceptibilidade, tanto no aquecimento como no resfriamento dos minerais que compõem a rocha (Figura 3.10b)
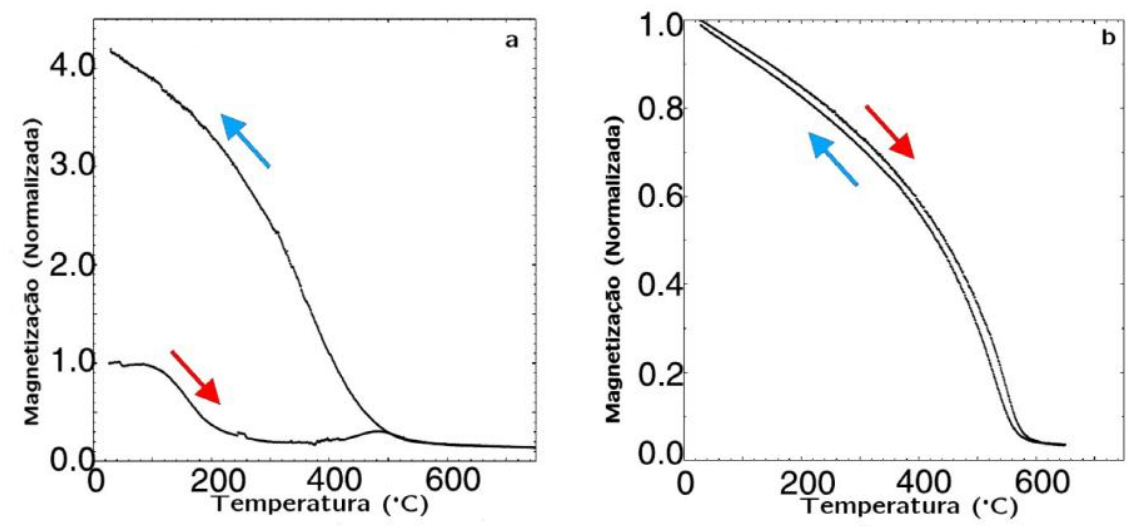

Figura 3.10. Comportamento de curvas termomagnéticas. (a) A curva termomagnética descreve duas trajetórias, uma no aquecimento e outra no resfriamento. Este comportamento caracteriza uma curva irreversível. A curva mostra a presença de titanomagnetita pouco oxidada com temperatura de Curie próxima de $220^{\circ} \mathrm{C}$. (b) Para o segundo caso, a curva representa o comportamento reversível. A curva termomagnética é característica de titanomagnetita pobre em titânio e rica em ferro. A temperatura de Curie está em torno de 570 ${ }^{\circ} \mathrm{C}$. [Modificado de Carvallo et al, 2004]

\subsubsection{Ciclos de Histerese Magnética}


A rocha é formada por concentrações variadas de minerais diamagnéticos, paramagnéticos e ferromagnéticos que respondem de forma diferente a campos magnéticos externos. Os minerais ferromagnéticos são os únicos a apresentar histerese magnética, isto é, quando submetidos a campos magnéticos preservam uma magnetização remanente quando o campo é retirado. Os minerais ferromagnéticos (e.g., titanomagnetica, magnetita, hematita), por sua vez, apresentam propriedades magnéticas próprias, as quais caracterizam a forma da curva definida pela magnetização em função do campo aplicado (curvas de histerese). Deste modo, as curvas de histerese podem ser usadas para identificar os minerais magnéticos presentes na rocha.

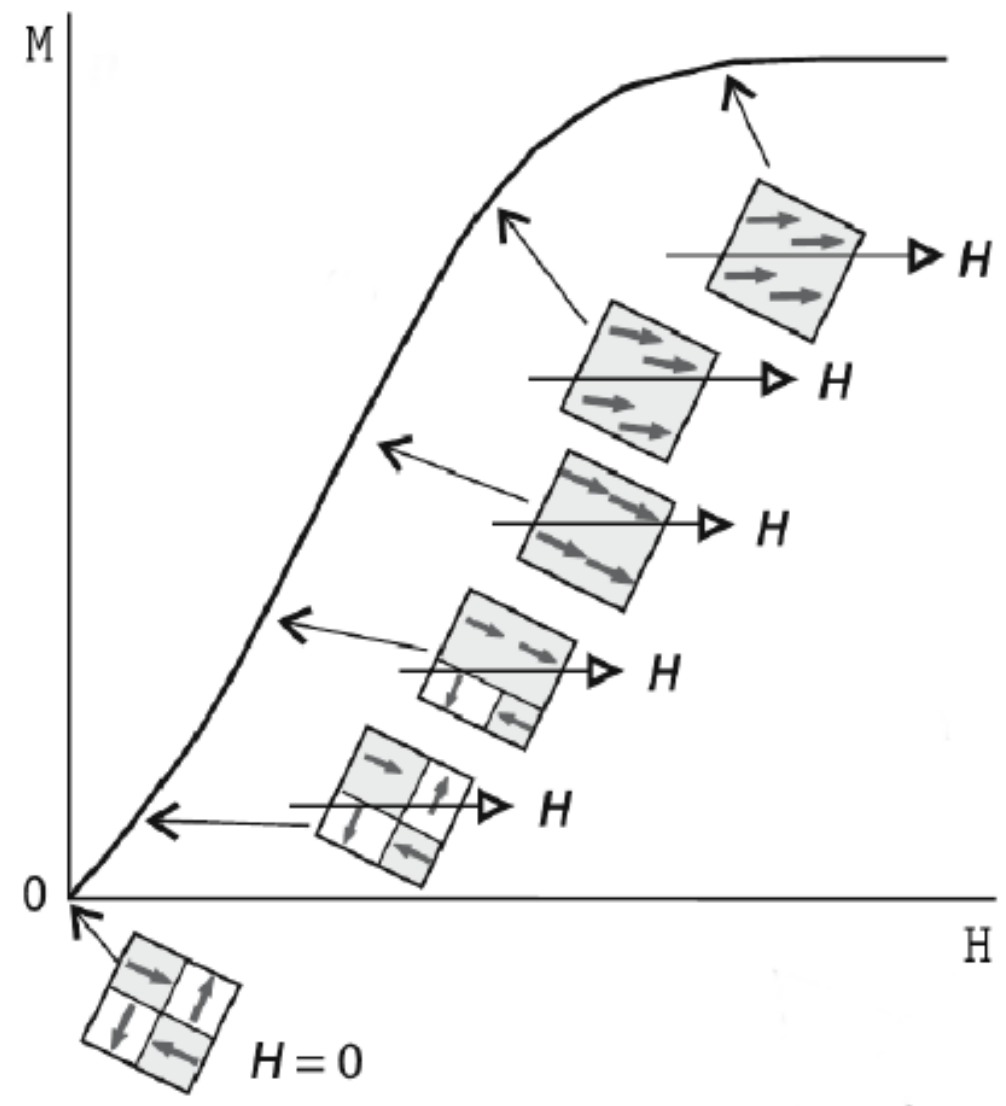

Figura 3.11: Histerese Magnética. Os domínios magnéticos têm comportamento concordante com o campo magnético $\mathrm{H}$, inicialmente crescendo nos domínios em que a magnetização tem a direção mais próxima de $\mathrm{H}$ e logo depois rotacionando no sentido do campo aplicado. [Modificado de R. Lanza and Meloni, 2006]

A curva de histerese para um conjunto de grãos de multi-domínios (MD) pode ser entendida da seguinte forma (Figura 3.11): no estado inicial, com a intensidade do campo $\mathbf{H = 0}$, cada 
um dos domínios da amostra está orientado segundo as próprias direções ou "eixos fáceis" de magnetização e a resultante vetorial da magnetização é nula $(\mathbf{M}=0)$. Acréscimos sucessivos na intensidade do campo magnético $\mathbf{H}$ modificam as paredes dos domínios magnéticos, favorecendo o crescimento dos domínios no sentido do campo magnético aplicado. Conforme a intensidade do campo magnético aumenta mais, alguns dos domínios magnéticos começam a rotacionar na direção de magnetização (como apresentado na Figura 3.11), com transições iniciais pequenas, desde um estado de energia menor, para estados de maior energia que são favorecidos pelo fato que a rotação reduz a energia associada ao campo $\mathbf{H}$. A intensidade da magnetização $\mathbf{M}$ aumenta de maneira acentuada no inicio, mas logo depois esta tendência diminui como a Figura 3.11 mostra. Conforme os momentos magnéticos ficam alinhados, cada vez mais são menos os momentos magnéticos que têm direções diferentes a do campo magnético aplicado. No instante em que os momentos magnéticos estão totalmente alinhados com $\mathrm{H}$, o campo magnético que gera este efeito é denominado de campo magnético de saturação e a magnetização atinge seu valor máximo (magnetização de saturação $-M_{s}$ na Figura 3.12). Acréscimos na intensidade do campo magnético não produzirão mais efeito na magnetização, pois não existem mais domínios magnéticos que possam ser alinhados com o campo. Quando o campo H decresce a interação entre o campo e os domínios magnéticos também decresce, mas nem todos os domínios são capazes de superar barreiras de energia e, assim, não retornam as suas posições de energia mínima inicial. Neste processo, quando o campo volta a ser nulo, permanece uma magnetização residual, a qual é chamada de magnetização remanente de saturação ( $\mathrm{M}_{\mathrm{rs}}$ na Figura 3.12). 


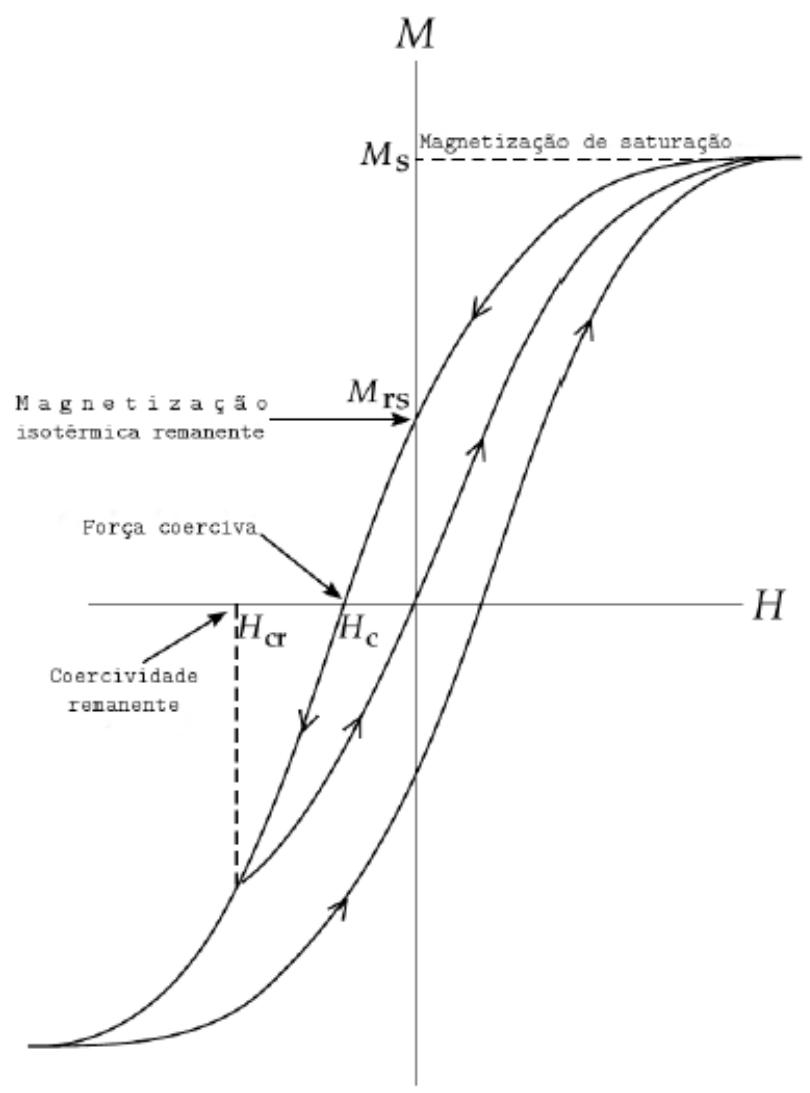

Figura 3.12. Ciclo de Histerese Magnética. Ciclo de histerese magnética para um mineral ferromagnético arbitrário. [Modificado de Fundamentals of Geophysics; W. Lowrie, 2007]

Para que a magnetização $\mathbf{M}_{\mathbf{r s}}$ volte a zero, o campo $\mathbf{H}$ deve ser aplicado na direção contrária. A força coerciva ( $\mathbf{H}_{\mathbf{c}}$ na Figura 3.12) é o valor do campo onde a magnetização medida volta a se anular $(\mathbf{M}=0)$. A coercividade de remanência $-\left(\mathbf{H}_{\mathbf{c r}}\right.$ na Figura 3.12) é o valor de campo necessário para reduzir a magnetização $\mathbf{M}_{\mathbf{r s}}$ a zero, isto é, a magnetização remanente se anula $\left(\mathbf{M}_{\mathbf{r}}=0\right)$ após a remoção do campo aplicado. Prosseguindo com o incremento da intensidade do campo magnético no sentido contrário (-H), a magnetização (-M) também aumenta até atingir o valor da magnetização de saturação $\left(-M_{\mathrm{s}}\right)$ para um campo de saturação $\left(-\mathrm{H}_{\mathrm{S}}\right)$, os quais têm os mesmos significados dos valores positivos. Retornando aos valores positivos de $\mathrm{H}$, fechamos o ciclo de histerese (Figura 3.12). 
Os ciclos de histerese podem ser obtidos através de um magnetômetro de amostras vibrantes (Vibrating sample magnetometer - VSM). Para o presente trabalho foi utilizado o aparelho da MicroMag-VSM, Model 3900 (Princeton Measurements Corporation): neste instrumento a amostra vibra na presença de um campo magnético $\mathrm{H}$ uniforme, campo este produzido por um eletroímã.

No caso de análises realizadas em amostras de rochas, o ciclo de histerese pode ser influenciado pelos minerais para- e diamagnéticos. Essa influência pode comprometer a identificação dos minerais ferromagnéticos presentes na rocha, no caso em que ela apresenta um conteúdo baixo de minerais ferromagnéticos. Todavia, o efeito dos minerais para e diamagnéticos pode ser facilmente identificado devido à relação linear que existe entre a magnetização induzida e a intensidade de campo.

Uma forma de identificar a estrutura de domínios magnéticos para grãos de titanomagnetitas foi apresentada por Day et al. (1977). Estes autores sugerem a construção de um gráfico com as razão $\mathrm{M}_{\mathrm{rs}} / \mathrm{M}_{\mathrm{S}}$ em função da razão $\mathrm{H}_{\mathrm{cr}} / \mathrm{H}_{\mathrm{c}}$ (conhecido como diagrama de Day). Neste diagrama são definidos campos com domínios de grãos de domínio simples (SD), de pseudodomínio simples (PSD) e de multi-domínios (MD). Recentemente, Dunlop (2002a, b) modificou o diagrama de Day propondo que misturas de grãos SD/MD (com porcentagens distintas de grãos MD) caem ao longo de uma curva no campo PSD (Figura 3.13). O mesmo autor define também curvas com misturas variadas de grãos SD e grãos superparamagnéticos $(\mathrm{SP})$.

Existem diferentes tipos de ciclos de histerese magnética para materiais geológicos (Figura 3.14). A Figura 3.14a representa o comportamento com inclinação negativa típica de materiais diamagnéticos, tais como quartzo e carbonatos. A Figura 3.14b mostra o comportamento para materiais paramagnéticos; tal comportamento é comum em amostras com pouco material ferromagnético e rico em fases que contêm ferro, como a biotita ou argila. Quando o tamanho dos grãos é muito pequeno $(<10 \mathrm{~nm})$, uma amostra pode apresentar comportamento de histerese típico de minerais superparamagnéticos (Figura 3.14c). Minerais com grãos estáveis orientados aleatoriamente podem produzir ciclos de histerese de várias formas, dependendo da origem da anisotropia magnética e a estrutura de domínio (L. Tauxe, 2008). A Figura 3.14d mostra um ciclo característico de amostras cuja 
remanência decorre de magnetita SD com anisotropia uniaxial. A Figura 3.14e indica a presença de hematita cuja anisotropia deve ser magnetocristalina/magnetoestrictiva na origem (hexagonal, com momentos magnéticos no plano basal). Finalmente, a Figura 3.14f apresenta um ciclo que tem razões $\mathbf{M}_{\mathbf{r}} / \mathrm{M}_{\mathbf{S}}$ menores do que para domínios simples. Ciclos deste tipo são caracterizados como PSD (Tauxe, 2008). Grãos de magnetita multi-domínio apresentam cinturas finas, normalmente menores do que as obtidas para grãos PSD.

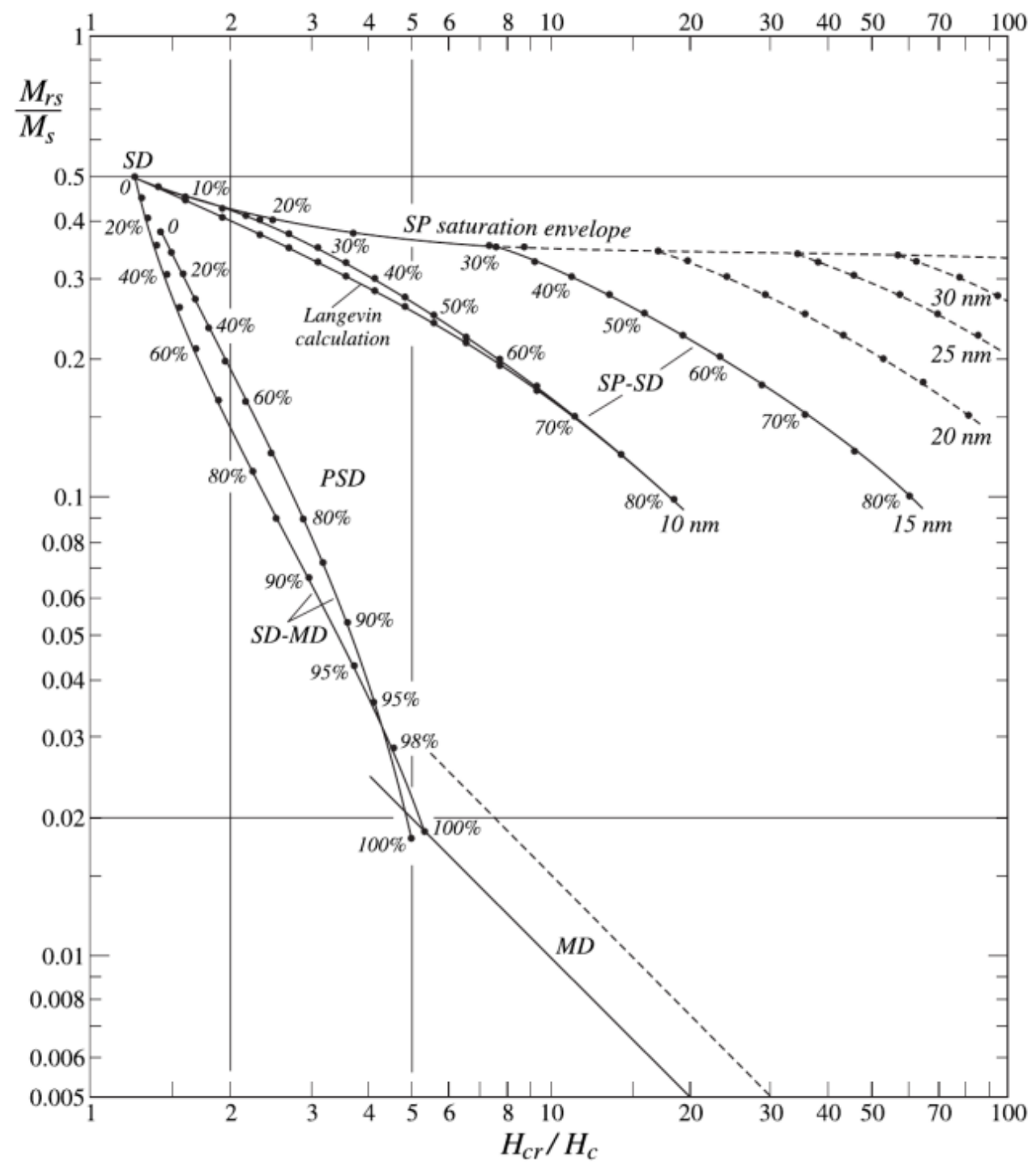

Figura 3.13. (a) Diagrama de Day et al. (1977) modificado por D. Dunlop (2002) evidenciando os diferentes domínios magnéticos presentes nas rochas: SD - domínio simples; PSD - pseudo-domínio simples; MD multi-domínios; curvas SD-MD indicam misturas de grãos SD e MD com diferentes porcentagens (indicadas na figura) de grãos MD; curvas SP-SD indicam misturas de grãos SD e SP com diferentes porcentagens (indicadas na figura) de grãos $S P$ de $10 \mathrm{~nm}, 15 \mathrm{~nm}, 20 \mathrm{~nm}, 25 \mathrm{~nm}$ e $30 \mathrm{~nm}$, respectivamente. 

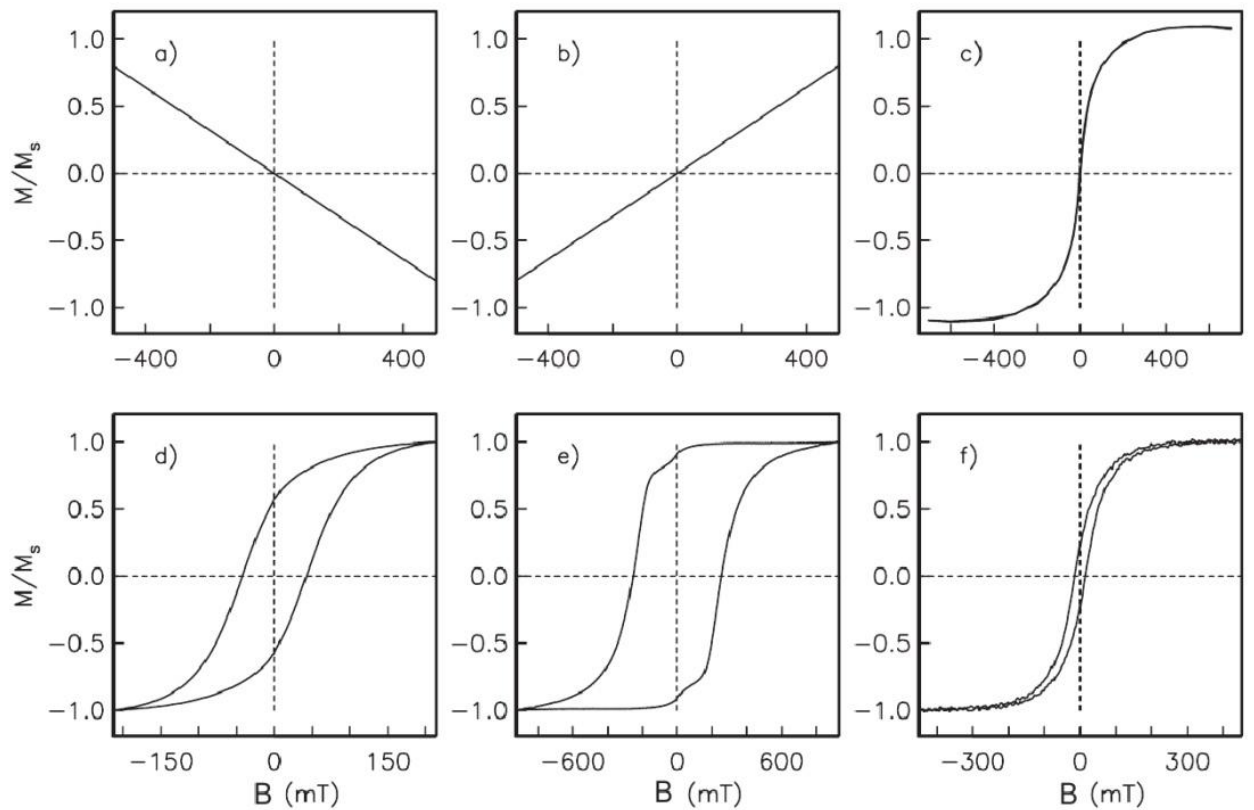

Figura 3.14. Ciclos de histerese magnética com comportamentos diferentes: (a) diamagnético, (a) paramagnético, (c) superparamagnético (e.g., vidro submarino basáltico), (d) uniaxial, monodomínio, (e) magnetocristalino, domínio simples, (f) pseudo-domínio simples. [Extraído de Essentials of Rock and Paleomagnetism ; L. Tauxe, 2008].

\subsubsection{Curvas de Magnetização Remanente Isotérmica(MRI)}

A magnetização remanente isotérmica (MRI) ou IRM (IRM do inglês isothermal remanent magnetization) resulta da aplicação de um campo magnético na amostra de rocha à temperatura constante. O método de análise consiste na aplicação de campos magnéticos com valores crescentes por meio de uma bobina ou por meio de eletroímãs, sendo que a magnetização remanente originada é medida após a aplicação de cada campo. Com isso, os momentos magnéticos dentro dos grãos vão sendo progressivamente alinhados na direção do campo aplicado (histereses parciais) até atingir o campo de saturação e, por consequência, a magnetização de saturação (Mrs) da amostra (Figura 3.15). Existe uma relação entre o grau de alinhamento dos grãos e a intensidade do campo aplicado, sendo que o alinhamento, além de depender da intensidade do campo aplicado, depende também da resistência dos minerais magnéticos a serem magnetizados, ou em outros termos, de suas coercividades. Assim, a forma da curva de MRI produzida para uma rocha revela as coercividades associadas aos seus minerais magnéticos e, por consequência, os minerais magnéticos presentes nas rochas 
(Figura 3.15). A aplicação do campo magnético é realizada para uma amostra já desmagnetizada (mediante campos magnéticos alternados).

O laboratório de paleomagnetismo do IAG tem dois aparelhos que podem ser usados para a construção de curvas de MRI: o MicroMag-VSM, Model 3900 (Princeton Measurements Corporation) em que a geração do campo é feita através de eletroímãs e o magnetizador de pulso da Magnetic Measurements, onde energia acumalada em capacitores cria um pulso de campo magnético em uma bobina indutora
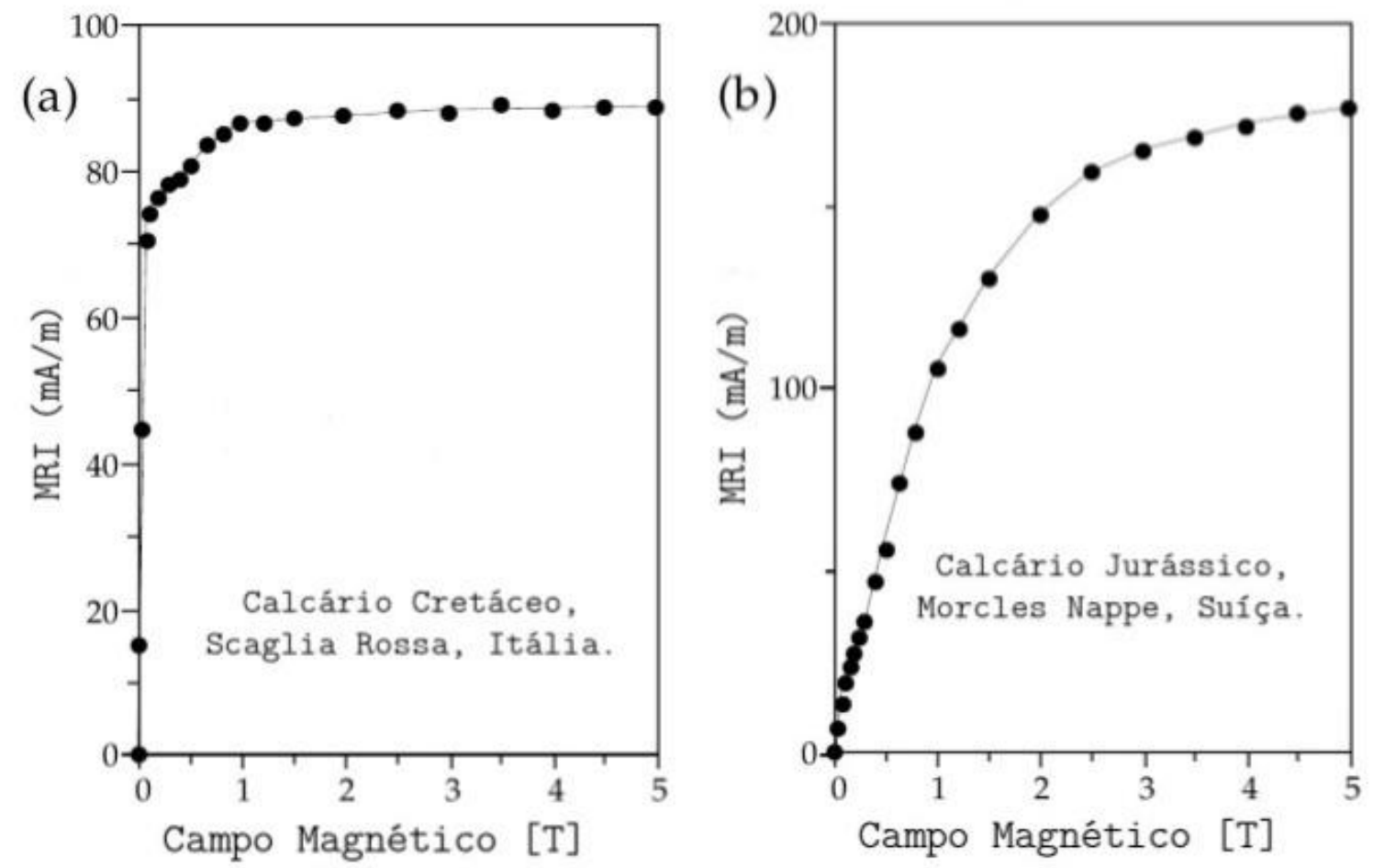

Figura 3.15: Exemplos de curvas de MRI obtidas para amostras de calcário do Cretácio (a) e do Jurássico (b). Em (a) a rocha apresenta magnetita e hematita e em (b) a rocha apresenta pirrotita e hematita [extraído de Lowrie, 1997].

\subsection{Análise Estatística de Direções Paleomagnéticas}

O método estatístico de análise de direções utilizado nos estudos paleomagnéticos foi desenvolvido pelo matemático, estatístico, biólogo evolutivo e geneticista inglês Sir Ronald Aylmer Fisher, no ano 1953. Nesta estatística, cada direção paleomagnética é considerada 
como sendo um vetor unitário, onde a ponta do vetor é representada por um ponto sobre uma esfera, também de raio unitário. Assim, os pontos representados por um conjunto de vetores ficam distribuídos sobre a superfície da esfera. Fisher (1953) mostra que a melhor estimativa da direção média de um conjunto de $\mathrm{N}$ vetores unitários é o vetor médio, $\mathrm{R}$, resultante da soma dos $\mathrm{N}$ vetores (Figura 3.16a). Como os vetores são unitários, o valor do módulo da resultante será sempre menor ou igual a $\mathrm{N}(\mathrm{R} \leq 5$, no exemplo da Figura 3.16b).

A densidade de probabilidade $\mathrm{P}(\theta, \kappa)$ do ângulo $\theta$ entre uma direção individual e a direção média da distribuição é:

$$
P(\theta, \kappa) \frac{\kappa}{4 \pi \sinh \kappa} \exp (\kappa \cos \theta)
$$

O parâmetro $\kappa$ é chamado de "parâmetro de precisão" e descreve a dispersão das direções. Este parâmetro pode ser comparado com o inverso da variância de uma distribuição. Os parâmetros calculados são estimativas aproximadas dos valores verdadeiros de uma população. Fisher (1953) mostra que a melhor estimativa $(\mathrm{k})$ do parâmetro de precisão $\kappa$ pode ser obtida pela seguinte expressão:

$$
k=\frac{N-1}{N-R}
$$

onde R é o módulo do vetor suma dos $\mathrm{N}$ vetores unitários, como mostrado na Figura 3.14b. Valores baixos de $\mathrm{k}$ indicam direções pouco agrupadas. Por outro lado, valores altos para $\mathrm{k}$ indicam direções bem agrupadas. A Figura 3.16c mostra grupos de direções com diferentes valores de $\mathrm{k}(10,50$ e 200$)$. 
(a)
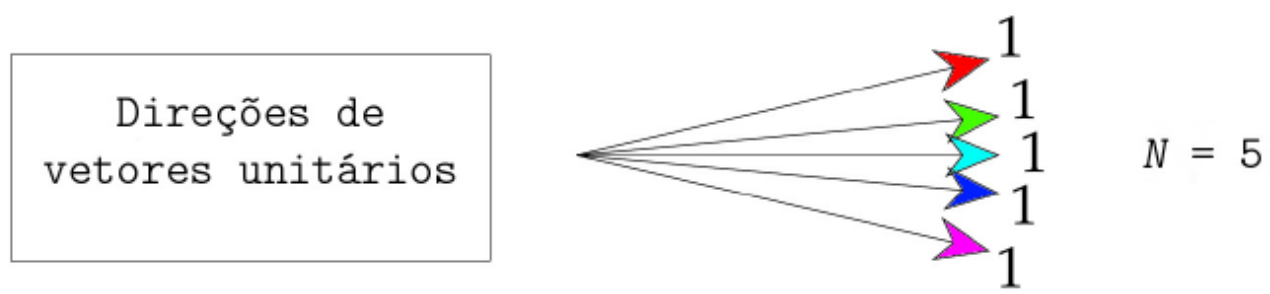

(b)

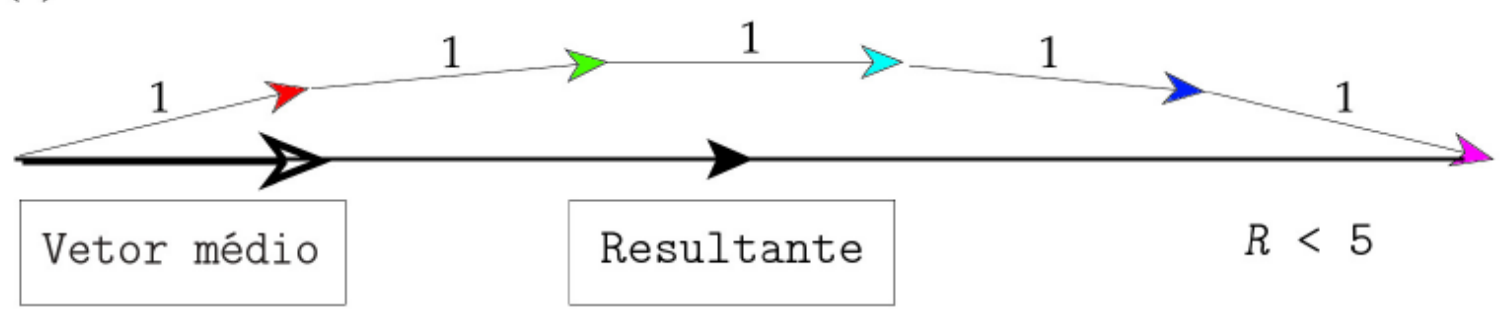

(c)

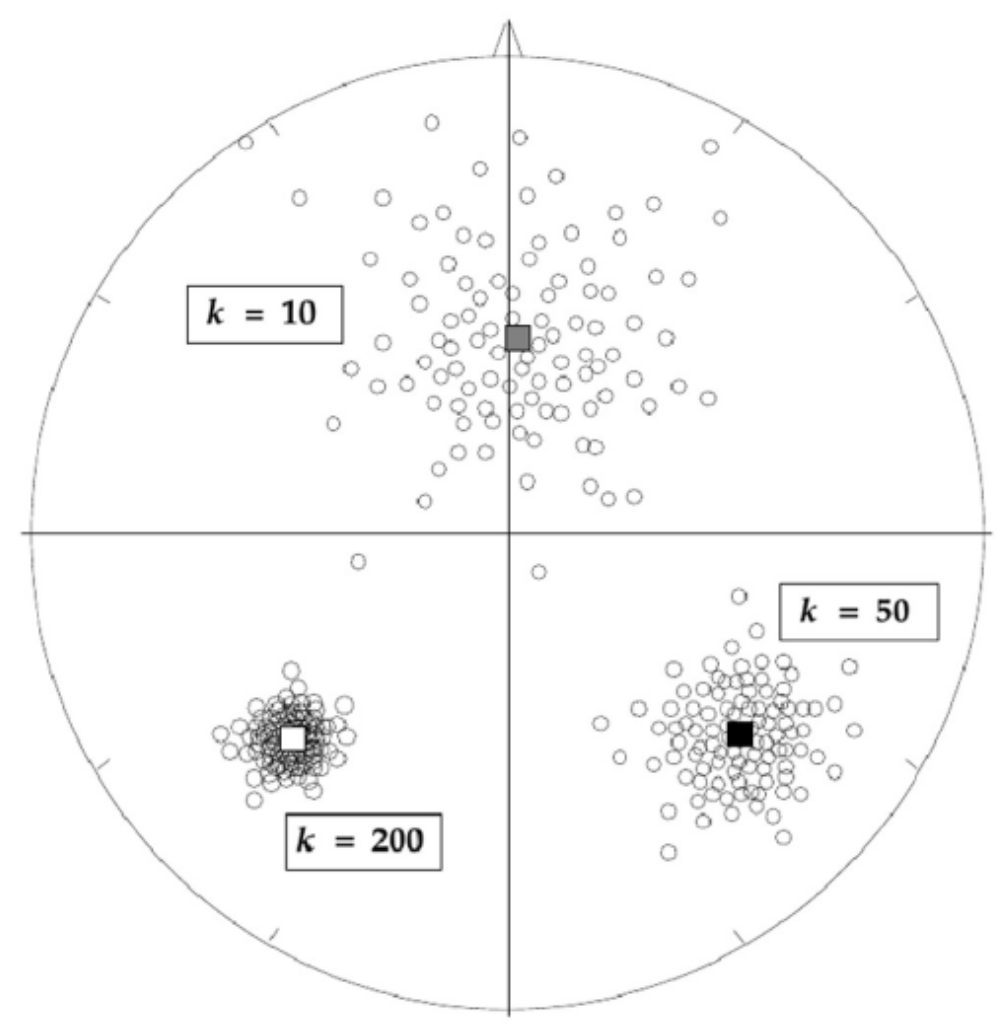

Figura 3.16. (a) Representação de cinco direções de magnetização como vetores unitários. (b) A direção do vetor médio é a direção do vetor resultante R. (c) Estereograma mostrando diferentes distribuições de direções paleomagnéticas: quanto maior o agrupamento das direções, maior o valor do parâmetro de precisão k [Modificado de Fundamentals of Geophysics; W. Lowrie, 2007]. 
Considerando um grupo de $\mathrm{N}$ direções com parâmetro de precisão k, será necessário também definir um parâmetro que determine um limite confiança para a direção média calculada. Este parâmetro seria análogo ao erro padrão estimado da média $\Delta \mathrm{m}$ de uma distribuição Gaussiana. Devemos lembrar que o valor verdadeiro da direção média não é conhecido e que a direção média que calculamos é simplesmente uma estimativa dela, com base nos dados disponíveis. Assim, a direção média estimada pode diferir de vários graus da direção verdadeira. Podemos estimar, entretanto, um limite de confiança definido por um cone circular em torno da direção média em que a direção verdadeira tem $95 \%$ de probabilidade de estar dentro deste cone. Considerando a estatística de Fisher, este limite de confiança (denominado de $\alpha_{95}$ ) é representado pelo semi-ângulo de um cone em torno da direção média calculada, o qual depende do número de direções $(\mathrm{N})$ da distribuição e do seu parâmetro de precisão $k$. Fisher (1953) mostra que a melhor estimativa para o valor do semi-ângulo do cone de confiança é representada pela equação:

$$
\alpha_{95}=\frac{140}{\sqrt{N k}}
$$

\subsection{Modelo de Dipolo Geocêntrico Axial}

Um conceito fundamental do paleomagnetismo é o de dipolo geocêntrico e axial, DGA ou GAD (do inglês - geocentric axial dipole). O modelo do GAD admite que, na média, o campo geomagnético pode ser representado pelo campo de um dipolo magnético localizado no centro da Terra e alinhado com o eixo de rotação da Terra (Figura 3.17). Neste modelo, a variação secular do campo geomagnético é eliminada na média e o polo magnético coincide com o polo geográfico. Assim, a declinação magnética, que representa o ângulo entre o polo geográfico e o polo magnético, vale zero para qualquer posição no globo terrestre. 


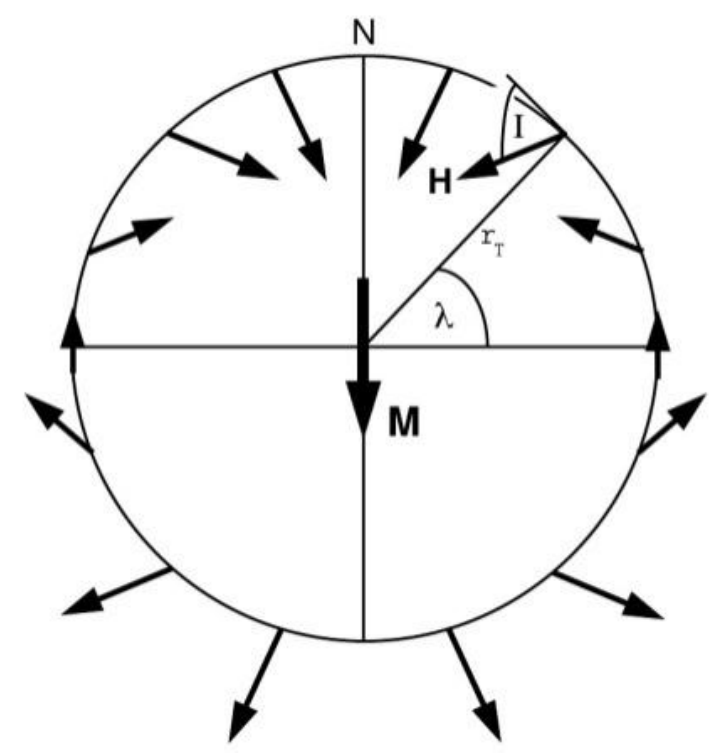

Figura 3.16. Representação de dipolo geocêntrico e axial. O momento de dipolo $\mathrm{M}$ acha-se localizado no centro da Terra e alinhado com o eixo de rotação; $\lambda$ é a latitude; $\mathrm{r}_{\mathrm{T}}$ é o rádio da Terra; as direções do campo magnético produzido na superfície estão mostrados esquematicamente: $\mathrm{H}$ representa o campo produzido pelo dipolo, I (inclinação) é mostrada para uma localização; $\mathrm{N}$ é o polo norte geográfico. [Modificado de Paleomagnetism: Magnetic Domains to Geologic Terranes; R. Butler, 1992]

O campo magnético $(\mathrm{H})$ produzido pelo dipolo pode ser decomposto nas componentes horizontal $\left(\mathrm{H}_{\mathrm{h}}\right)$ e vertical $\left(\mathrm{H}_{\mathrm{v}}\right)$, as quais podem ser expressas em função do momento magnético do dipolo $(\mathrm{M})$, da latitude local $(\lambda)$ e do raio da Terra $\left(\mathrm{r}_{\mathrm{T}}\right)$ :

$$
\begin{gathered}
H_{h}=\frac{M \cos \lambda}{r_{T}^{3}} \\
H_{v}=\frac{2 M \sin \lambda}{r_{T}^{3}} \\
H=\frac{M}{r_{T}^{3}} \sqrt{1+3 \sin ^{2} \lambda}
\end{gathered}
$$

As componentes horizontal $\left(\mathrm{H}_{\mathrm{h}}\right)$ e vertical $\left(\mathrm{H}_{\mathrm{v}}\right)$ do campo $\mathrm{H}$ podem ser usadas para o cálculo da inclinação do campo (I), através das equações 3.10 e 3.11 :

$$
\tan I=\left(\frac{H_{v}}{H_{h}}\right)=\left(\frac{2 \sin \lambda}{\cos \lambda}\right)=2 \tan \lambda
$$


Note que devido à simetria do modelo GAD, paralelos representam linhas de igual inclinação I (definida pela equação 3.13), a qual varia de zero no equador até $90^{\circ}$ nos polos, com valores positivos no hemisfério norte e com valores negativos no hemisfério sul. A relação simples entre a inclinação do campo (I) e a latitude $(\lambda)$ da equação 3.10 pode ser utilizada para definir a paleolatitude de um bloco continental nas reconstruções paleogeográficas (vide abaixo).

\subsection{Polo Paleomagnético}

O polo calculado de um sítio de amostragem representa a direção do campo geomagnético de um único instante do tempo geológico, o qual é chamado de polo geomagnético virtual (abreviado por PGV). A hipótese do dipolo geocêntrico e axial estabelece que se a variação secular do campo geomagnético for adequadamente amostrada, a posição média de polo magnético coincide com o polo geográfico. Desta maneira, se um conjunto de sítios paleomagnéticos registra adequadamente a variação secular do campo geomagnético a média dos respectivos PGVs calculados fornece um polo paleomagnético, o qual deve coincidir com o polo geográfico.

Devido à deriva continental, o polo paleomagnético determinado para uma unidade geológica pode não coincidir com o polo geográfico. Entretanto, se ele representa o campo de um dipolo geocêntrico e axial, podemos determinar a paleolatitude do sítio de amostragem através da inclinação media $\left(\mathrm{I}_{\mathrm{m}}\right)$ da direção média das direções de magnetização adquiridas pelas rochas durante a sua formação, utilizando a equação 3.10. No modelo GAD, a declinação magnética vale zero para o campo normal e $180^{\circ}$ para um campo reverso. Um valor de declinação média $\left(\mathrm{D}_{\mathrm{m}}\right)$ diferente de zero (ou $180^{\circ}$ no campo reverso) indica rotação do bloco continental em torno do sítio de amostragem.

\subsubsection{Determinação de Polos Paleomagnéticos}

A posição de um polo pode ser calculada utilizando trigonometria esférica. A Figura 3.18 ilustra como as coordenadas do polo P $(\lambda p, \varphi p)$ são calculadas de uma direção média (Dm, Im) para um conjunto de sítios de amostragem, cuja localização média é representada pelo ponto $\mathrm{S}(\lambda \mathrm{s}, \varphi s)$. 


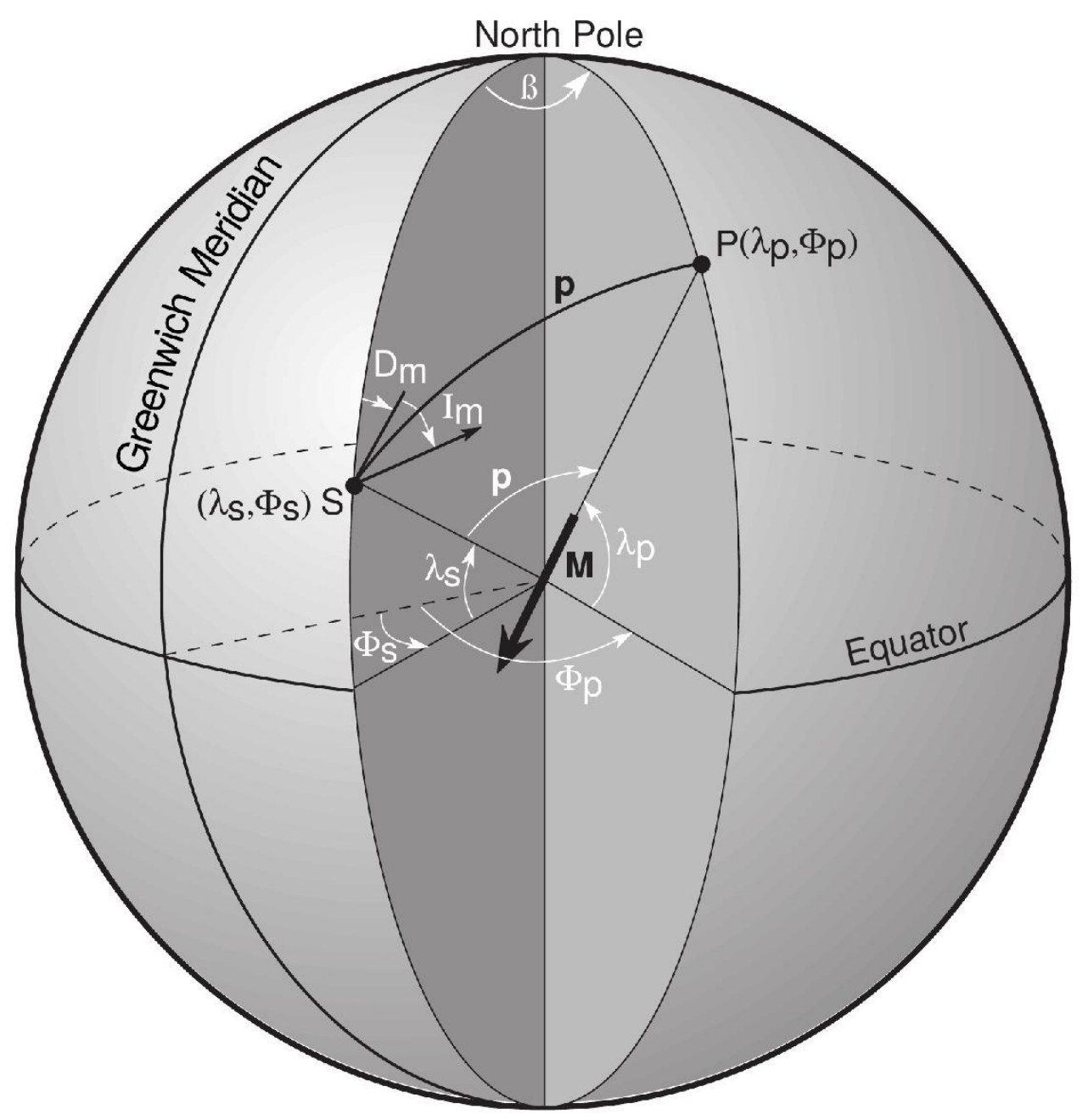

Figura 3.17. Localização do polo paleomagnético a partir da direção média do campo geomagnético registrado pelas rochas. A localização média dos sítios amostrados é representada por $\mathrm{S}(\lambda \mathrm{s}, \varphi s)$; direção média do campo geomagnético Dm, Im; M é o dipolo geocêntrico que pode ser responsável pela direção do campo geomagnético observado; P é a localização do polo paleomagnético com coordenadas $(\lambda \mathrm{p}, \varphi \mathrm{p}) ; \mathrm{p}$ é a colatitude magnética; O Polo Norte é o norte geográfico; $\beta$ é a diferença angular entre os meridianos que passam pelo polo magnético $(\mathrm{P})$ e pelo sítio (S). [Extraído de Paleomagnetism: Magnetic Domains to Geologic Terranes; R. Butler, 1992]

Inicialmente, calcula-se a colatitude $p$, a qual é representada pela distância angular entre o sítio S e o polo P na Figura 3.18 .

$$
p=\cot ^{-1}\left(\frac{\tan I_{m}}{2}\right)=\tan ^{-1}\left(\frac{2}{\tan I_{m}}\right)
$$

a latitude do polo é dada por:

$$
\lambda_{p}=\sin ^{-1}\left(\sin \lambda_{s} \cdot \cos p+\cos \lambda_{s} \cdot \sin p \cdot \cos D_{m}\right)
$$


A diferença angular entre os meridianos que passam pelo polo $\mathrm{P}$ e pelo sítio de amostragem $\mathrm{S}$ é indicado por $\beta$ na Figura 3.17, sendo positivo na direção leste. O ângulo $\beta$ pode ser calculado pela seguinte expressão:

$$
\beta=\sin ^{-1}\left(\frac{\sin p \cdot \sin D_{m}}{\cos \lambda_{p}}\right)
$$

Agora, existem duas possibilidades para a longitude do polo. A primeira:

$\mathrm{Se}$

$$
\cos p \geq \sin \lambda_{s} \cdot \sin \lambda_{p}
$$

a longitude do polo $\left(\lambda_{\mathrm{p}}\right)$ é dada por:

$$
\phi_{p}=\phi_{s}+\beta
$$

Mas, se

$$
\cos p<\sin \lambda_{s} \cdot \sin \lambda_{p}
$$

Então,

$$
\phi_{p}=\phi_{s}+180^{\circ}-\beta
$$

Qualquer direção média por sítio (Im, Dm) tem associado um limite de confiança $\alpha_{95}$. Este limite de confiança em torno da direção média é transformado em uma elipse de confiança em torno da posição do polo calculado (vide Figura 3.19). O semi-eixo da elipse de confiança ao longo do círculo máximo que passa pelo sítio $(\mathrm{S})$ e pelo polo $(\mathrm{P})$ tem um comprimento angular $d_{p}$, calculado pela seguinte expressão:

$$
d p=\alpha_{95}\left(\frac{3 \cos ^{2} p+1}{2}\right)=\alpha_{95}\left(\frac{2}{3 \cos ^{2} I_{m}+1}\right)
$$

O semi-eixo $\mathrm{d}_{\mathrm{m}}$, perpendicular a este círculo máximo é dado por:

$$
d m=\alpha_{95}\left(\frac{\sin p}{\cos I_{m}}\right)
$$




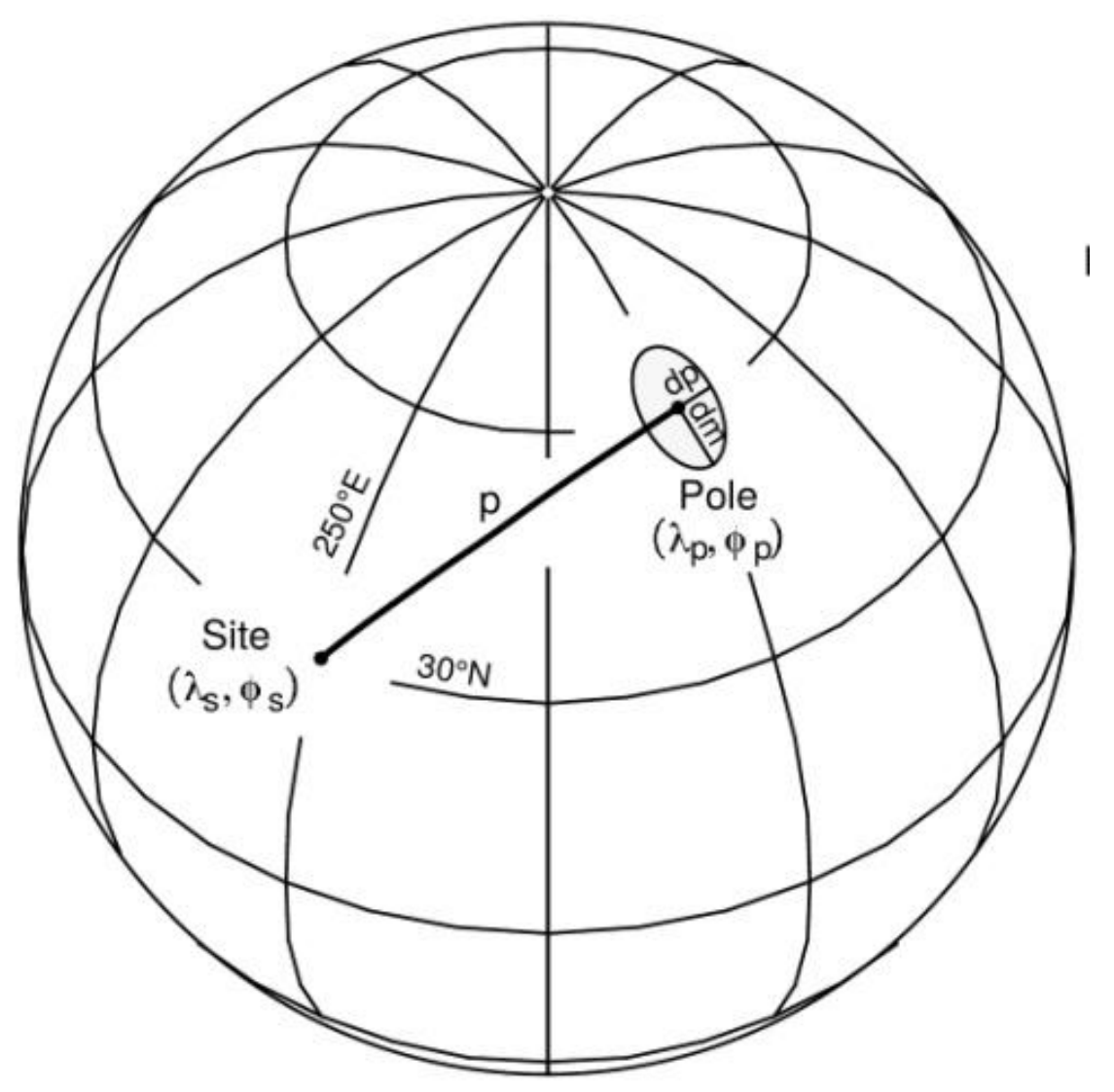

Figura 3.19. Elipse de confiança em torno do polo: $p$ é a colatitude magnética; $d p$ é o semi-eixo da elipse de confiança ao longo do círculo máximo que passa pelo sítio amostrado e pelo polo; $d m$ é o semi-eixo da elipse de confiança perpendicular ao círculo máximo descrito acima. [Extraido de Paleomagnetism: Magnetic Domains to Geologic Terranes; R. Butler, 1992].

\subsubsection{Polo Paleomagnético de Referência (PPR)}

$\mathrm{Na}$ literatura, polos paleomagnéticos bem-definidos obtidos para diferentes crátons estão disponíveis para o período Proterozoico, embora somente alguns deles estejam datados com a precisão requerida para que eles possam ser considerados polos paleomagnéticos de referência. A obtenção de polos de referência é fundamental para estabelecer reconstruções paleogeográficas no intuito de elucidar a formação e ruptura de supercontinentes.

Na última década do século XX e inicio do século XXI foram propostos critérios de confiabilidade (Van der Voo, 1990; Buchan et al., 2001) que atualmente são utilizados para classificar polos paleomagnéticos. Os critérios foram propostos diante da controvérsia criada quanto à reconstrução do supercontinente Rodínia há $1.000 \mathrm{Ma}$ 
atrás: quais crátons formaram este supercontinente? Quais eram suas posições relativas e orientações? Quanto tempo decorreu até a sua formação e quando houve a sua ruptura? Os dados paleomagnéticos são críticos para elucidar estas questões. No entanto, apesar de existir uma quantidade considerável de dados paleomagnéticos précambrianos, as tentativas de usar o paleomagnetismo para testar reconstruções do Rodínia têm sido frustradas pela falta de paleopolos bem datados para alguns blocos cratônicos (Buchan et al, 2001).

Com a finalidade de realizar reconstruções paleocontinentais mais rigorosas, Buchan et al. (2001) propôs dois critérios básicos para que o paleopolo possa ser utilizado em reconstruções paleogeográficas:

1 Idade do paleopolo: O paleopolo deve ser representado por uma direção de origem primária e a datação deve ser efetuada por métodos que apresentem precisão adequada. Para rochas do Pré-cambriano somente os métodos radiométricos $\mathrm{U}-\mathrm{Pb} \mathrm{e}^{40} \mathrm{Ar}-{ }^{39} \mathrm{Ar}$ conseguem atender este critério.

2 Qualidade do paleopolo: A componente de remanência primária do paleopolo deve ser isolada de maneira apropriada: isto é, através de experimentos de desmagnetização por meio de campos magnéticos alternados e/ou desmagnetização térmica. Vários sítios devem ser amostrados, os quais registrem o campo geomagnético por um intervalo de tempo suficiente para eliminar a variação secular.

Van der Voo (1990) publicou um conjunto de critérios de confiabilidade para classificar polos paleomagnéticos. Os sete critérios propostos por ele passaram a ser referência na prática paleomagnética. Um fator de qualidade $Q(0 \leq \mathrm{Q} \leq 7)$ foi estabelecido como critério de confiabilidade, o qual tem como base os critérios de avaliação satisfeitos. Os sete critérios de confiabilidade definidos por R. Van der Voo são:

1 A idade de formação da unidade geológica deve ser bem determinada, apresentando erro inferior a 4\%. Além disso, a magnetização remanente característica isolada para as rochas deve ser da mesma idade; 
2 Parâmetros estatísticos adequados: a quantidade de amostras deve superior a 24, o valor do parâmetro $\mathrm{K}$ deve ser maior que 10.0 e o valor de $\alpha_{95}$ deve ser menor que $16^{\circ}$;

3 Procedimentos adequados de desmagnetização: desmagnetizações por campos magnéticos alternados e térmico devem ser aplicados e a magnetização característica deve ser determinada a partir da subtração de componentes secundárias em diagramas vetoriais. As direções de magnetização devem ser determinadas através da análise por componentes principais;

4 Testes de campo (vide abaixo) que estabeleçam o intervalo temporal da componente de magnetização isolada. Os testes de campo (teste da dobra, do conglomerado e do contato cozido) nem sempre são possíveis de serem efetuados por diferentes razões, mas são sempre significativos, pois avaliam a natureza da magnetização isolada, se primária ou secundária;

5 Controle estrutural e coerência tectônica para a unidade cratônica estudada: a unidade em estudo não deve ter sofrido movimentos tectônicos internos que tenham afetado a posição do polo paleomagnético que representa a unidade como um todo;

6 Presença de reversões: indica que a magnetização foi adquirida em um intervalo de tempo significativo necessário para eliminar a variação secular do campo geomagnético;

7 O polo paleomagnético não deve coincidir com paleopolos de épocas posteriores que indiquem remagnetizações mais recentes;

Quanto mais critérios são satisfeitos, maior a qualidade (fator Q) do polo. Entretanto, dois dos critérios descritos acima são fundamentais para que um polo seja considerado como de referência: o critério 1 que estabelece a obtenção da idade da rocha com a devida precisão e, por consequência, a idade da magnetização adquirida pela rocha durante a sua formação e o critério 4 que impõe a necessidade de um teste de campo que estabeleça a natureza primária da magnetização remanente característica.. 


\subsubsection{Testes de campo.}

Os testes de campo, como descrito acima, são importantes para estabelecer a natureza das magnetizações remanentes isoladas para as amostras investigadas de uma formação geológica. Existem quatro testes que são usualmente utilizados (Butler, 1992): o teste da dobra, o teste do conglomerado, o teste do contato cozido e o teste das reversões. Cada um destes testes é descrito brevemente a seguir:

1 Teste de dobra: Este teste é aplicado em amostras obtidas de camadas que estavam inicialmente horizontais e foram inclinadas por efeitos tectônicos posteriores. No caso ideal que a rocha retém a direção de magnetização de maneira estável, as direções de magnetização determinadas irão variar em torno da dobra. Com este teste pode ser avaliada a época de aquisição da componente de magnetização remanente característica. O teste será positivo se as direções de magnetização estiverem mais agrupadas após a correção tectônica. Isto significa que a magnetização foi adquirida antes do evento tectônico que afetou as rochas.

2 Teste de Conglomerado: O teste de conglomerado é um teste de campo que avalia a estabilidade da magnetização. Lowrie (2007) exemplifica este teste da seguinte forma: Vamos supor que estudamos uma formação calcária a qual contem um conglomerado composto por seixos da rocha calcária. Assumindo que os seixos foram reorientados de forma aleatória pelos processos de erosão, transporte e deposição, as direções paleomagnéticas, se estáveis, devem estar distribuídas aleatoriamente. Entretanto, se achamos direções sistematicamente parecidas para todos os seixos, a magnetização do calcário pode ter uma componente secundária significativa.

3 Teste do Contato Cozido: Intrusões de rochas ígneas em rochas hospedeiras permitem verificar a estabilidade magnética da rocha através do teste de contato cozido. Durante a intrusão (um sill ou um dique), as bordas da rocha hospedeira em contato com a intrusão adquirem magnetização termoremanente similar a da própria intrusão, isto é, a rocha hospedeira é aquecida pelo contato com a lava quente e adquire a MTR quando esfria. As composições mineralógicas da rocha 
hospedeira e da rocha ígnea podem ser absolutamente diferentes. $\mathrm{O}$ teste fica completo se a direção da rocha hospedeira (diferente a da intrusão) é encontrada para distâncias maiores, onde ela não sofre mais a influência térmica da intrusão.

4 Teste de Reversão: O teste da reversão só pode ser aplicado quando as amostras paleomagnéticas representam um intervalo de tempo suficientemente grande para registrar mudanças de polaridade do campo geomagnético. As magnetizações remanentes adquiridas entre intervalos sucessivos de polaridade constante do campo geomagnético devem ser exatamente antiparalelas. Para qualquer localização, as direções do campo geomagnético médio durante um intervalo de polaridade normal e durante um intervalo de polaridade reversa diferem $180^{\circ}$.

\subsection{Reconstruções Paleogeográficas}

De acordo com o modelo de dipolo geocêntrico axial (DGA) polos paleomagnéticos obtidos para unidades geológicas recentes agrupam-se próximos ao polo geográfico. De modo geral, quando os polos geomagnéticos são calculados para unidades geológicas mais antigas de um continente, eles situam-se distantes do polo geográfico, na maioria dos casos. Se o modelo de dipolo geocêntrico axial é válido para unidades geológicas de todas as idades e o polo geográfico não mudou de posição ao longo do tempo geológico, conclui-se que é o continente que se movimenta em relação ao polo geográfico.

Com base nesta hipótese, os polos paleomagnéticos podem ser usados para determinar a paleogeografia dos continentes e outras unidades cratônicas no passado. A reconstrução paleogeográfica pode ser realizada através da rotação do polo paleomagnético fazendo-o coincidir com o polo geográfico, efetuando a mesma rotação para o bloco continental. A localização antiga do continente pode ser obtida também através da direção média da formação estudada. A declinação média $(\mathrm{Dm})$ representa a rotação do corpo em torno do sítio de amostragem e a paleolatitude pode ser determinada por meio da inclinação média (Im) (através da equação 3.13), a qual define a latitude do sítio de amostragem na época em que a rocha registrou a magnetização. No caso da paleolongitude, esse valor é indeterminado devido à simetria do modelo de campo de dipolo geocêntrico axial. 


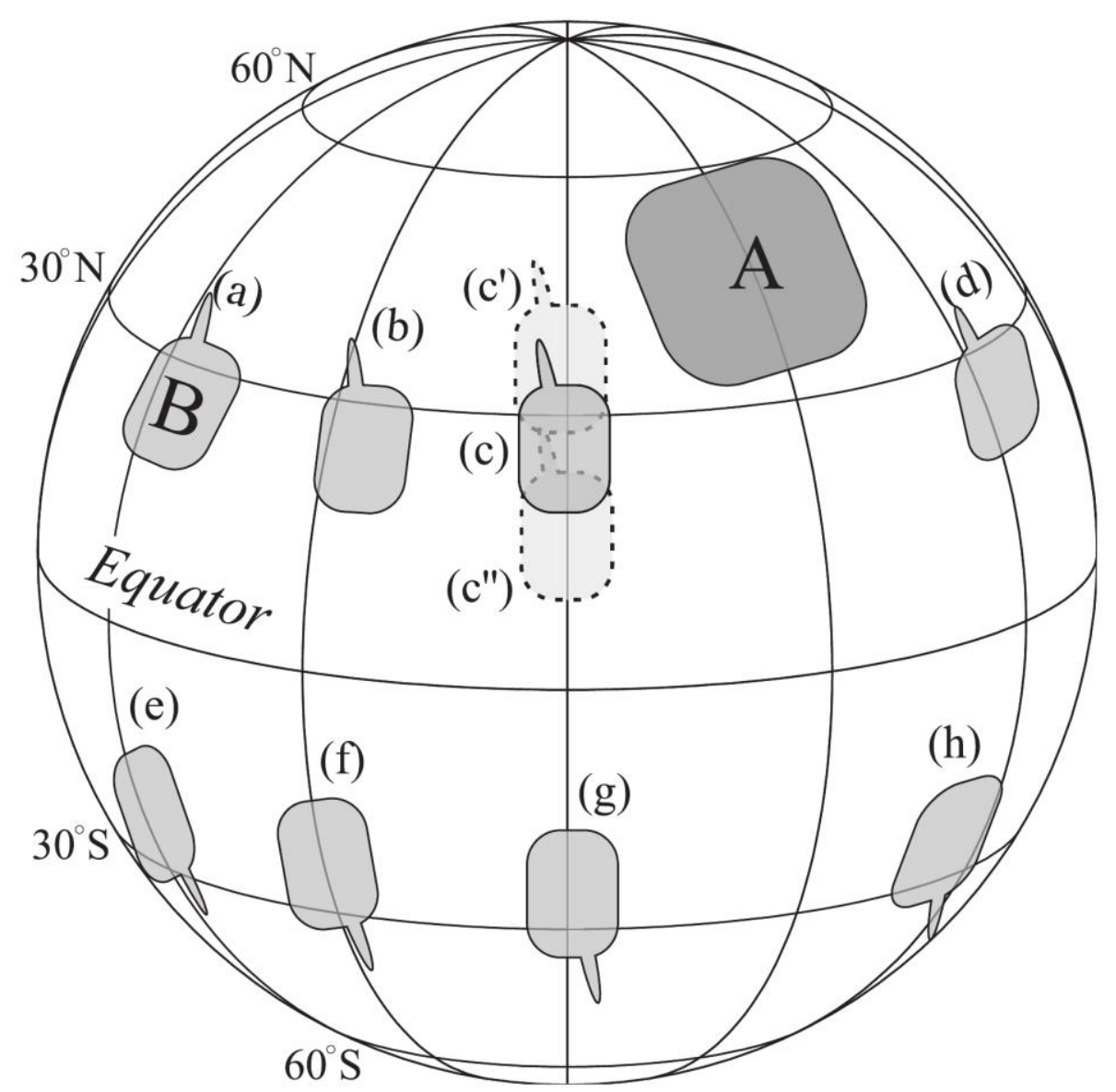

Figura 3.20. Representação esquemática da técnica paleomagnética para realizar reconstruções paleogeográficas. A e B são blocos continentais hipotéticos plotados a partir dos respectivos dados de paleolatitude e paleoorientação, com base nos respectivos polos paleomagnéticos. As posições de a a d indicam possíveis posições do continente $\mathbf{B}$ no hemisfério norte; de modo análogo, as posições de $\mathbf{e}$ a $\mathbf{h}$ indicam possíveis posições do continente $\mathbf{B}$ no hemisfério sul. Estas ambigüidades nas localizações dos blocos continentais resultam das indefinições na paleolongitude e na polaridade do pólo, a qual é desconhecida para épocas mais antigas. [Extraído de Pesonen et al., 2003]

A técnica de reconstrução paleogeográfica a partir de polos paleomagnéticos de referência é ilustrada na Figura 3.20. Neste exemplo, consideram-se dois continentes, A e B. Polos paleomagnéticos de mesma idade definem as paleolatitudes dos continentes A e B através da equação 3.10 e as paleoorientações são definidas pela declinação magnética média. Para este tipo de reconstrução, dois fatos ambíguos se sobressaem:

1 Paleolatitude: os continentes A e B podem ocupar qualquer posição mantendo a mesma latitude (em relação ao local de amostragem em que a paleolatitude foi calculada), considerando que a paleolongitude é indeterminada devido à simetria do modelo de campo de dipolo geocêntrico e axial;

2 Polaridade magnética: o continente A ou B podem se posicionar em qualquer um dos hemisférios, norte ou sul, porém rotacionandos de $180^{\circ}$. Isto se deve- ao 
fato de que o campo geomagnético tem dois estados possíveis, normal e reverso, ficando assim, indefinida a polaridade do polo encontrado (norte ou sul). Deste modo, as mesmas direções podem ser registradas pela rocha para o continente situado no hemisfério norte e polaridade normal ou para o mesmo continente situado no hemisfério sul, rotacionado de $180^{\circ}$, com polaridade reversa.

Esta ambiguidade na polaridade para períodos mais recentes não existe, pois é possível identificar a trajetória aparente do polo sul ou do polo norte magnético para o bloco continental em estudo, ao longo do tempo geológico.

\subsection{Curva de Deriva Polar Aparente (CDPA)}

A construção de curva de deriva polar aparente (CDPA) é uma técnica que se utiliza para representar polos paleomagnéticos de diferentes idades obtidos para um determinado bloco continental. Para tal, reúne-se certo conjunto de polos de diferentes idades para construir a trajetória polar para um continente na sua posição atual (Figura 3.21). As trajetórias construídas para diferentes continentes são utilizadas para determinar movimentos relativos entre eles, levando em consideração os mesmos intervalos de tempo. O termo "aparente" na CDPA denota o fato de que uma curva de deriva polar representa o movimento aparente do eixo de rotação com relação ao continente.

Existem dois modos de se construir uma curva de deriva polar aparente: o primeiro utiliza polos médios obtidos para cada intervalo de tempo pré-estabelecido (Figura 3.21a), independentemente da qualidade de cada polo. O segundo modo, utiliza polos de referência para a construção da curva e os outros polos, menos confiáveis, são usados como suporte para a definição da curva. De todo modo, para realizar a construção da CDPA de um determinado bloco continental, com o intuito de estabelecer a sua evolução paleogeográfica, é imperativo obter polos paleomagnéticos de referência (Buchan et al., 2000) (Figura 3.21b) 

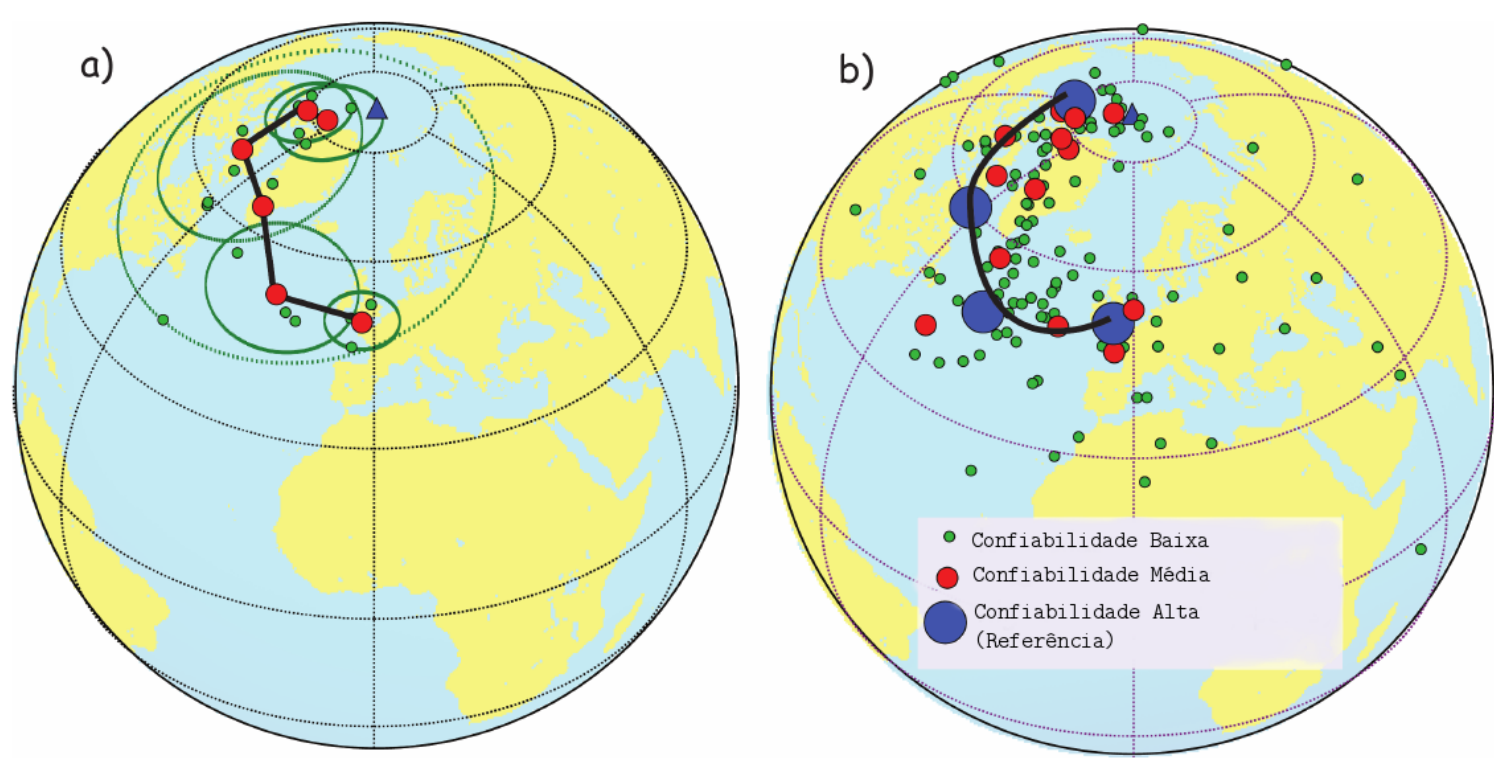

Figura 3.21. Exemplo de construção de uma curva de deriva polar aparente para um bloco continental. (a) com polos médios calculados para intervalos de tempo pré-estabelecidos. (b) para polos paleomangnéticos de alta confiabilidade (polos de referência). [Modificado de L. Tauxe, 2008]

Comparações entre curvas de deriva polar definidas para diferentes blocos continentais, para o mesmo intervalo de tempo, representam uma ferramenta importante para a determinação da movimentação relativa entre continentes. São a partir dessas comparações que se pode afirmar que os continentes mudaram suas posições na Terra. 


\section{Capítulo 4.}

\section{Resultados Paleomagnéticos}

Este capítulo apresenta os resultados paleomagnéticos obtidos neste trabalho. Serão descritos os resultados obtidos das análises de anisotropia de susceptibilidade magnética (ASM) e do estudo da mineralogia magnética visando identificar os minerais magnéticos portadores das magnetizações remanentes e verificar a estabilidade magnética das mesmas. Os métodos utilizados foram desmagnetização por campos alternados (CA), desmagnetização térmica, curvas termomagnéticas, curvas de histerese e curvas de magnetização remanente isotérmica (MRI). Além disso, serão apresentados os resultados obtidos da decomposição vetorial das magnetizações adquiridas pelas rochas decorrentes das análises por componentes principais aplicadas às projeções de Zijderveld, resultantes das desmagnetizações por campos alternados e térmicas.

\subsection{Anisotropia de Susceptibilidade Magnética}

As medidas de ASM indicam dois intervalos de suscetibilidades magnéticas médias $(\mathrm{Km})$ associadas às amostras analisadas (Figura 4.1a). O primeiro apresenta valores entre $2,6 \times 10^{-4}$ e $220 \times 10^{-4}$ (SI) e o segundo, entre $250 \times 10^{-2}$ e $860 \times 10^{-2}$ (SI). As medidas indicam também graus de anisotropia $(\mathrm{P})$ desde valores compatíveis com rochas máficas intrusivas não deformadas $(<1,1)$ até valores bastante elevados com um máximo de 1,584 (Figura 4.1a), indicando que as amostras foram submetidas a algum tipo de deformação. O parâmetro de Jelinek (T) índica um predomínio de elipsóides oblatos $(0<\mathrm{T}<1)$ sugerindo também predominância de foliação magnética (Figura 4.1b).

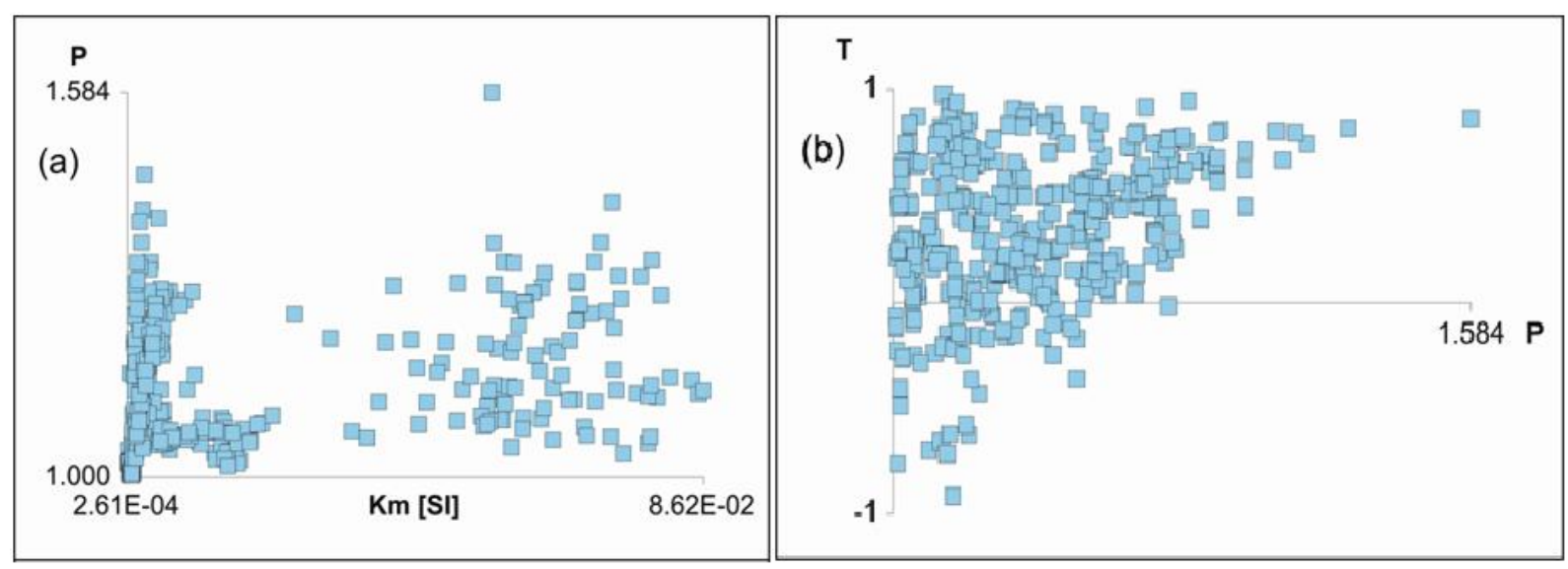

Figura 4.1. (a) Grau de anisotropia (P) contra suscetibilidade média (Km) por amostra; (b) parâmetro de Jelinek $(\mathrm{T})$ contra grau de anisotropia $(\mathrm{P})$ por amostra. 


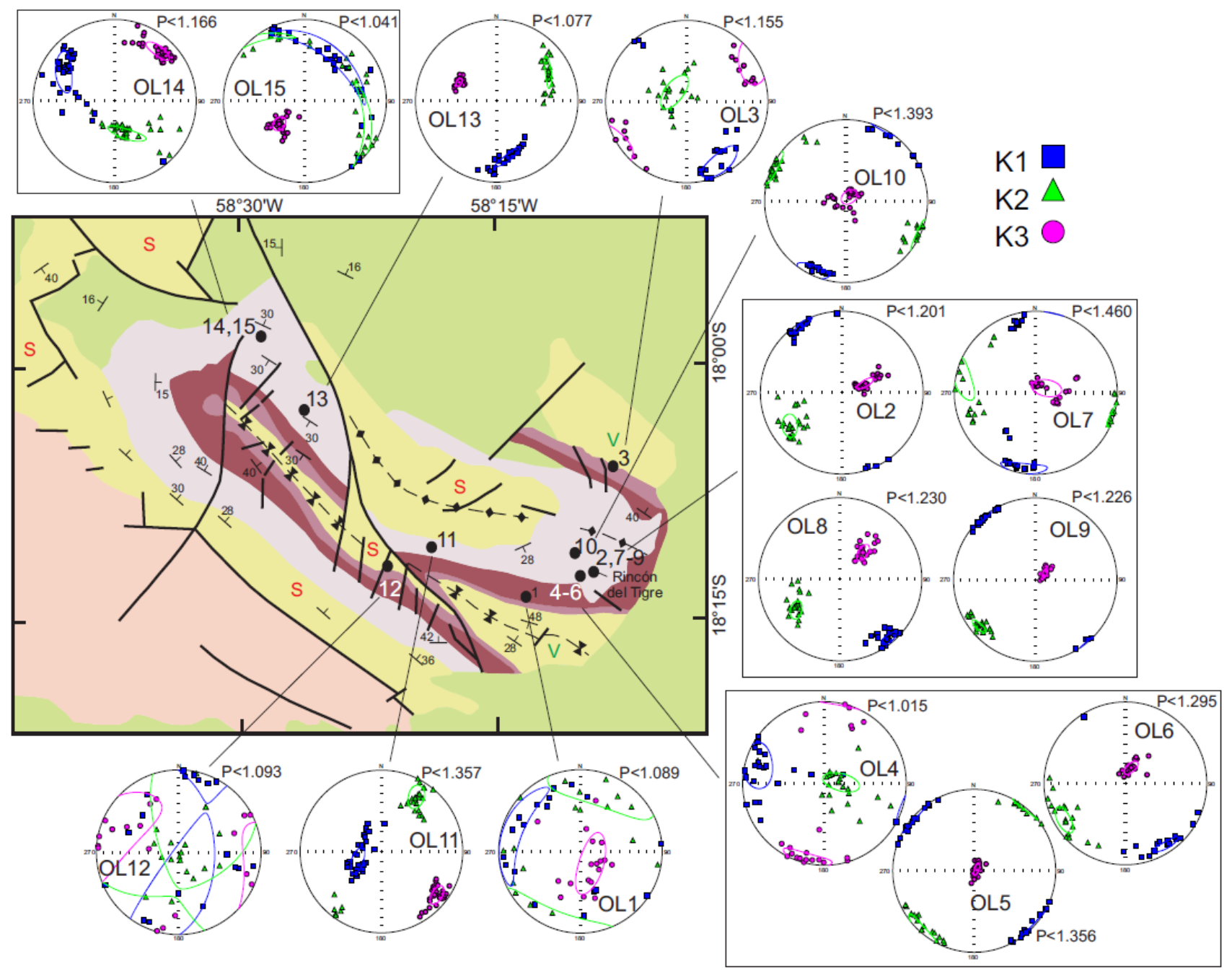

Figura 4.2. Estereogramas mostrando as direções dos eixos de suscetibilidade magnética (máxima $\left(\mathrm{k}_{1}\right)$, intermediária $\left(\mathrm{k}_{2}\right)$ e mínima $\left.\left(\mathrm{k}_{3}\right)\right)$ para cada sítio analisado, relacionado a sua posição geográfica indicado no mapa geológico. 
A Figura 4.2 mostra as direções dos eixos de suscetibilidade $\mathrm{k}_{1}, \mathrm{k}_{2}$ e $\mathrm{k}_{3}$, os quais indicam os eixos principais do elipsoide de anisotropia magnética obtidos para cada um dos sítios investigados. A trama horizontal predomina para os sítios OL1, OL2, OL5, OL6, OL7, OL8, OL9, OL10, OL13 e OL15 (eixo k k $_{3}$ próximo do centro do estereograma). Nestas amostras, pode-se observar um predomínio da lineação magnética (definida pelo eixo k1) com direção NW/SE, concordante com o eixo da dobra observada em escala de mapa na região de estudo. Para alguns destes sítios, entretanto, a lineação magnética tende para N-NE/S-SW (sítios OL7, OL10 e OL13) ou os eixos $\mathrm{k}_{1}$ são mal definidos (Sítio OL15). Três sítios investigados (OL3, OL4 e OL14) mostram os eixos $\mathrm{k}_{2}$ e $\mathrm{k}_{3}$ invertidos quando comparados aos sítios descritos acima. Todavia, apresentam lineação magnética bem definida também na direção NW/SE, como a maioria dos outros sítios. O sítio OL12 não apresenta uma trama magnética bem definida e a trama magnética obtida para o sítio OL11 pode ser considerada exceção, onde o eixo $\mathrm{k}_{1}$ define uma lineação magnética quase vertical.

\subsection{Mineralogia Magnética}

\subsubsection{Tratamentos por Campos Alternados (CA) e Térmicos}

As amostras analisadas pertencentes ao Complexo Rincón del Tigre apresentam intensidades de magnetização remanente natural no intervalo de $2.13 \times 10^{-3}$ a $186 \mathrm{~A} / \mathrm{m}$, sendo tais valores devido à contribuição dos minerais ferromagnéticos presentes nas rochas. $\mathrm{O}$ tratamento mediante campos magnéticos alternados foi eficiente para revelar a magnetização presente na maioria das amostras. A partir dos resultados observa-se a presença de minerais de baixa coercividade, indicando a presença de magnetita ou titanomagnetita como minerais portadores do magnetismo. Exemplos deste comportamento são mostrados na Figura 4.3 (amostras OL1C2 e OL6G2). Para algumas amostras, entretanto o tratamento por CA não foi totalmente eficiente, i.e., a magnetização remanente não foi removida totalmente em campos de até $100 \mathrm{mT}$ (amostra OL4C1 na Figura 4.3b). Neste caso, somente 80\% da magnetização presente na amostra foi eliminado, indicando a presença de minerais com coercividades mais altas.

Através do tratamento de desmagnetização térmica, a maioria das amostras apresentou temperaturas de bloqueio altas. Para os casos OL2A2 e OL11E2, Mais de $70 \%$ da intensidade total é representada por grãos com temperaturas de bloqueio acima de $500{ }^{\circ} \mathrm{C}$ sendo totalmente desmagnetizadas em cerca de $580{ }^{\circ} \mathrm{C}$, sugerindo a presença de magnetita 
como sendo o principal portador magnético da rocha. Outro comportamento observado, por exemplo, para a amostra OL14I2 (Figura 4.3f), é caracterizado por uma queda acentuada da intensidade entre 350 e $500^{\circ} \mathrm{C}$ indicando a provável presença de titanomagnetita como portador magnético da rocha. Nesta amostra, observa-se também uma queda na intensidade entre $660-680^{\circ} \mathrm{C}$, indicando também a presença hematita. O tratamento de desmagnetização térmica permite identificar que os grãos magnéticos com altas temperaturas de bloqueio são os portadores magnéticos da componente característica.

$\mathrm{OL} 1 \mathrm{C} 2$

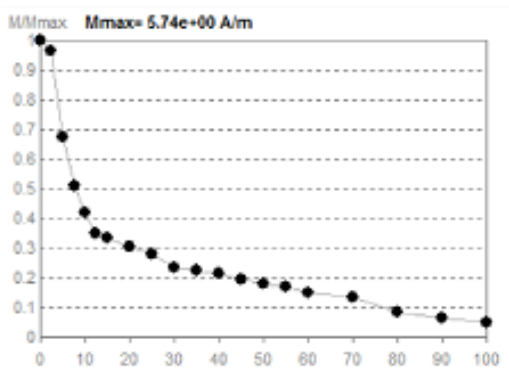

OL2A2

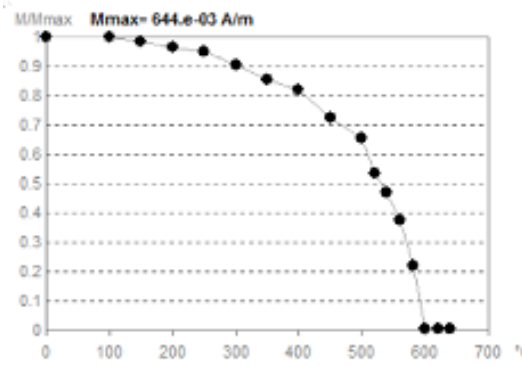

$\mathrm{OL} 4 \mathrm{Cl}$

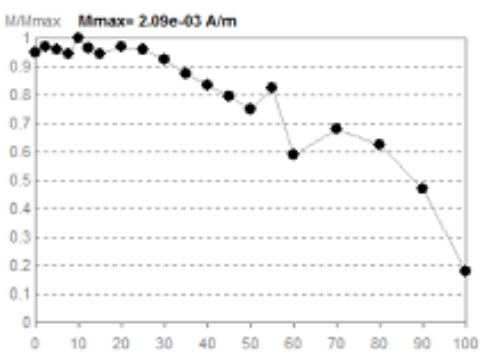

OL11E2

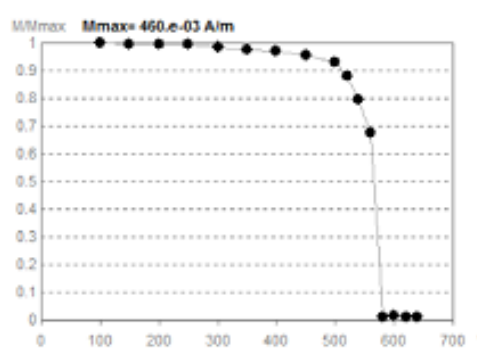

OL6G2

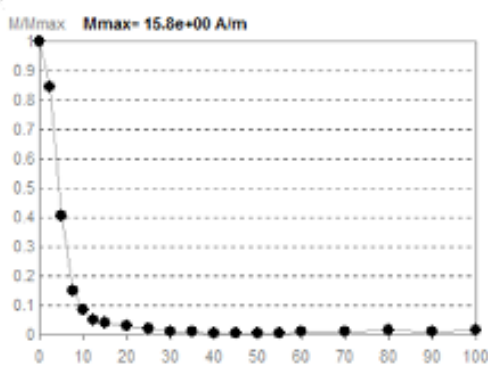

OL 14 I2

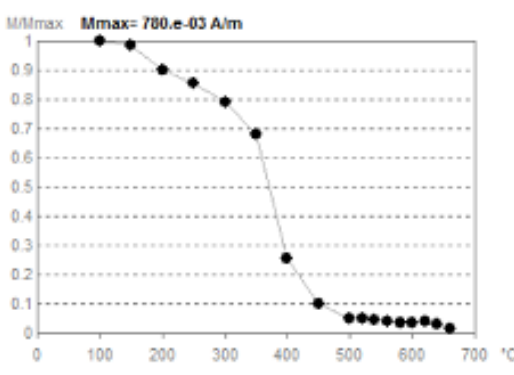

Figura 4.3: (a) Curvas de desmagnetização por campos magnéticos alternados para amostras diferentes apresentam diferentes comportamentos na coercividade. (b) Curvas de intensidade de desmagnetização térmica.

\subsubsection{Curvas Termomagnéticas}

As curvas termomagnéticas de altas e baixas temperaturas foram obtidas para dezesseis amostras dos quinze sítios amostrados do complexo. As curvas termomagnéticas foram classificadas em três grupos segundo as características de reversibilidade ou irreversibilidade durante o aquecimento e resfriamento, em alguns dos casos gerando alterações químicas nos minerais portadores do magnetismo.

O primeiro grupo é composto por amostras que apresentam comportamento reversível durante o processo de aquecimento e resfriamento. Exemplos deste grupo são mostrados na Figura 4.4, através das amostras OL1A2 e OL11D1, as quais apresentam temperatura de Curie em torno de $580^{\circ} \mathrm{C}$, pico de Hopkinson bem acentuado e transição de Verwey (em 
torno de $-153^{\circ} \mathrm{C}$ ) bem caracterizada, indicando a presença de magnetita ou titanomagnetita pobre em titânio.
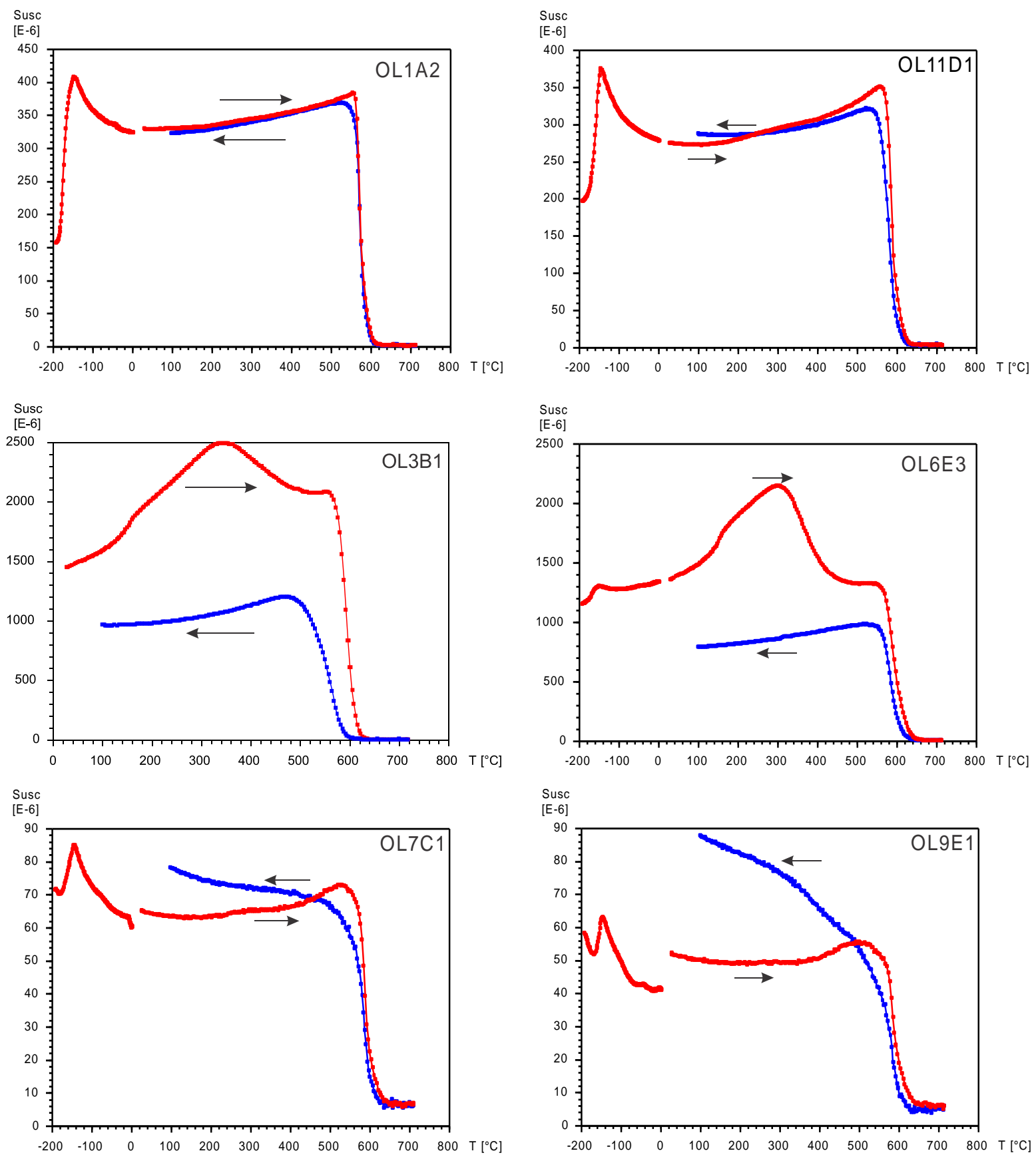

Figura 4.4. Curvas termomagnéticas (susceptibilidade (SI) contra temperatura $\mathrm{T}\left[{ }^{\circ} \mathrm{C}\right]$ ) para amostras de rochas máficas do Complexo Rincón del Tigre. As setas com direção à direita e à esquerda indicam o processo de aquecimento e resfriamento, respectivamente.

Os outros dois grupos são caracterizados por amostras com comportamento irreversível, entretanto, com diferentes alterações mineralógicas durante o processo de aquecimento e resfriamento. Um destes grupos é exemplificado pelas amostras OL3-B1 e OL6-E3 na Figura 4.4. As curvas obtidas para estas amostras indicam temperaturas de Curie pouco 
acima de $600^{\circ} \mathrm{C}$, as quais podem ser decorrentes de magnetitas parcialmente oxidadas. A queda em torno de $350-450^{\circ} \mathrm{C}$ sugere também a presença de maghemita. A queda substancial na suscetibilidade durante o resfriamento sugere também que a maghemita e parte da magnetita oxidada presentes na rocha se oxidam para formar hematita. Nestas amostras a transição de Verwey é atenuada (amostra OL6-E3), provavelmente pela oxidação da magnetita. Finalmente, o terceiro grupo de amostras é exemplificado pelas amostras OL7C1 e OL9E1 na Figura 4.4. Estas amostras, como no caso do primeiro grupo, apresentam temperatura de Curie em torno de $580-600^{\circ} \mathrm{C}$, pico de Hopkinson bem acentuado e transição de Verwey (em torno de $-153^{\circ} \mathrm{C}$ ) bem caracterizada, indicando a presença de magnetita como sendo o principal portador magnético. Entretanto, muito provavelmente, magnetita está sendo formada durante o aquecimento, como sugere o aumento na suscetibilidade magnética apresentada pela curva de resfriamento. As curvas indicam também a provável presença de hematita, em decorrência da queda da suscetibilidade acima de $600^{\circ} \mathrm{C}$.

\subsubsection{Curvas de Histerese Magnética}

Para a maioria das amostras analisadas (Figura 4.5) foram obtidos ciclos de histerese magnética com cintura fina e com coercividades entre $2.3 \mathrm{mT}$ e $27 \mathrm{mT}$. Estes valores são típicos de mineral titanomagnetita ou magnetita. Para a amostra do sítio OL15 (Figura 4.6), a pequena quantidade de minerais ferrimagnéticos é mascarada pela maior presença de minerais paramagnéticos. Mediante as curvas de histerese magnética foram determinados os seguintes parâmetros: $i$. coercividade volumétrica $\left(\mathrm{H}_{\mathrm{c}}\right)$, ii. coercividade de remanência $\left(\mathrm{H}_{\mathrm{cr}}\right)$, iii. magnetização de saturação $\left(\mathrm{M}_{\mathrm{s}}\right)$ e $i v$. magnetização remanente de saturação $\left(\mathrm{M}_{\mathrm{r} s}\right)$. Esses parâmetros supracitados são apresentados na Tabela 4.1, juntamente com as razões $\mathrm{H}_{\mathrm{cr}} / \mathrm{H}_{\mathrm{c}} \mathrm{e}$ $\mathrm{M}_{\mathrm{rs}} / \mathrm{M}_{\mathrm{s}}$ as quais são plotadas no gráfico de Day (Day et al., 1977, modificado por Dunlop, 2002a) da Figura 4.7. A maioria das amostras situa-se ao longo das curvas teóricas traçadas por Dunlop (2002a, b), as quais indicam uma mistura de grãos SD-MD, com concentração de grãos MD menores do que 40\%-60\% (Dunlop, 2002a, b). No diagrama de Day (Figura 4.7), alguns espécimes analisados, entretanto, situam-se à direita destas curvas, podendo ser interpretados como decorrentes de uma mistura de magnetita grãos SD estáveis e grãos finos superparamagnéticos (SP) com tamanhos entre 9 a 12 nm (Dunlop, 2002a, b). 
Tabela 4.1 Parâmetros obtidos de curvas de histerese

\begin{tabular}{|c|c|c|c|c|c|c|}
\hline Amostra & Mrs [Oe] & Ms & Hc & Hcr & Hcr/Hc & Mrs/Ms \\
\hline OL1A2 & 0.0022398 & 0.0166090 & 111.5298000 & 300.8063000 & 2.6970935 & 0.1348527 \\
\hline OL2E1 & 0.0004040 & 0.0033247 & 133.5496000 & 268.2620000 & 2.0087069 & 0.1215142 \\
\hline OL3B1 & 0.3705253 & 0.9664814 & 270.3387000 & 442.7142000 & 1.6376279 & 0.3833755 \\
\hline OL3E1 & 0.0039831 & 0.0152385 & 176.4014000 & 279.9347000 & 1.5869188 & 0.2613817 \\
\hline OL4B1 & 0.0002285 & 0.0008202 & 243.5725000 & 591.5135000 & 2.4284905 & 0.2785835 \\
\hline OL5F1 & 0.0903541 & 0.2440451 & 178.8399000 & 242.8102000 & 1.3576959 & 0.3702353 \\
\hline OL6E3 & 0.1695015 & 0.524316 & 199.5050000 & 321.1178000 & 1.6095727 & 0.3232812 \\
\hline OL7C1 & 0.0011021 & 0.0062875 & 125.6557000 & 179.6392000 & 1.4296144 & 0.1752791 \\
\hline OL8C1 & 0.0083423 & 0.0337377 & 156.2093000 & 263.4059000 & 1.6862370 & 0.2472704 \\
\hline OL9E1 & 0.0061203 & 0.0268119 & 155.5558000 & 265.9450000 & 1.7096437 & 0.228268 \\
\hline OL10C1 & 0.0076718 & 0.0299323 & 115.3240000 & 180.9194000 & 1.5687923 & 0.2563041 \\
\hline OL11D1 & 0.0662659 & 0.1865297 & 185.6054000 & 231.3431000 & 1.2464244 & 0.3552565 \\
\hline OL12B1 & 0.0021377 & 0.0078383 & 198.9631000 & 354.6774000 & 1.7826290 & 0.272728 \\
\hline OL13D1 & 0.0048221 & 0.0627486 & 43.3265600 & 253.1858000 & 5.8436626 & 0.0768475 \\
\hline OL14C1 & 0.1209206 & 0.5865284 & 120.2170000 & 202.4546000 & 1.6840763 & 0.2061632 \\
\hline OL15C1 & 0.0000087 & 0.0003349 & 23.8723100 & 336.3270000 & 14.0885821 & 0.0258475 \\
\hline
\end{tabular}



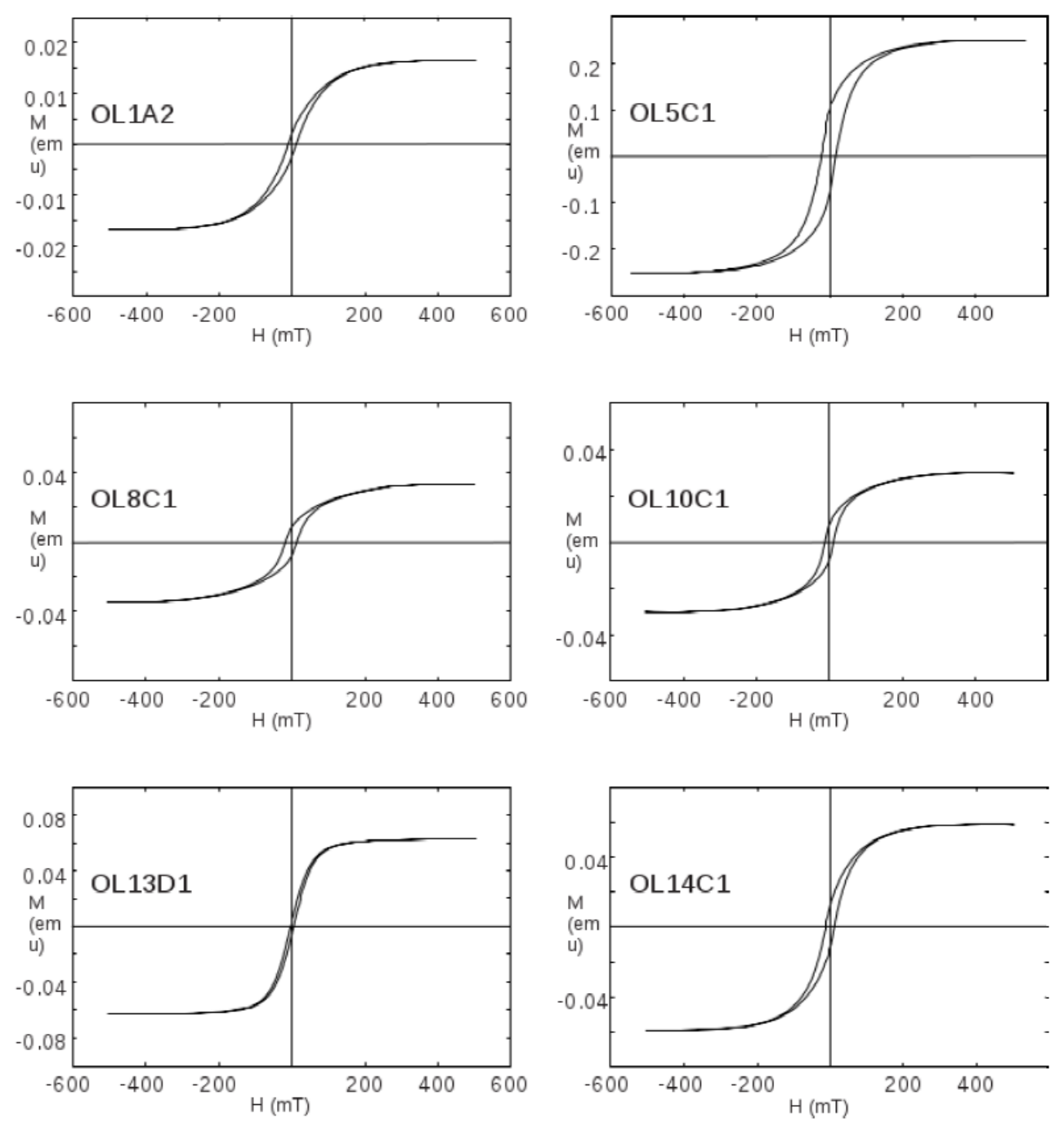

Figura 4.5. Curvas de histerese para distintas amostras analisadas do Complexo Rincón del Tigre. Os resultados obtidos para as amostras apresentam cintura fina e saturação em torno de $300 \mathrm{mT}$.

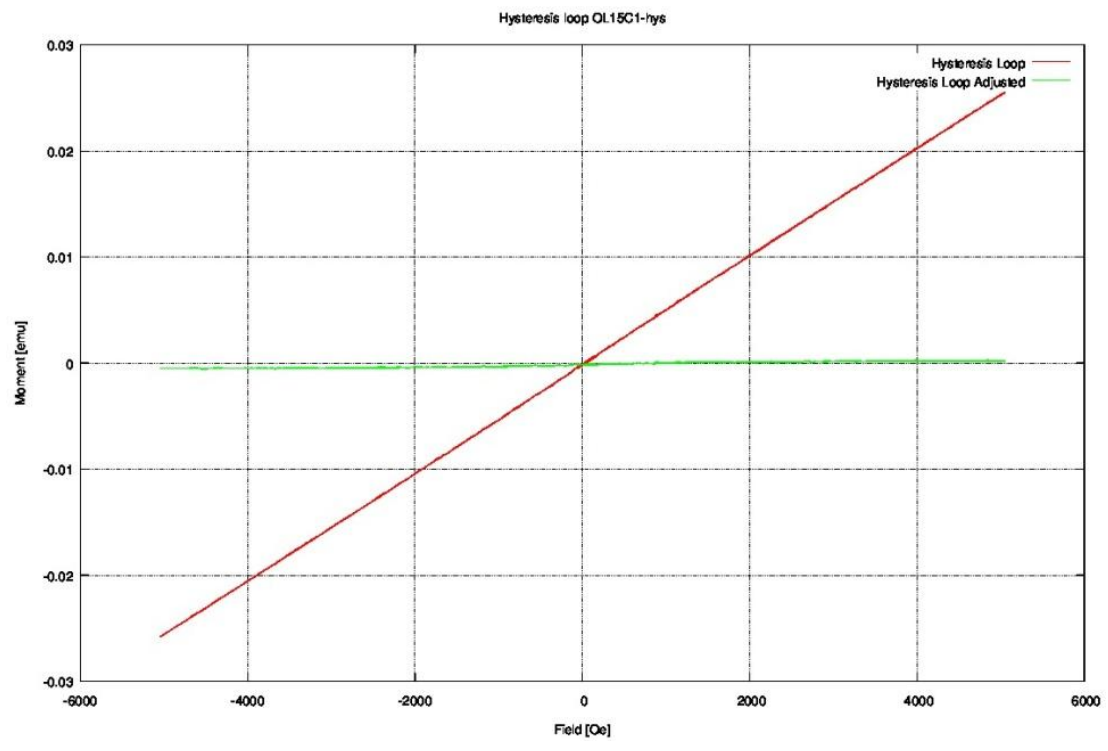

Figura 4.6. Curva de histerese para a amostra OL15C. A pequena quantidade de mineral ferromagnético é mascarada pela maior presença de minerais paramagnéticos presentes na amostra. 


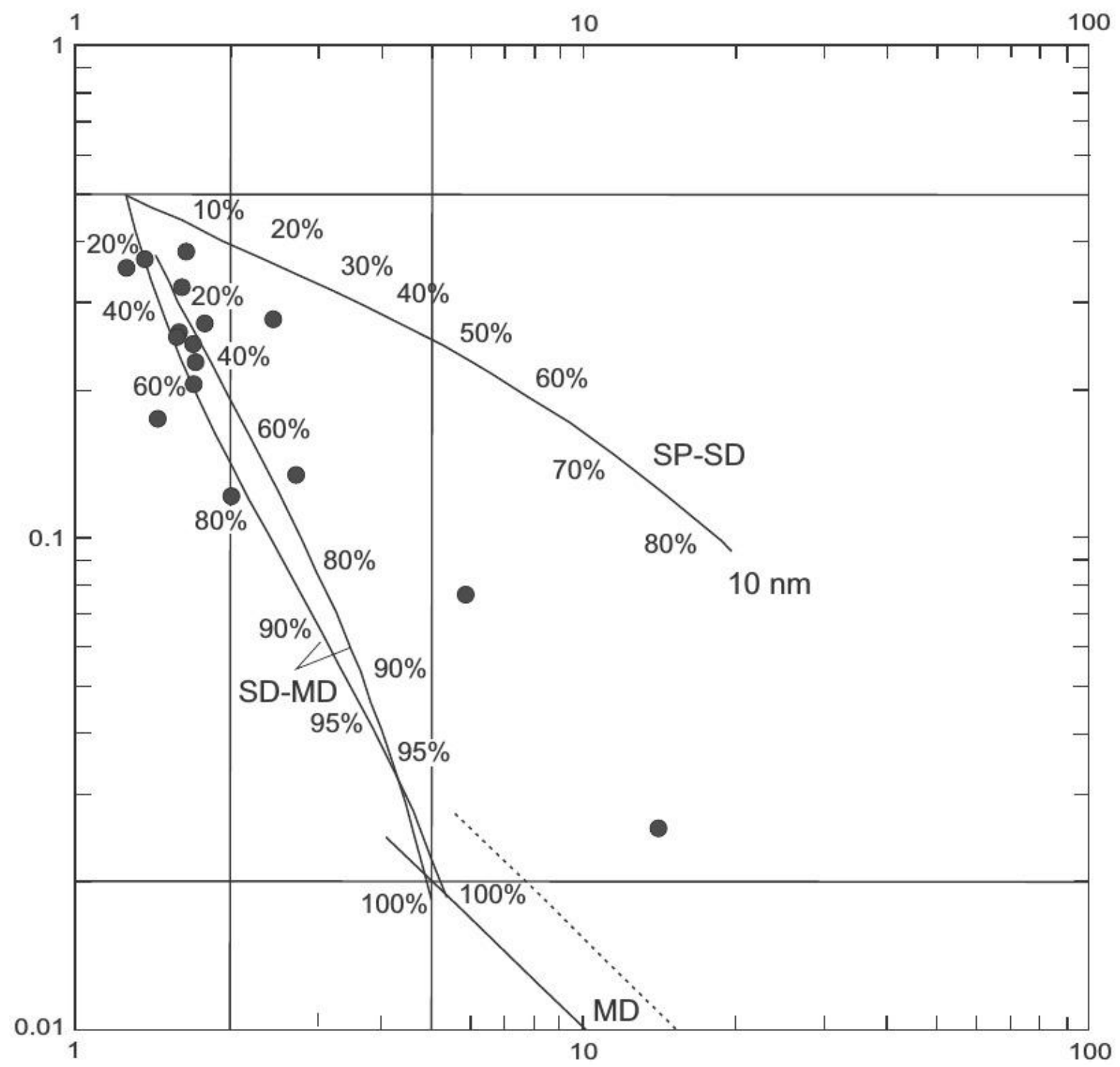

Figura 4.7. Diagrama de Day (Day et al., 1977, modificado por Dunlop, 2002a) indicando a estrutura de domínios magnéticos das amostras analisadas do Complexo Rincón del Tigre. A Figura mostra as curvas teóricas propostas por Dunlop (2002a) que indicam misturas de grãos de domínio simples com diferentes porcentagens de grãos multi-domínios (curvas SD-MD) e de misturas de grãos de domínio simples com diferentes porcentagens de grão superparamagnéticos com tamanhos de $10 \mathrm{~nm}$ (curva SP-SD). Os círculos indicam amostras analisadas.

\subsubsection{Curvas de Magnetização Remanente Isotérmica (MRI)}

Os experimentos de aquisição da magnetização remanente isotérmica (MRI) efetuadas para amostras do Complexo Rincón del Tigre resultaram em comportamentos praticamente idênticos e homogêneos, atingindo a magnetização remanente de saturação em campos inferiores a $300 \mathrm{mT}$, indicando uma distribuição de grãos de baixas coercividades (Figura 4.8). Este comportamento é típico da magnetita ou titanomagnetita. A presença de magnetita, entretanto, é corroborada pelas outras técnicas de análise empregadas nos outros experimentos: tratamentos por campos magnéticos alternados, desmagnetização térmica, curvas de histerese e curvas termomagnéticas. 


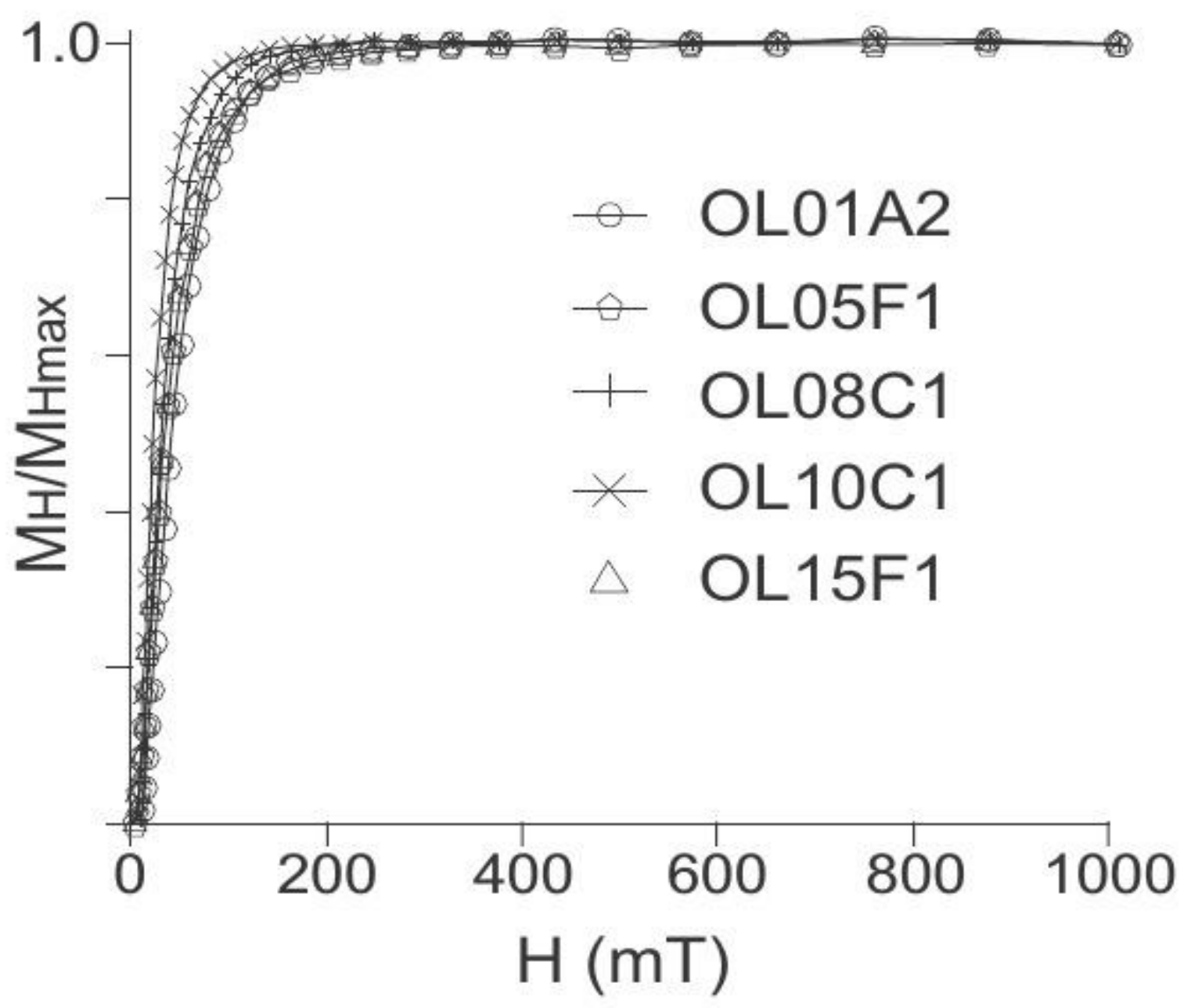

Figura 4.8: Exemplos de curvas de aquisição da magnetização remanente isotérmica (MRI) obtidas para rochas do Complexo Rincón del Tigre.

\subsection{Análise Paleomagnética}

\subsubsection{Componentes de Magnetização}

Os dados de mineralogia magnética apontam para a presença de magnetita SD estável para a maioria das amostras estudadas (vide descrição acima). Em decorrência disto, as desmagnetizações por campos alternados e térmico mostraram-se eficientes para separar as componentes de magnetização nas rochas, onde direções estáveis e coerentes foram identificadas para boa parte dos espécimes analisados de cada sítio. Entretanto, a mesma coerência não é observada quando comparamos as direções médias calculadas para cada sítio (Figura 4.9, Tabela 4.2). Dois grupos de direções com alguma coerência pode ser identificado: o primeiro apresenta direções oeste (leste) com inclinações baixas, as quais foram isoladas para espécimes dos sítios OL1, OL2, OL3, OL4, OL10, OL14 e OL15. Exemplos de desmagnetização de amostras que apresentaram direções identificadas neste grupo são mostrados na Figura 4.10. O outro grupo de direções é formado pelos sítios OL7, 
OL8, OL9, OL11 e OL12, os quais apresentam direções noroeste (sudeste) com inclinações positivas (negativas) moderadas (Figura 4.10, Tabela 4.2). Exemplos de desmagnetização que forneceram direções neste grupo são apresentados na Figura 4.11. Uma inspeção da Figura 4.9 mostra que os sítios OL3 e OL4 poderiam também pertencer a este grupo de amostras. Amostras pertencentes aos demais sítios (5, 6 e 13) apresentaram direções norte (sul) com inclinações negativas (positivas) e poderiam, a princípio, corresponder a direções afetadas por eventos recentes, já que se situam próximas do campo atual normal (reverso).

Tabela 4.2 - Dados paleomagnéticos de Rincón del Tigre

\begin{tabular}{|l|l|l|l|l|l|l|l|}
\hline SÍTIO & \multicolumn{3}{|c|}{ DIREÇÃO MÉDIA POR SÍTIO } & \multicolumn{3}{c|}{ PGV } \\
\hline & Dec. $\left(^{\circ}\right)$ & Inc. $\left(^{\circ}\right)$ & N/n & $\alpha_{95}\left(^{\circ}\right)$ & K & Plong $\left({ }^{\circ} \mathrm{E}\right)$ & Plat $\left(^{\circ} \mathrm{N}\right)$ \\
\hline 1 & 108,9 & 21,0 & $11 / 10$ & 6,3 & 59,4 & 26.9 & -21.2 \\
\hline 2 & 247,4 & 8,3 & $10 / 9$ & 11,6 & 20,7 & 208,7 & $-22,8$ \\
\hline $3^{*}$ & 102,5 & $-34,8$ & $11 / 4$ & 10,3 & 80,3 & 234,0 & 5,3 \\
\hline $4^{*}$ & 127,8 & $-20,3$ & $11 / 10$ & 8,9 & 30,3 & 236,8 & 31,0 \\
\hline 5 & 187,0 & 1,3 & $9 / 8$ & 9,9 & 32,2 & 144,0 & $-71,1$ \\
\hline 6 & 339,6 & $-13,1$ & $11 / 9$ & 6,9 & 56,3 & 59,5 & $-67,0$ \\
\hline $7^{*}$ & 332,1 & 33,2 & $11 / 10$ & 10,4 & 22,7 & 263,3 & 44,4 \\
\hline $8^{*}$ & 327,6 & 29,2 & $10 / 9$ & 11,5 & 20,9 & 256,5 & 43,5 \\
\hline $9^{*}$ & 347,1 & 35,4 & $10 / 10$ & 8,0 & 37,0 & 282,7 & 50,2 \\
\hline 10 & 298,9 & $-12,0$ & $12 / 9$ & 8,9 & 34,6 & 35,1 & $-29,3$ \\
\hline $11^{*}$ & 335,8 & 55,9 & $10 / 3$ & 19,9 & 39,4 & 279,1 & 30,8 \\
\hline $12^{*}$ & 172,9 & $-49,0$ & $10 / 5$ & 13,9 & 31,4 & 293,4 & 41,4 \\
\hline 13 & 190,2 & 21,1 & $7 / 5$ & 15,5 & 25,4 & 177,1 & $-77,8$ \\
\hline 14 & 258,4 & 0,1 & $13 / 10$ & 7,3 & 45,3 & 207,9 & $-11,0$ \\
\hline 15 & 301,1 & 1,2 & $9 / 9$ & 5,7 & 83,4 & 222,7 & 29,2 \\
\hline
\end{tabular}

Dec. - Declinação; Inc. - Inclinação; N/n - número de espécimes analisados/número de espécimes usados no cálculo da média; PGV - Polo Geomagnético Virtual; Plong - longitude do polo; Plat - latitude do polo. 


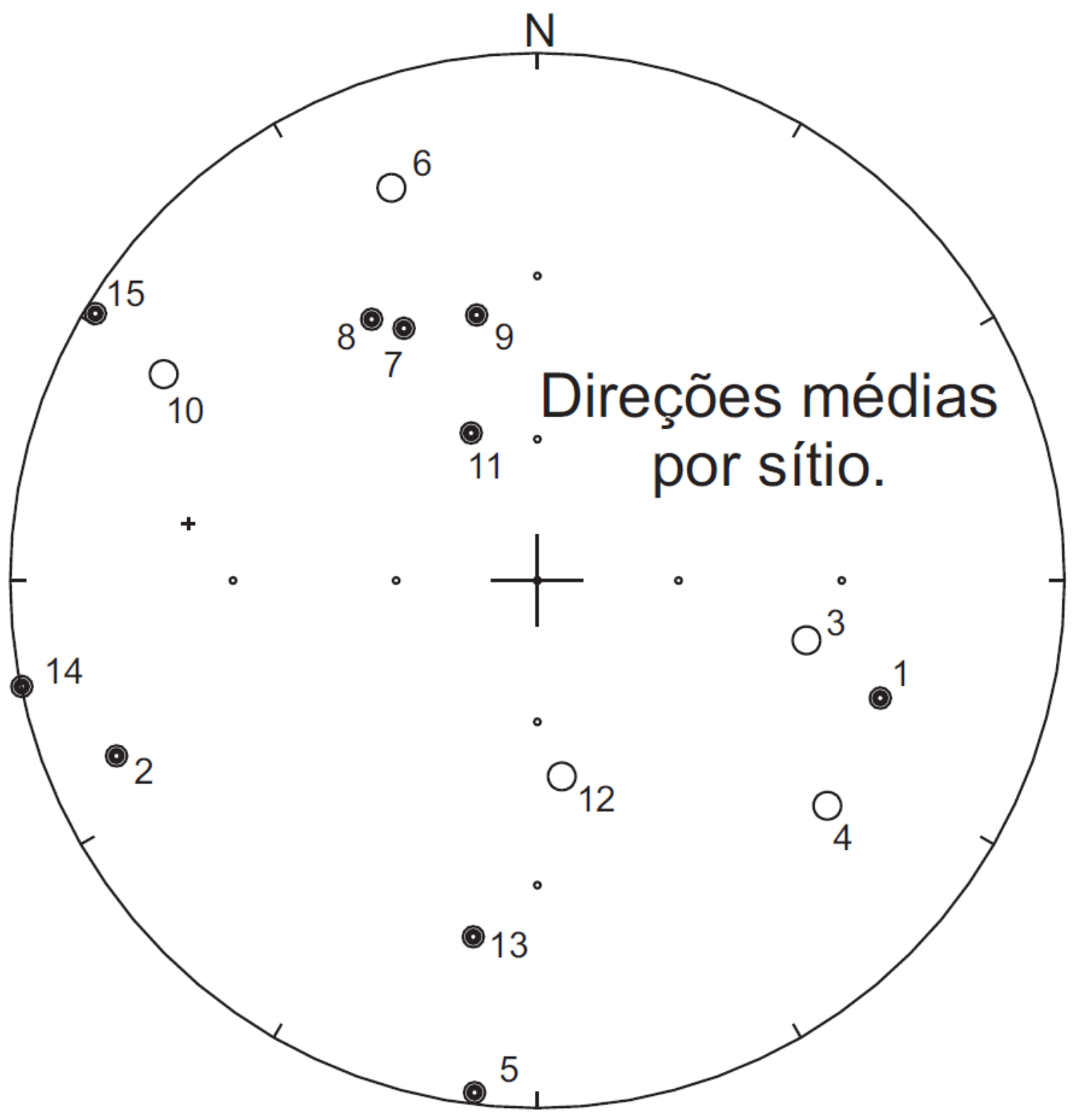

Figura 4.9. Projeção estereográfica das direções médias por sítio. Símbolos cheios (vazios) representam direções com inclinação positiva (negativa). 
OL1A2
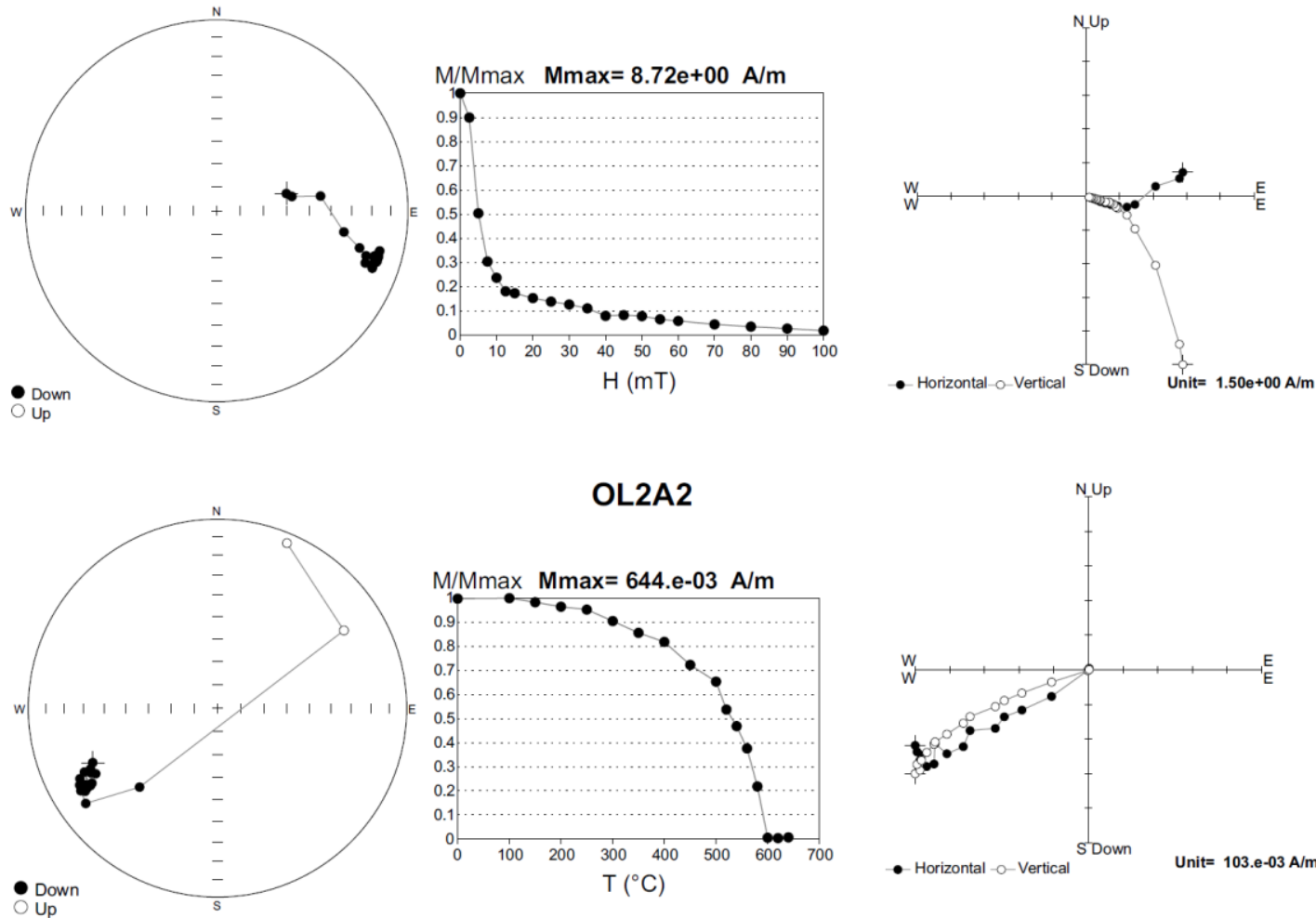

OL2A2
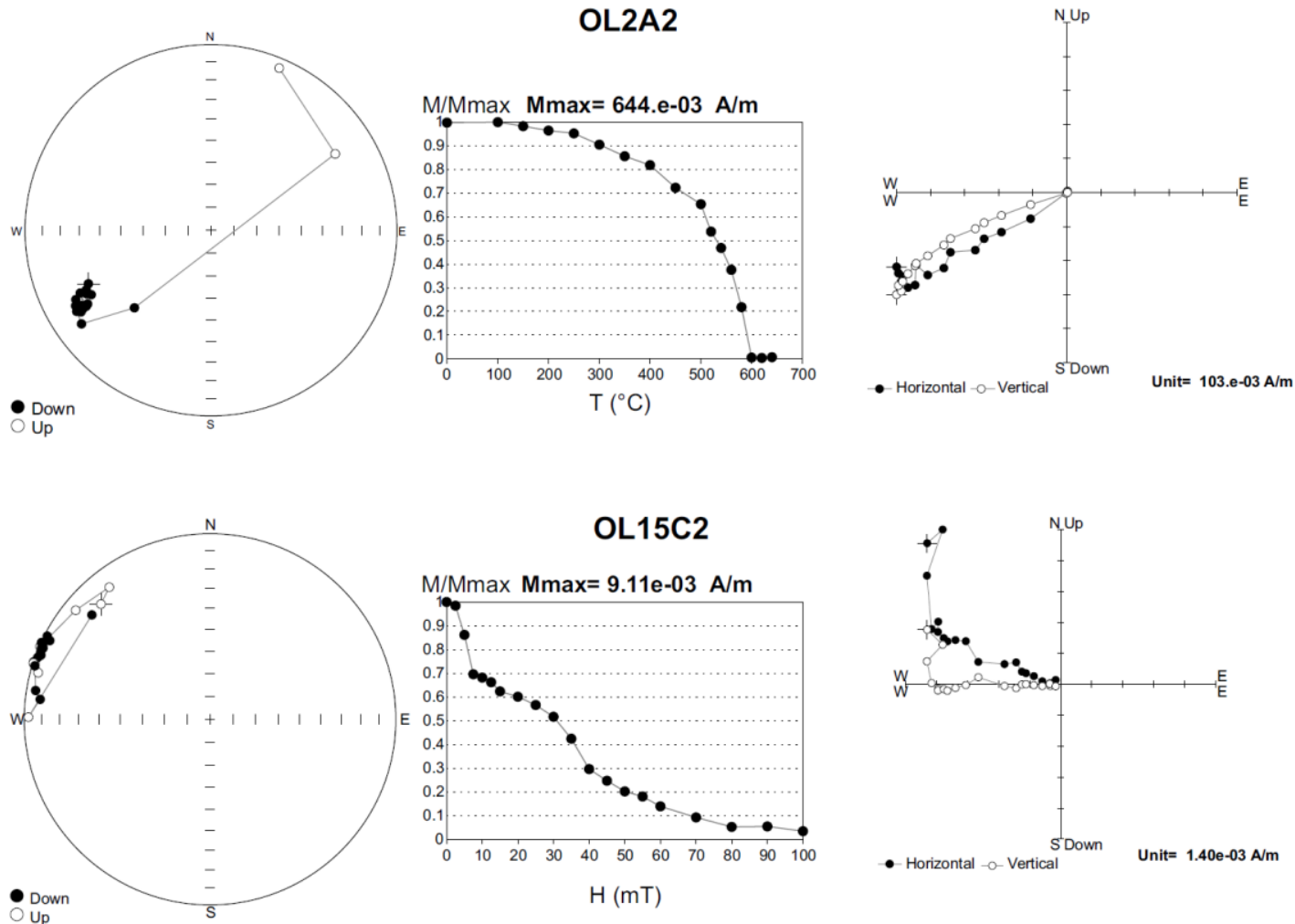

Figura 4.10. Exemplos de desmagnetização de amostras que apresentaram direções Leste (oeste) com inclinações baixas. São mostradas para cada amostra, da esquerda para a direita, a projeção estereográfica, a curva de intensidade normalizada (M/Mmax versus campo alternado ou temperatura) e as projeções ortogonais (Zijderveld). 


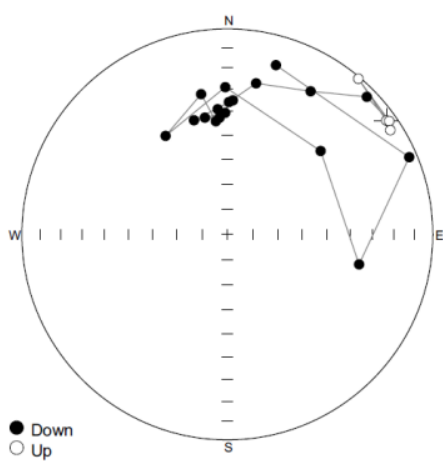

OL7F1
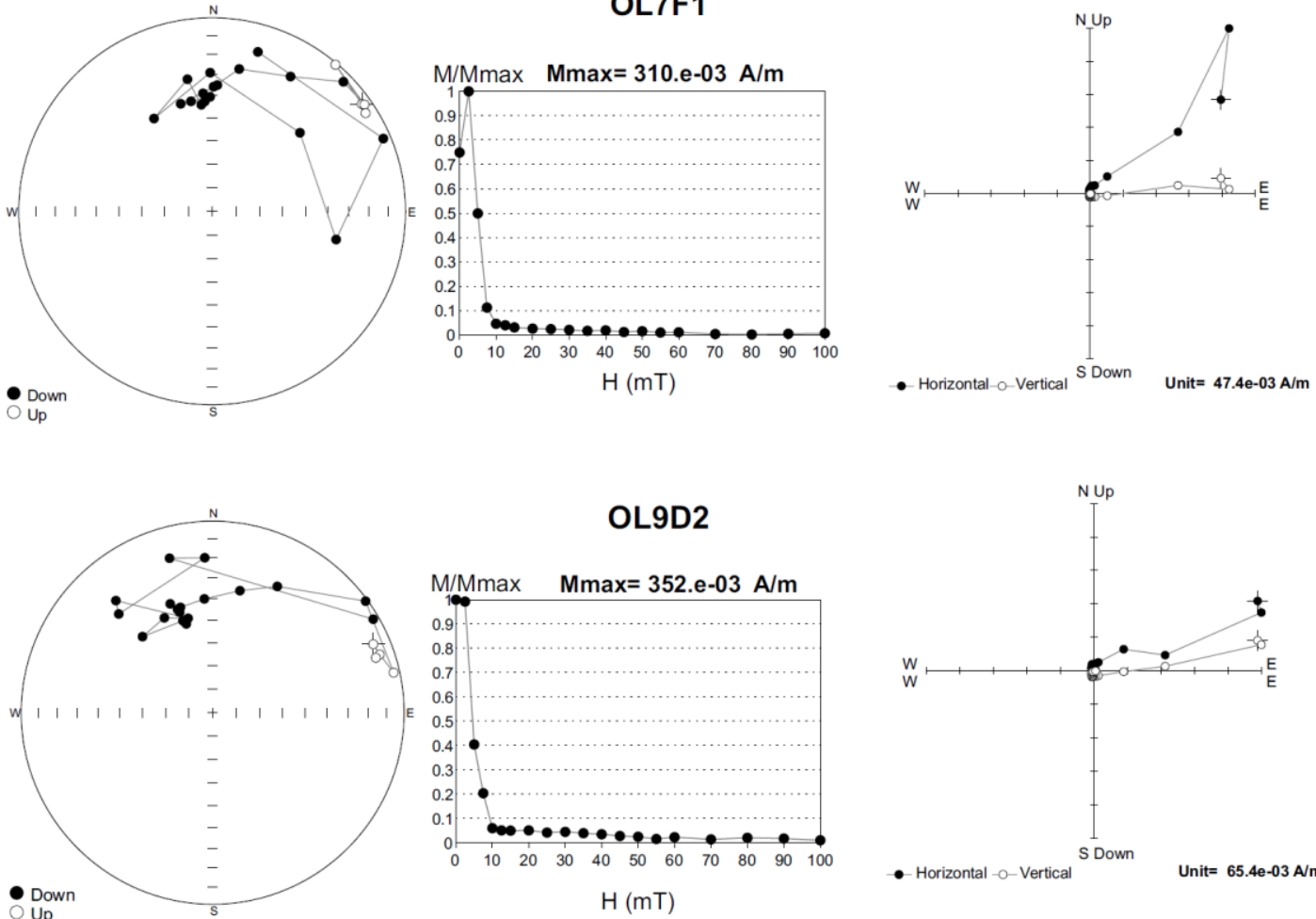

OL9D2
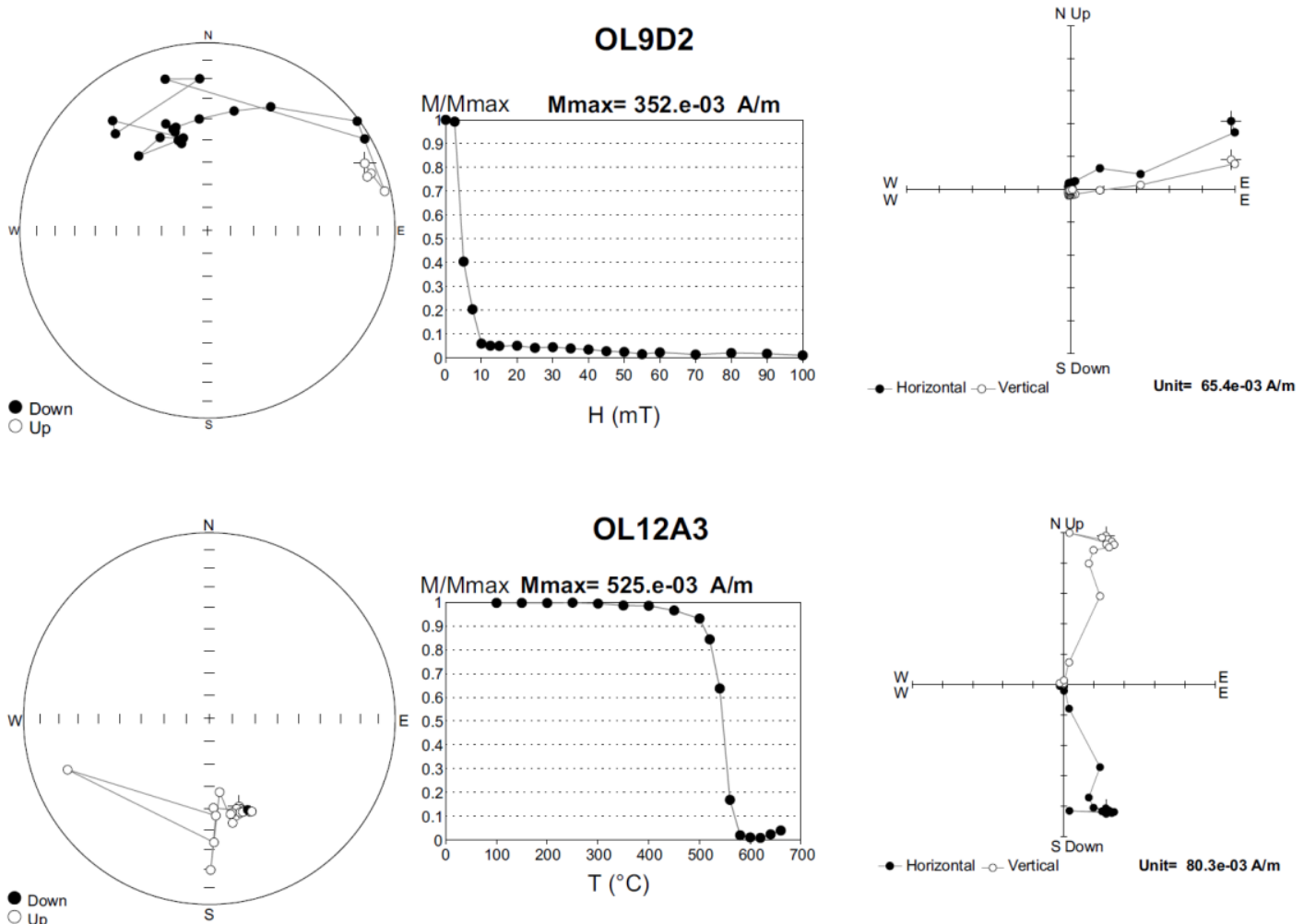

OL12A3
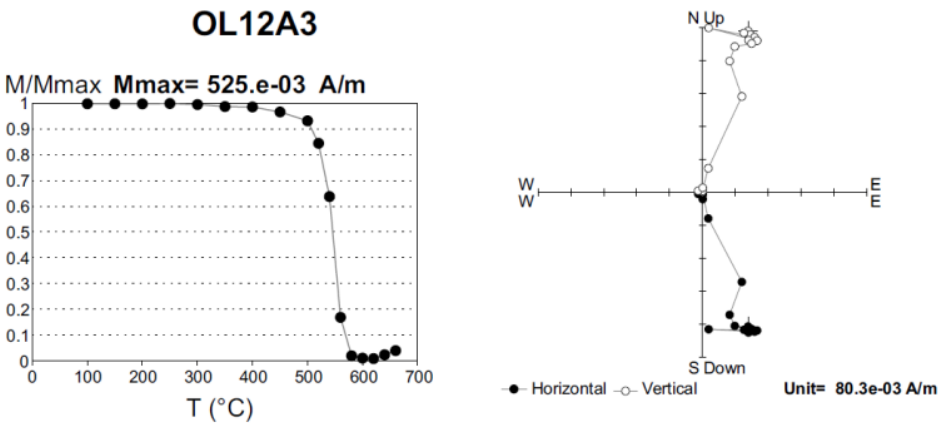

Figura 4.11. Exemplos de desmagnetização de amostras que apresentaram direções norte (sul) com inclinações positivas (negativas. São mostradas para cada amostra, da esquerda para a direita, a projeção estereográfica, a curva de intensidade normalizada (M/Mmax versus campo alternado ou temperatura) e as projeções ortogonais (Zijderveld). 


\section{Capítulo 5}

\section{Discussão}

As rochas do Complexo Rincón del Tigre foram afetadas pela orogênese Sunsás, cujo eixo de dobra apresenta direção NW-SE (Figura 2.3.). Os resultados de ASM mostram lineação magnética nesta direção para a maioria dos sítios investigados, mostrando que este evento de deformação afetou as rochas do complexo. Todavia, a análise petrográfica mostra textura ígnea preservada nestas amostras (informação pessoal, Vinícius Tieppo Meira), o que sugere que a mineralogia magnética deve ter sido também preservada. Sendo assim, podemos aplicar o teste da dobra à coleção de sítios amostrados para verificarmos se há um agrupamento melhor das direções obtidas para as rochas de Rincón del Tigre após a correção tectônica. Para tal, usamos as informações de determinações de planos de dobra fornecidos nos mapas geológicos publicados por Teixeira et al. (2015) e Litherland et al. (1989). As direções corrigidas (juntamente com as direções dos planos de dobra e respectivos ângulos de inclinação utilizados nas correções) e respectivos polos geomagnéticos virtuais (PGVs) são apresentados na Tabela 5.1. A Figura 5.1 mostra as direções antes e após a correção tectônica. A Figura 5.2 mostra que após a correção tectônica os sítios OL3, OL4, OL7, OL8, OL9, OL11 e OL12 são os que melhor se agrupam. As direções médias antes e após a correção tectônica são, respectivamente, $\mathrm{Dm}=325,5^{\circ}, \mathrm{Im}=39,0^{\circ}\left(\alpha_{95}=17,2, \mathrm{~K}=13,3, \mathrm{~N}=7\right)$; $\mathrm{Dm}=327,9^{\circ}, 53,5^{\circ}\left(\alpha_{95}=13,1, \mathrm{~K}=22,6, \mathrm{~N}=7\right)$. Os parâmetros estatísticos indicam um agrupamento significativo das direções após a correção tectônica para estes sítios, sugerindo que suas magnetizações foram adquiridas antes da dobra (teste da dobra positivo). Um polo paleomagnético situado em $271,7^{\circ} \mathrm{E} ; 28,6^{\circ} \mathrm{S}\left(\mathrm{A}_{95}=17,6\right)$ foi calculado através da média dos respectivos PGVs. 
Tabela 5.1- Uso da correção tectônica para corrigir direções.

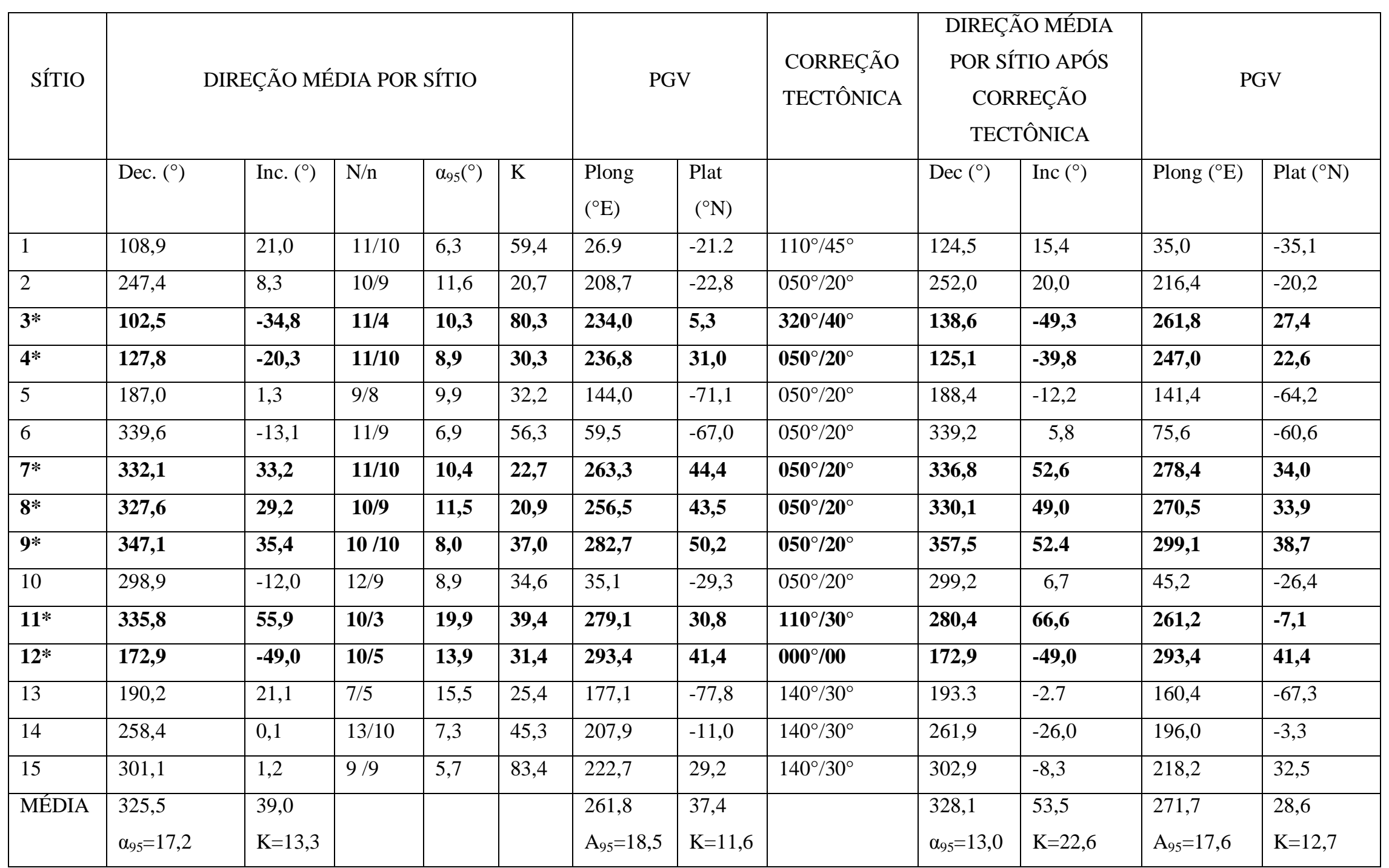

Dec. - Declinação; Inc. - Inclinação; N/n - número de espécimes analisados/número de espécimes usados no cálculo da média; PGV - Polo Geomagnético Virtual; Plong longitude do polo; Plat - latitude do polo. * sítios usados nas médias. 
Todas as amostras sem correção tectônica

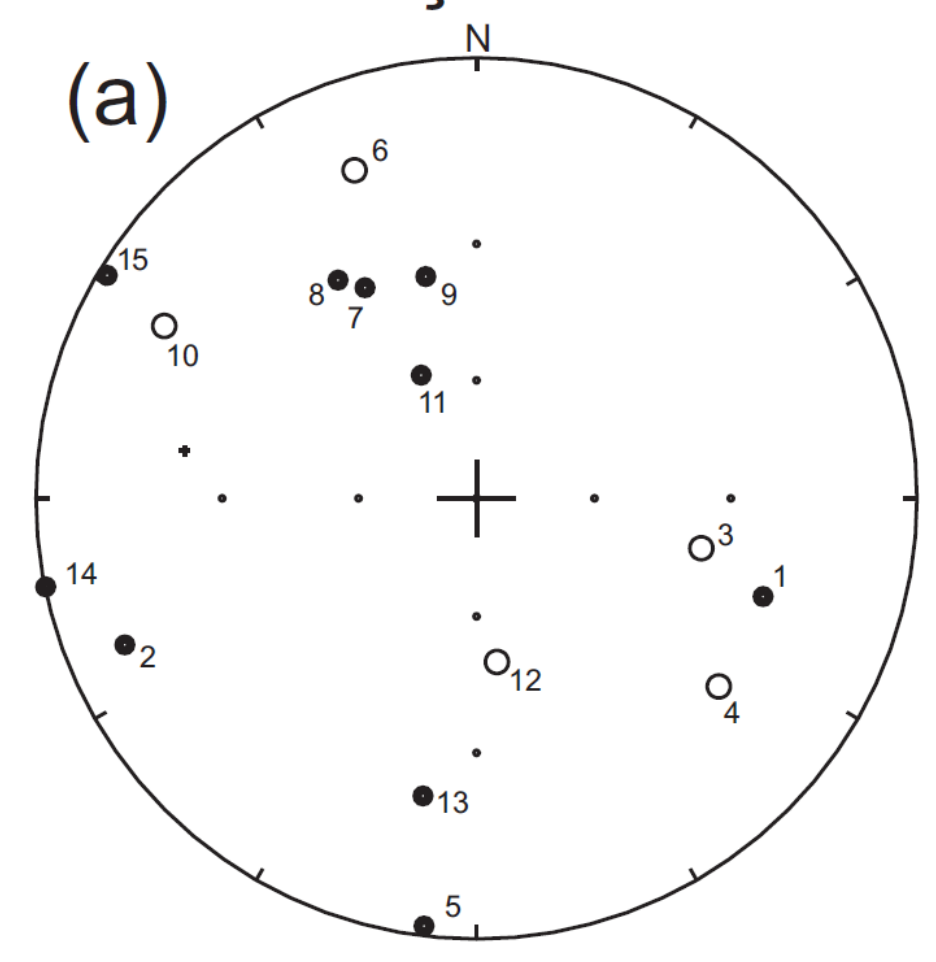

\section{Todas as amostras} com correção tectônica

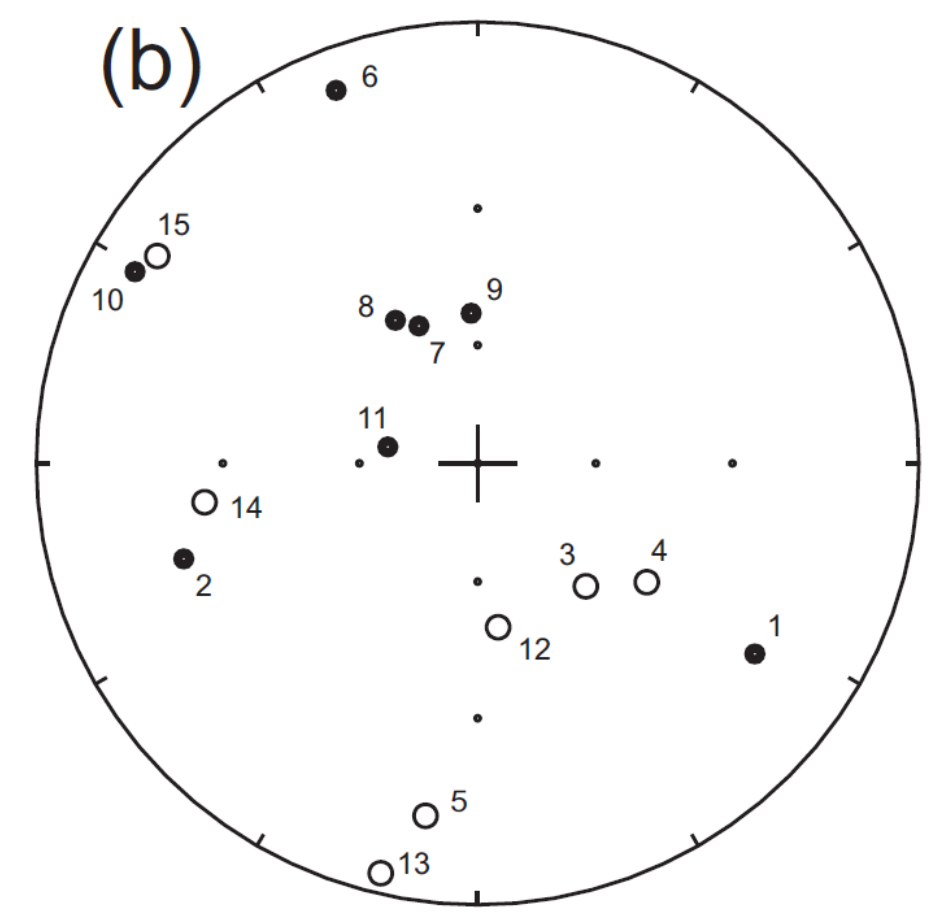

Figura 5.1. Direções médias por sítio: (a) sem correção tectônica; (b) com correção tectônica. Símbolos cheios (vazios) representam direções com inclinação positiva (negativa). 


\section{Direções médias por sítio sem correção tectônica}
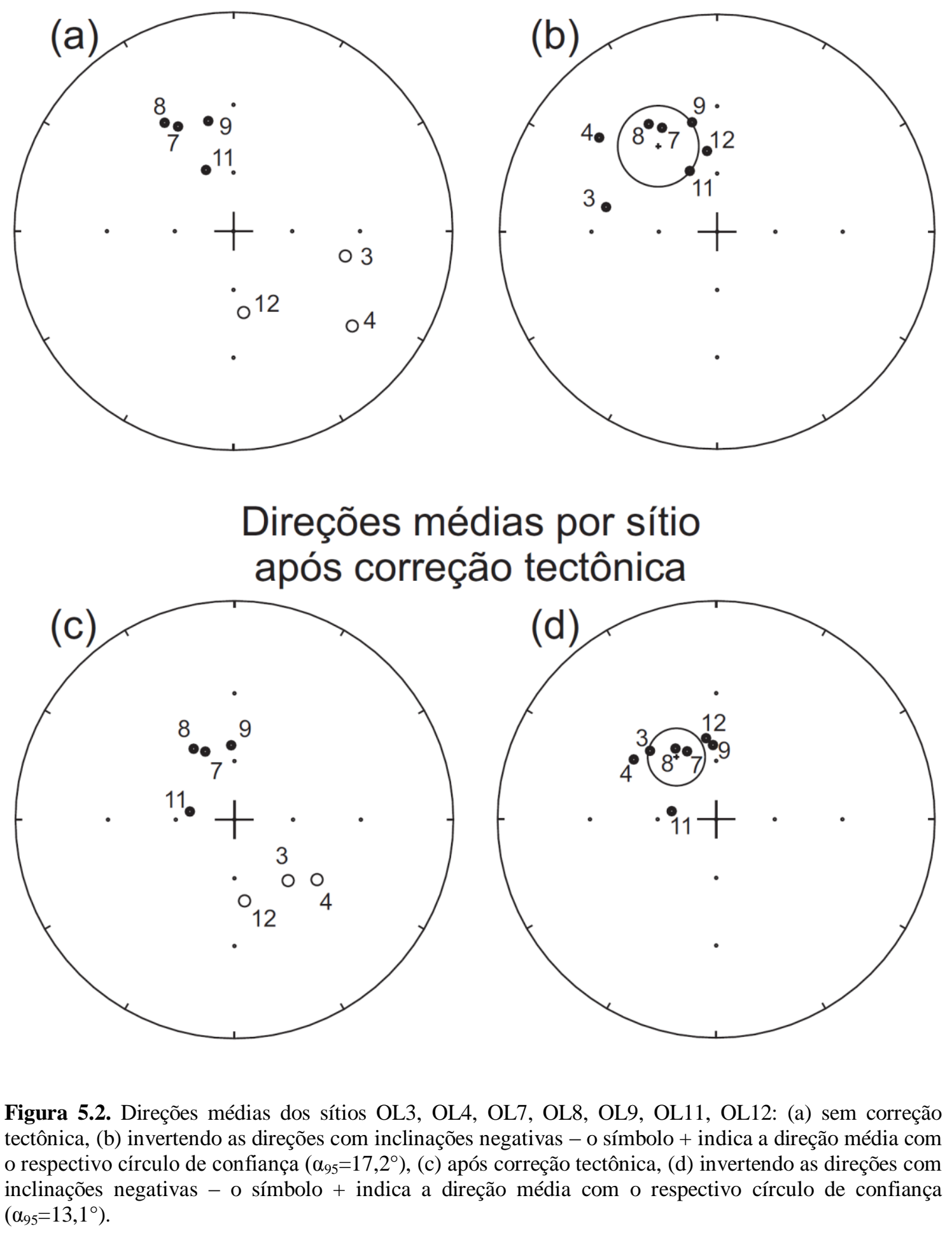
Por outro lado, as correções tectônicas utilizadas foram inferidas através de alguns locais onde os planos de dobra puderam ser determinados. Entretanto, fica difícil saber se a correção utilizada para um determinado sítio é a mesma do local onde ocorreu a medida, já que estes locais não coincidem. Outra forma de corrigirmos uma movimentação tectônica é através das medidas de ASM. Supondo que o Complexo Rincón del Tigre é composto por sills acamadados, esperaríamos obter uma trama horizontal $\left(\mathrm{k}_{3}=90^{\circ}\right)$ para as medidas de ASM. Isto realmente ocorre para boa parte dos sítios medidos (vide descrição acima), embora o eixo k3 apresente inclinação diferente de $90^{\circ}$ indicando que a trama magnética (inicialmente horizontal) pode ter sido influenciada pela tectônica que afetou o Complexo Rincón del Tigre. Assim, as direções dos planos (e ângulos de inclinação) usados para a correção de ASM foram obtidas através da direção média do eixo $\mathrm{k}_{3}$ das ASMs medidas para cada sítio (plano perpendicular à direção do eixo $\mathrm{k}_{3}$ ). As direções destes planos (e ângulo de inclinação) que corrigem a trama magnética de cada sítio trazendo-a para o plano horizontal são apresentadas na Tabela 5.2 e utilizadas para a correção das direções médias medidas dos respectivos sítios. Note que com exceção de 4 sítios (1, 11, 12 e 13), os demais apresentam eixos $\mathrm{k}_{3}$ inclinados para $\mathrm{o}$ primeiro ou para $\mathrm{o}$ terceiro quadrantes, concordante com uma possível inclinação tectônica para estes quadrantes em relação a direção do eixo da dobra que é NW-SE (Figura 4.2). O sítio 13 apresenta uma trama magnética que sugere uma rotação de $-67,9^{\circ}$ em torno de um eixo vertical local, além da rotação ao longo do eixo da dobra. Assim, após subtrair a declinação magnética de $67,9^{\circ}$, utilizou-se o plano de direção $318,5^{\circ}$ e inclinação de $42,9^{\circ}$ para a correção da direção. Note que esta direção de plano é parecida com as dos planos usados para os sítios 14 e 15, embora eles tenham inclinado, aparentemente, para lados opostos, o que é coerente diante das duas medidas de planos tectônicos efetuados nas proximidades destes sítios e que também apresentam inclinações opostas (vide Figura 4.2). Os outros três sítios que apresentaram tramas magnéticas distintas $(1,11$ e 12) indicam eixos k3 inclinados para sudeste (sítios 1 e 11) e noroeste (sítio 12) (Figura 4.2). Entretanto, esta trama pode estar coerente com a tectônica que afetou esta região se o plano de dobra determinado para a localidade situada a leste do sítio 11 e a norte do sítio 1 (direção NE-SW - inclinação da dobra de $28^{\circ}$ ) tiver a mesma direção nas áreas onde os sítios 1 , 11 e 12 foram amostrados (vide Figura 4.2). 
As direções corrigidas de ASM e respectivos polos geomagnéticos virtuais (PGVs) também são apresentados na Tabela 5.2. A Figura 5.3 mostra as direções antes e após a correção tectônica. A Figura 5.4 mostra que após a correção de ASM os sítios OL1, OL3, OL4, OL10, OL11, OL13, OL14 e OL15 são os que melhor se agrupam. As direções médias antes e após a correção de ASM são, respectivamente, $\mathrm{Dm}=122,3^{\circ}$, $\operatorname{Im}=-7,8^{\circ} \quad\left(\alpha_{95}=32,5, \mathrm{~K}=3,9, \mathrm{~N}=8\right) ; \mathrm{Dm}=118,6^{\circ}, 20,7^{\circ} \quad\left(\alpha_{95}=16,5, \mathrm{~K}=12,2, \mathrm{~N}=8\right)$. Os parâmetros estatísticos indicam um agrupamento significativo das direções após a correção de ASM para estes sítios. Um polo paleomagnético situado em $28,5^{\circ} \mathrm{E} ; 30,0^{\circ} \mathrm{S}$ $\left(\mathrm{A}_{95}=12,8\right)$ foi calculado através da média dos respectivos PGVs.
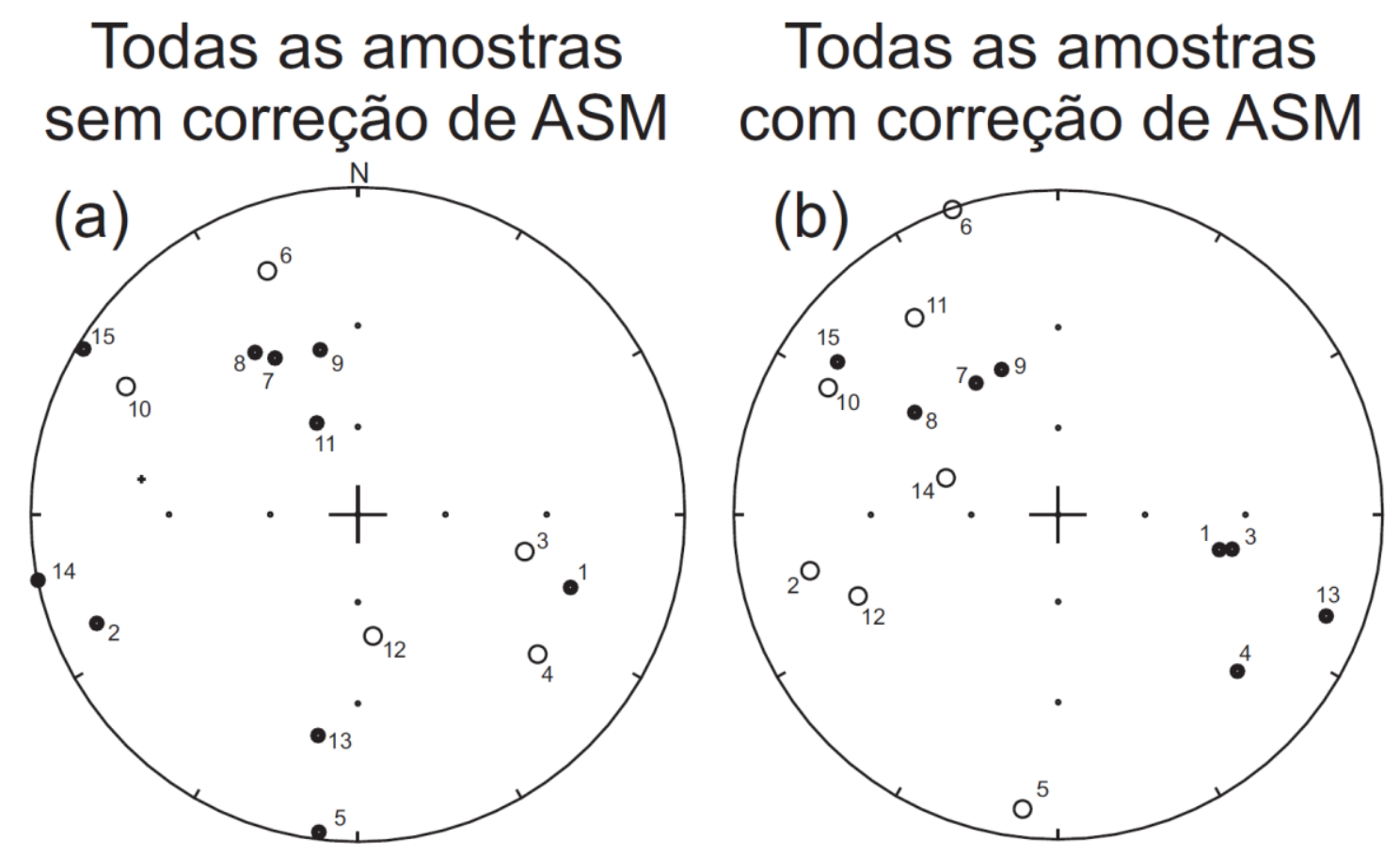

Figura 5.3. Direções médias por sítio: (a) sem correção de ASM; (b) com correção de ASM. Símbolos cheios (vazios) representam direções com inclinação positiva (negativa). 
Tabela 5.2. Uso da ASM para corrigir direções, assumindo uma trama original horizontal $\left(\mathrm{k}_{3}=90^{\circ}\right)$.

\begin{tabular}{|c|c|c|c|c|c|c|c|c|c|c|c|c|}
\hline \multirow[t]{2}{*}{ SÍTIO } & \multicolumn{5}{|c|}{ DIREÇÃO MÉDIA POR SÍTIO } & \multicolumn{2}{|c|}{ PGV } & \multirow[t]{2}{*}{ CORREÇÃO - ASM } & \multicolumn{2}{|c|}{$\begin{array}{c}\text { DIREÇÃO MÉDIA CORRIGIDA } \\
\text { DE ASM }\end{array}$} & \multicolumn{2}{|c|}{ PGV } \\
\hline & Dec. $\left(^{\circ}\right)$ & Inc. $\left(^{\circ}\right)$ & $\mathrm{N} / \mathrm{n}$ & $\alpha_{95}\left({ }^{\circ}\right)$ & K & Plong $\left({ }^{\circ} \mathrm{E}\right)$ & Plat $\left({ }^{\circ} \mathrm{N}\right)$ & & $\operatorname{Dec}\left({ }^{\circ}\right)$ & $\operatorname{Inc}\left({ }^{\circ}\right)$ & Plong $\left({ }^{\circ} \mathrm{E}\right)$ & Plat $\left({ }^{\circ} \mathrm{N}\right)$ \\
\hline $1 *$ & 108,9 & 21,0 & 11/10 & 6,3 & 59,4 & 26.9 & -21.2 & $234,4^{\circ} / 19,3^{\circ}$ & 102,2 & 36,1 & 15,8 & $--18,2$ \\
\hline 2 & 247,4 & 8,3 & $10 / 9$ & 11,6 & 20,7 & 208,7 & $-22,8$ & $159,0^{\circ} / 25,7^{\circ}$ & 257,3 & $-13,8$ & 21,0 & 9,7 \\
\hline $3 *$ & 102,5 & $-34,8$ & $11 / 4$ & 10,3 & 80,3 & 234,0 & 5,3 & $149,7^{\circ} / 84,0^{\circ}$ & 101,2 & 32,7 & 17,9 & $-15,7$ \\
\hline 4* & 127,8 & $-20,3$ & 11/10 & 8,9 & 30,3 & 236,8 & 31,0 & $287,3^{\circ} / 83,8^{\circ}$ & 131,1 & $\mathbf{1 7 , 5}$ & 36,1 & $-41,7$ \\
\hline 5 & 187,0 & 1,3 & $9 / 8$ & 9,9 & 32,2 & 144,0 & $-71,1$ & $129,3^{\circ} / 7,7^{\circ}$ & 186,9 & $-5,2$ & 320,8 & 68,1 \\
\hline 6 & 339,6 & $-13,1$ & $11 / 9$ & 6,9 & 56,3 & 59,5 & $-67,0$ & $110,0^{\circ} / 16,6^{\circ}$ & 340,9 & $-0,3$ & 73,8 & $-64,0$ \\
\hline 7 & 332,1 & 33,2 & $11 / 10$ & 10,4 & 22,7 & 263,3 & 44,4 & $104,6^{\circ} / 8,0^{\circ}$ & 328,0 & 38,9 & 262,7 & 39,1 \\
\hline 8 & 327,6 & 29,2 & $10 / 9$ & 11,5 & 20,9 & 256,5 & 43,5 & $130,7 / 35,4^{\circ}$ & 305,5 & 33,0 & 243,0 & 25,4 \\
\hline 9 & 347,1 & 35,4 & $10 / 10$ & 8,0 & 37,0 & 282,7 & 50,2 & $146,6^{\circ} / 11,5^{\circ}$ & 338,7 & 38,7 & 273,6 & 44,9 \\
\hline $10 *$ & 298,9 & $-12,0$ & $12 / 9$ & 8,9 & 34,6 & 35,1 & $-29,3$ & 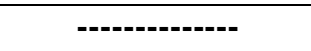 & 298,9 & $-12,0$ & 35,0 & $-29,3$ \\
\hline $11 *$ & 335,8 & 55,9 & $10 / 3$ & 19,9 & 39,4 & 279,1 & 30,8 & $218,1 / 75,9$ & 323,9 & $-16,2$ & 42,6 & $-53,6$ \\
\hline 12 & 172,9 & $-49,0$ & $10 / 5$ & 13,9 & 31,4 & 293,4 & 41,4 & $18,0^{\circ} / 81,6^{\circ}$ & 247,9 & $-22,7$ & 12,8 & 16,6 \\
\hline $13 *$ & 190,2 & 21,1 & $7 / 5$ & 15,5 & 25,4 & 177,1 & $-77,8$ & $318,5^{\circ} / 42,9^{\circ}$ & 110,7 & 7,1 & 34,6 & $-20,8$ \\
\hline $14 *$ & 258,4 & 0,1 & $13 / 10$ & 7,3 & 45,3 & 207,9 & $-11,0$ & $132,6^{\circ} / 71,0^{\circ}$ & 288,2 & $-50,0$ & 5,2 & $-24,4$ \\
\hline $15^{*}$ & 301,1 & 1,2 & $9 / 9$ & 5,7 & 83,4 & 222,7 & 29,2 & $318,5^{\circ} / 34,7^{\circ}$ & 304,7 & 10,8 & 49,5 & $-30,6$ \\
\hline MÉDIA & $\begin{array}{c}122,3 \\
\alpha_{95}=32,5\end{array}$ & $\begin{array}{c}-7.8 \\
K=3,9\end{array}$ & & & & $\begin{array}{c}229,1 \\
A_{95}=26,1\end{array}$ & $\begin{array}{c}30,8 \\
K=5,5\end{array}$ & & $\begin{array}{c}118,6 \\
\alpha_{95}=16,5\end{array}$ & $\begin{array}{c}20,7 \\
K=12,2\end{array}$ & $\begin{array}{c}28,5 \\
A_{95}=12,8\end{array}$ & $\begin{array}{c}-30,0 \\
K=19,8\end{array}$ \\
\hline
\end{tabular}

Dec. - Declinação; Inc. - Inclinação; N/n - número de espécimes analisados/número de espécimes usados no cálculo da média; PGV - Polo Geomagnético Virtual; Plong - longitude do polo; Plat - latitude do polo. * sítios usados nas médias.

Obs.: Os dados de ASM indicam a possibilidade do sítio 13 ter rotacionado de $-67,9^{\circ}$ ao longo de um eixo vertical local. Assim, a declinação média do sítio foi subtraída deste valor, antes da correção de $\mathrm{BP}\left(318,5^{\circ} / 42,9^{\circ}\right)$. O sítio 10 apresentou $\mathrm{k}_{3}$ muito próximo de $90^{\circ}$. Assim, não foi feita correção de ASM. 


\section{Direções médias por sítio sem correção de ASM}
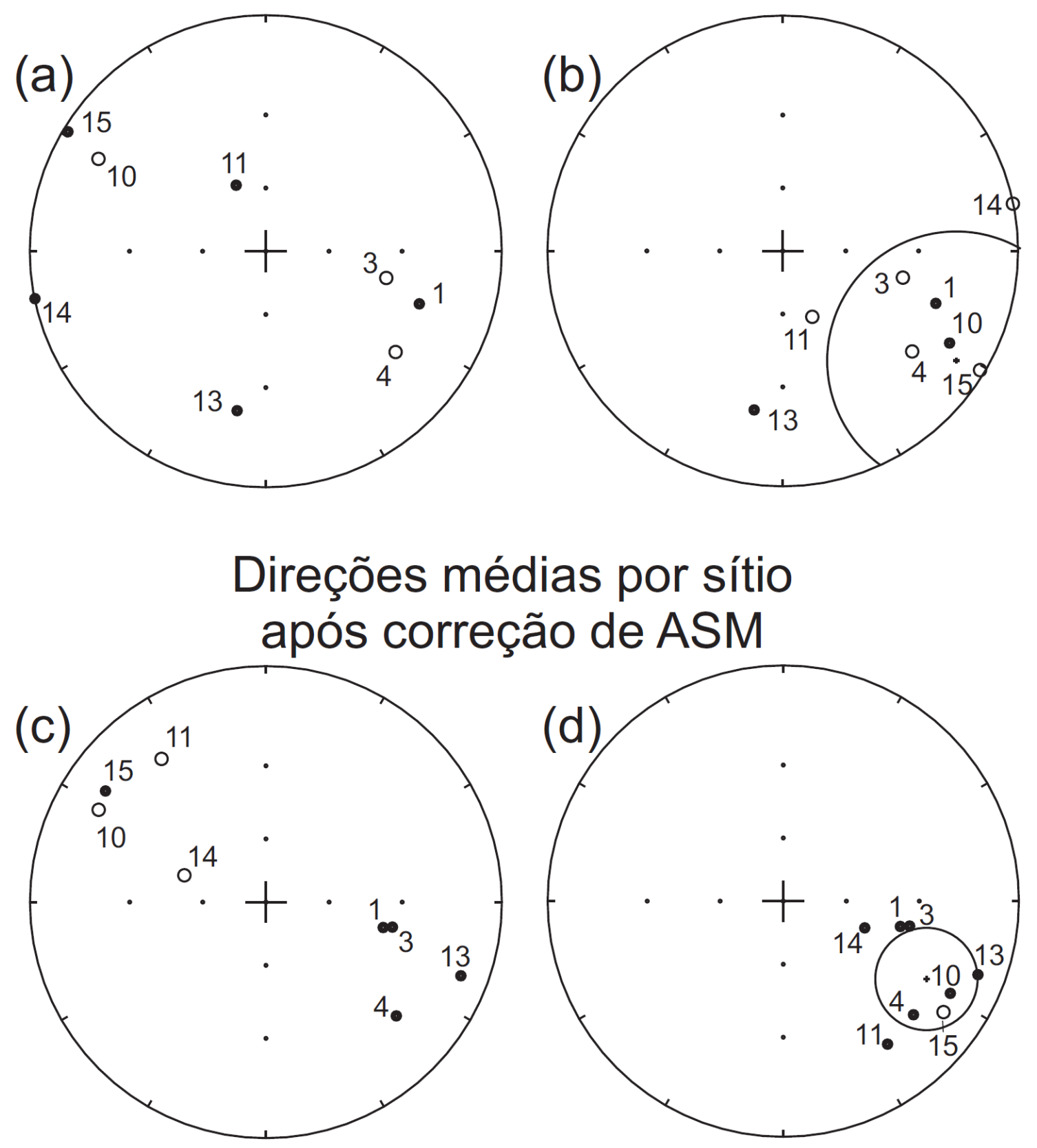

Figura 5.4. Direções médias dos sítios OL1, OL3, OL4, OL10, OL11, OL13, OL14, OL15: (a) sem correção de ASM, (b) invertendo as direções com inclinações negativas - o símbolo + indica a direção média com o respectivo círculo de confiança $\left(\alpha_{95}=17,2^{\circ}\right)$, (c) após correção tectônica, (d) invertendo as direções com inclinações negativas $-\mathrm{o}$ símbolo + indica a direção média com o respectivo círculo de confiança $\left(\alpha_{95}=13,1^{\circ}\right)$. 


\subsection{Paleogeografia do Cráton Amazônico no Columbia.}

O Cráton Amazônico é uma das maiores unidades cratônicas do mundo e teve participação ativa nas configurações dos Supercontinentes Columbia e Rodínia. Modelos paleogeográficos propõem que o Cráton Amazônico estava unido com o Cráton OesteÁfrica desde o Paleoproterozoico em uma configuração em que as zonas de cisalhamentos Guri (Escudo das Guianas) e Sassandra (Oeste África) faziam parte do mesmo lineamento (Onstott and Hargraves, 1981, Nomade et al., 2003, Bispo-Santos et al., 2014b). Em 2009, Johansson propôs que a parte noroeste do Cráton Amazônico (juntamente com o Cráton Oeste-África) estava unida ao sul da Baltica em um modelo que ele denominou de SAMBA (South America and Baltica). Dados paleomagnéticos obtidos para o sills e diques máficos pertencentes ao Evento Avanavero, com idade de 1788 \pm 2 Ma, apoiam o modelo SAMBA (Reis et al., 2013, Bispo-Santos et al., 2014a).

No modelo proposto por Johansson (2009), a Laurentia (ao longo da atual costa sudeste da Groelândia) aparece unida a Baltica (ao longo margem noroeste da Fenoscândia), os quais, juntamente com o Cráton Amazônico/Oeste-África formavam o núcleo do supercontinente Columbia. Dados paleomagnéticos obtidos para a Laurentia e Baltica também apoiam uma união da Baltica com a Laurentia, desde 1830 Ma até 1270 Ma, embora em uma configuração um pouco diferente da proposta por Johansson (2009). No modelo com base em dados paleomagnéticos, a margem Ártica da Baltica aparece unida à costa leste da Groelândia (Buchan et al., 2000, Salminen e Pesonen, 2007, Evans e Pisarevsky, 2008, Pisarevsky e Bylund, 2010, Evans e Mitchell, 2011, Mertanen e Pesonen, 2012, Pesonen et al., 2012, Zhang et al., 2012, Salminen et al., 2013, Johansson, 2014, Bispo-Santos et al., 2014a). A Figura 5.5 apresenta a reconstrução proposta por Bispo-Santos et al. (2014a) com base em dados paleomagnéticos para o núcleo do supercontinente Columbia. 


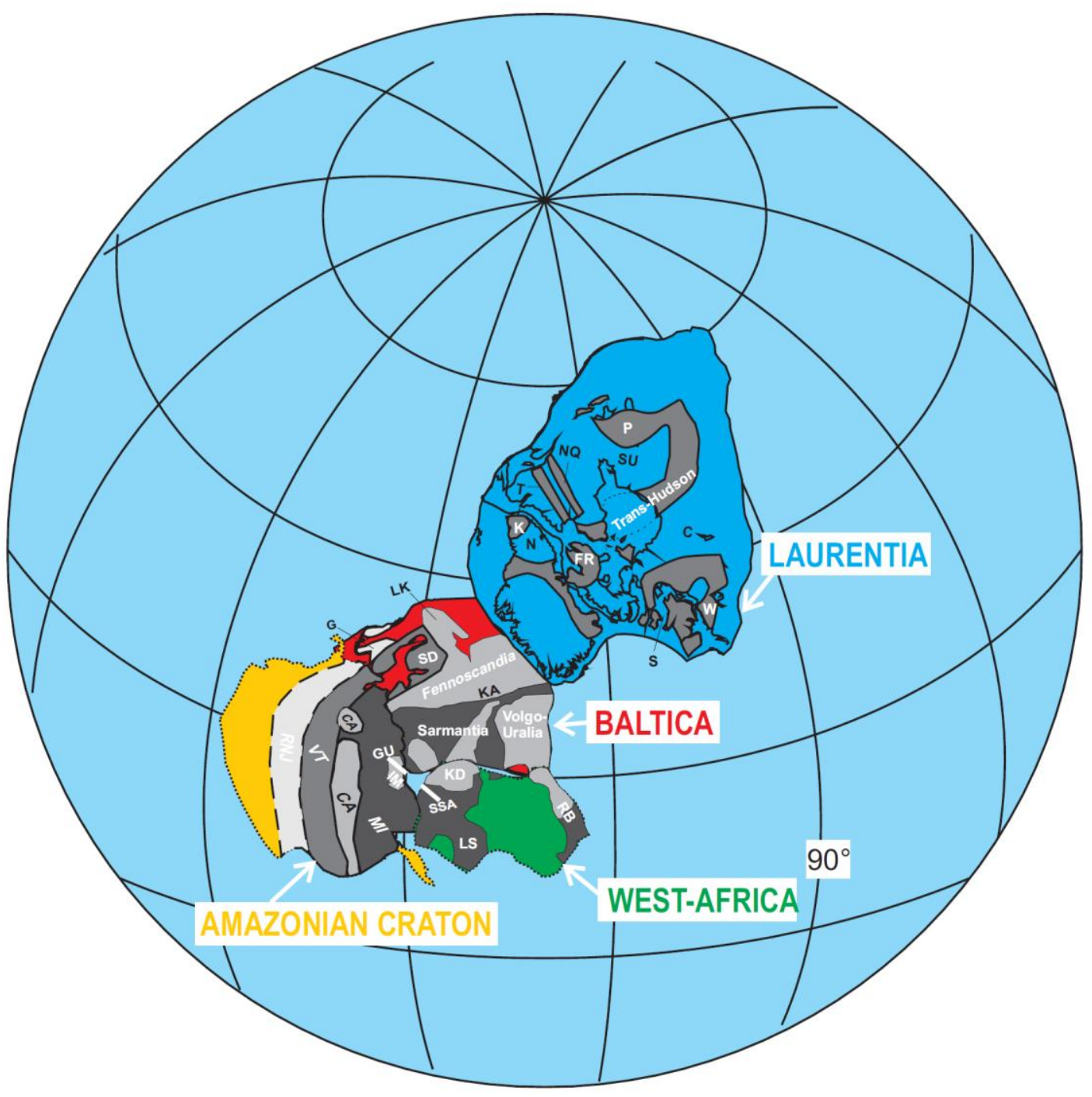

Figura 5.5. Configuração do núcleo do Columbia proposto por Bispo-Santos et al. (2014a). Cinturões orogênicos Paleoproterozoicos e áreas Arqueanas (cor cinza): Laurentia (S - Slave; C - Churchill; SU Superior; N - Nain, NQ - New Quebec; T - Tornget; W - Wopmay; P - Penokean; K - Kefilidian; NA Nagssugtoqidian; FR - Foxe-Rinklan), Báltica (KO - Kola; KA - Karelia, LK - Lapland-Kola; SD Svecofennian Domain; G - Gothian Province), Amazonia (CA - Amazonia Central, MI - MaroniItacaiunas; VT - Ventuari-Tapajos; RNJ - Rio Negro-Juruena, GU - lineamento Guri) e Cráton Oeste África (LS - Leo Shield, KD - Domínio Kenemanan; RB - Requibat Shield, SSA - lineamento Sassandra) e Cráton Norte da China (YB - bloco Yinshan; OB - bloco Ordos; WB - bloco West; EB - bloco East, NH - cinturão North Hebei/Khondolite; TNC - cinturão Trans-North China; JLJ - cinturão Jiao-Liao-Ji). 


\subsection{Paleogeografia do Cráton Amazônico - do Columbia ao Rodinia.}

A ruptura do Supercontinente Columbia deu origem a formação do supercontinente Rodina no final do Mesoproterozoico/ início do Neoproterozoico (McMenamin e McMenamin, 1990). Entretanto, a geodinâmica que originou o Rodinia ainda é um tema muito debatido na literatura, sendo que o Cráton Amazônico teve participação ativa nesta história (Hoffman, 1991, Weil et al., 1998, D’Agrella et al., 1998, 2008, Dalziel et al., 2000, Tohver et al., 2002, 2004b, Pisarevsky et al., 2003, Meert e Torsvik, 2003, Li et al., 2008, Piper, 2010). Desde a última década do século passado, correlações geológicas e dados paleomagnéticos vêm mostrando que a parte sudoeste do Cráton Amazônico interagiu dinamicamente com o sudeste da Laurentia, ao longo dos cinturões orogênicos Sunsás e Grenville, respectivamente (Hoffman, 1991, Sadowski e Bettencourt, 1996, Tohver et al., 2002, 2004a, D’Agrella-Filho et al., 2008, Li et al., 2008, Elming et al., 2009). O modo como ocorreu esta interação, entretanto, é ainda muito debatido, tendo sido propostos modelos bastante distintos. Li et al. (2008) propõem uma colisão frontal do Cráton Amazônico com a Laurentia ao longo da região do Labrador, enquanto Tohver et al. (2004b) sugerem uma colisão oblíqua do Cráton Amazônico com a Laurentia ao longo da região do Texas (cinturão Llano), há cerca de 1200 Ma atrás, e posterior movimento transcorrente do Cráton Amazônico até uma posição mais central do cinturão Grenville, correspondente a região de Ontário-Nova York. Tohver e colaboradores propuseram seu modelo com base em dados paleomagnéticos obtidos para rochas máficas da Formação Nova Floresta, as quais foram datadas em cerca de 1200 Ma, além de evidências geológicas, geocronológicas e isotópicas (Tohver et al., 2002, 2004a, 2004b, 2005a, 2005b, 2006).

Em 2008, D’Agrella-Filho e colaboradores apresentaram dados paleomagnéticos para rochas sedimentares da Formação Fortuna (Grupo Aguapeí), os quais parecem corroborar o modelo apresentado por Tohver et al. (2004b). Mais recentemente, Elming et al. (2009) apresentaram dados paleomagnéticos para sills máficos da região de Rio Branco (Estado do Mato Grosso), os quais foram datados pelo método Ar-Ar em 980 2 Ma. Estes autores apresentaram um modelo de transcorrência do Cráton Amazônico, que segue os modelos propostos por Tohver et al. (2004b) e D’Agrella-Filho et al. (2008), o qual é reapresentado na Figura 5.6. Este modelo foi também seguido por Ibanez-Mejia et al. (2011) que tentam explicar a origem do sistema de arcos em franja que margeiam o Cráton Amazônico na 
Colômbia (Orogênese Putumayo). Todavia, idades U-Pb em badeleítas pertencentes aos

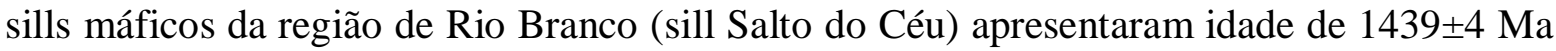
(Teixeira et al., 2015), sugerindo que o polo paleomagnético determinado para estas rochas tem idade de 1440 Ma e não de 980 Ma, como sugerido pela idade Ar-Ar. Se a idade do polo dos sills de Rio Branco for realmente mais antiga, então a reconstrução proposta por Elming et al. (2009) para a posição do Cráton Amazônico em relação à Laurentia em 980 Ma deve ser revista.

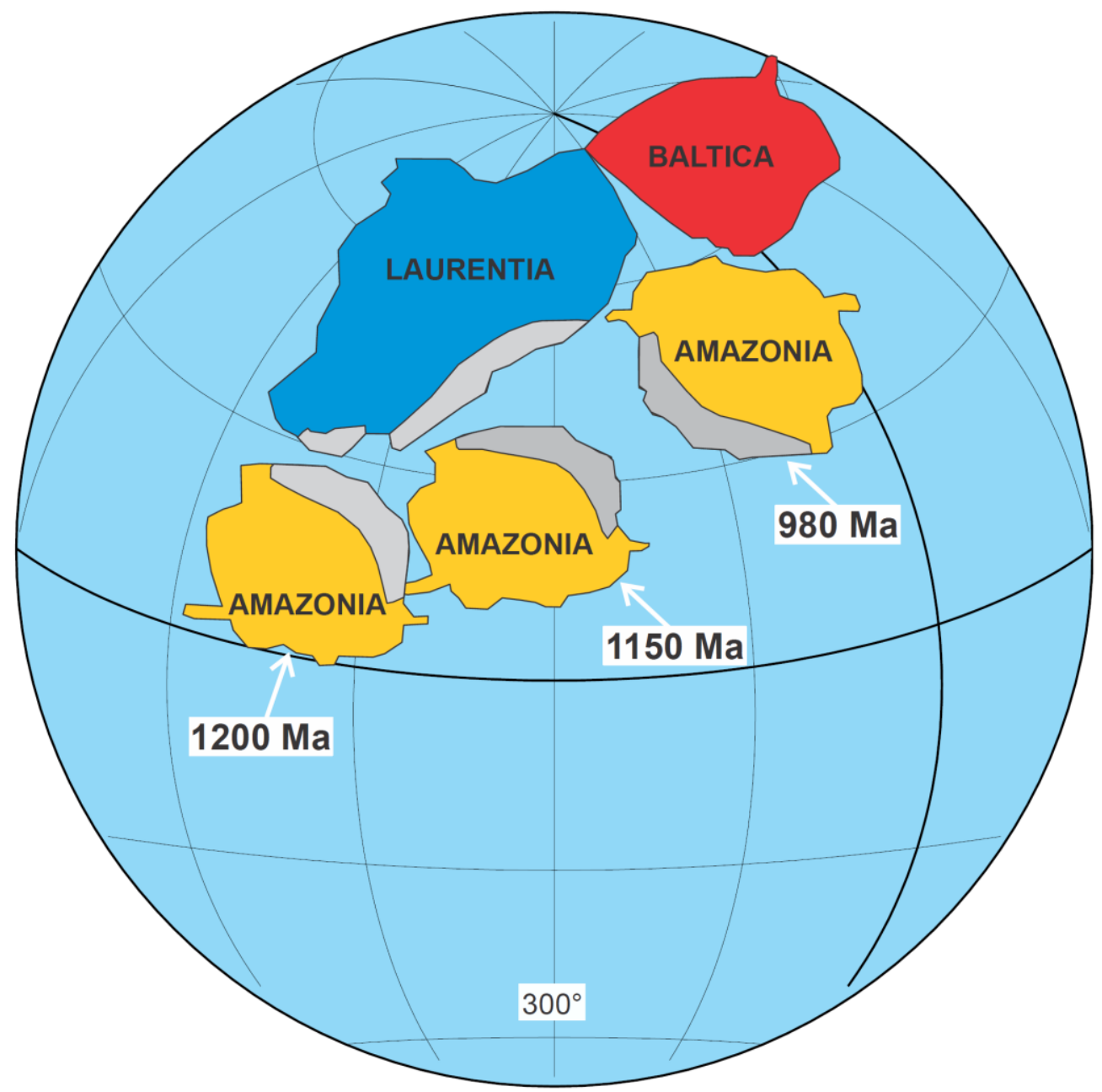

Figure 5.6. Interação dinâmica entre o Cráton Amazônico a e a Laurentia ente 1200 e 980 Ma com base em dados paleomagnéticos (modificado de Elming et al. 2009). Posição do Cráton Amazônico relativo à Laurentia (América do Norte na posição atual) são mostrados para $1200 \mathrm{Ma}$ (baseado no polo Nova Floresta - Tohver et al. 2002), para 1150 Ma (baseado no polo Formação Fortuna - D’Agrella-Filho et al. 2008) e para $980 \mathrm{Ma}$ (baseado no polo Salto do Céu (sills da região de Rio Branco - Elming et al. 2009).

Recentemente, Evans (2013) propôs um cenário alternativo para a dinâmica de interação entre o Cráton Amazônico e a Laurentia (Figura 5.7), a qual contrasta totalmente com a proposta por Tohver et al. (2004b), D’Agrella-Filho et al. (2008) e Elming et al. (2009). Tendo a possibilidade de utilizar das polaridades opostas do polos Mesoproterozoicos (Nova 
Floresta, Formação Fortuna) obtidos para o Cráton Amazônico (tendo em vista a ambiguidade na polaridade quando estudamos rochas do Precambriano), Evans (2013) argumenta que após a ruptura da configuração SAMBA no Columbia, a Baltica e o Cráton Amazônico realizaram um movimento de rotação no sentido horário e colidiram novamente com a Laurentia. No modelo, o Cráton Amazônico colide com a Laurentia ao longo do cinturão Grenville na região do Labrador (Figura 5.7).

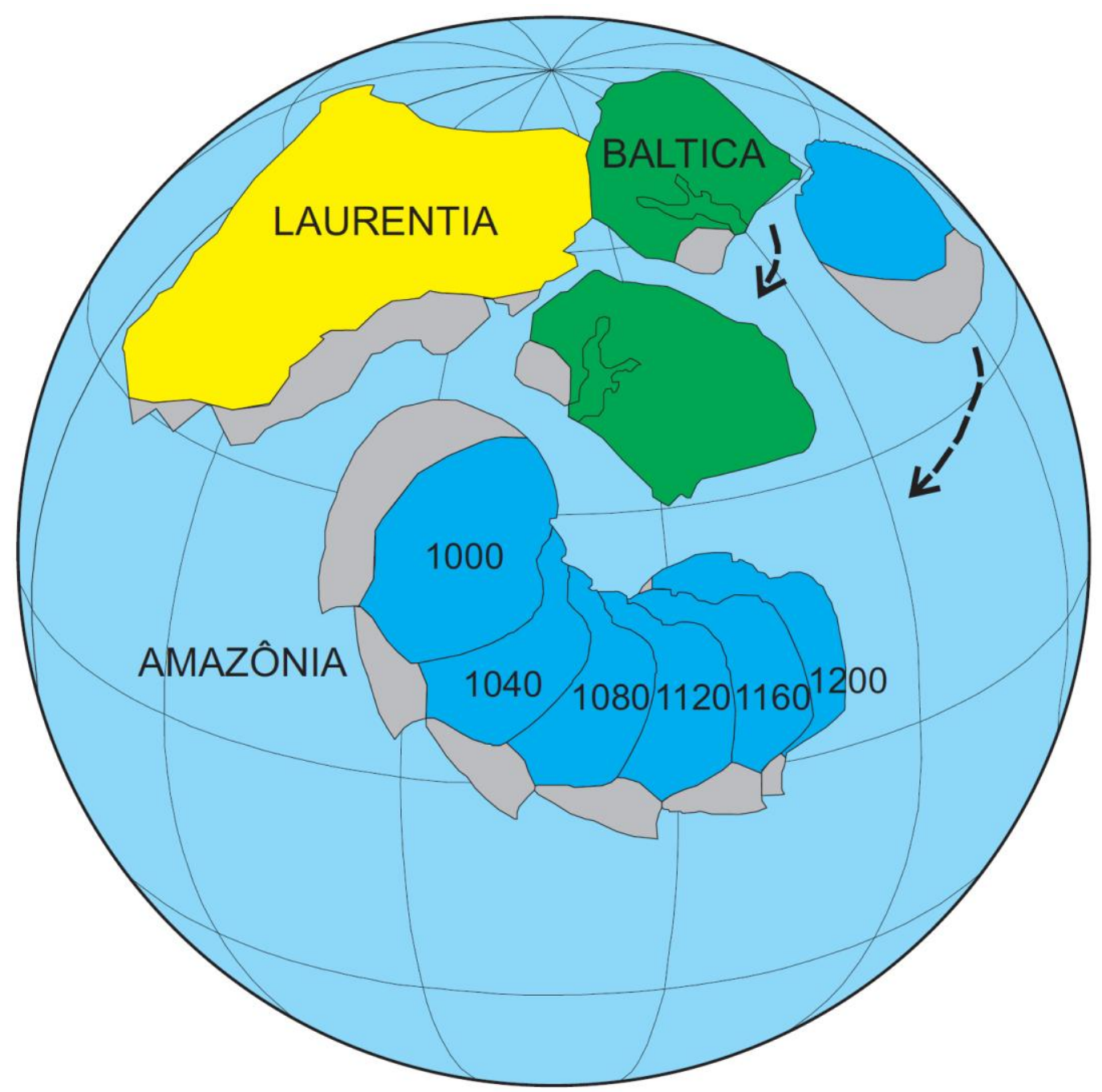

Figura 5.7. Modelo proposto por Evans (2013) para a ruptura do Columbia e aglutinação do Rodinia envolvendo a Laurentia, a Baltica e o Cráton Amazônico. Após a ruptura do Columbia, a Baltica e o Cráton Amazônico executam um movimento de rotação horária até colidirem novamente com a Laurentia.

Podemos testar o modelo de rotação proposto por Evans (2013) utilizando os novos dados obtidos neste trabalho. Iniciaremos com o teste utilizando o polo de Rincón del Tigre, obtido após a correção de ASM, admitindo que ele tenha uma idade de 1100 Ma. A Figura 5.8 mostra um possível cenário de ruptura, rotação no sentido horário do Cráton 
Amazônico/Oeste-África e da Báltica e posterior colisão destes blocos com a Laurentia. Paleogeografias envolvendo estas três unidades foram construídas para 1265 Ma, $1200 \mathrm{Ma}$, 1150 Ma, 1100 Ma e 1000 Ma. Neste intervalo de tempo, temos polos paleomagnéticos disponíveis para na Laurentia (todas as idades) e para o Cráton Amazônico (para as idades de $1200 \mathrm{Ma}, 1150 \mathrm{Ma}$ e $1100 \mathrm{Ma}$ ) (Tabela 5.3). Para a Báltica não temos polos paleomagnéticos confiáveis para este intervalo de idades e as posições relativas deste bloco continental são especulativas.

Tabela 5.3- Polos paleomagnéticos selecionados para o Cráton Amazônico e Laurentia no intervalo entre 1270 e $1100 \mathrm{Ma}$.

\begin{tabular}{|l|l|l|l|l|l|}
\hline & Idade & $\mathrm{A}_{95}$ & Plat. $\left({ }^{\circ} \mathrm{N}\right)$ & Plong. $\left({ }^{\circ} \mathrm{E}\right)$ & Ref. \\
\hline Laurentia: & & & & & \\
\hline Diques MacKenzie & $1.267 \pm 2$ & 5 & 4 & 190 & 1 \\
\hline Upper Bylot & $1.204 \pm 22$ & 4 & 8 & 205 & 2 \\
\hline Diques Abitibi & $1.141 \pm 1$ & 14 & 43 & 208 & 3,4 \\
\hline Sills Logan & $1.109+4-2$ & 4 & 49 & 220 & 5,6 \\
\hline & & & & & \\
\hline Cráton Amazônico: & & & & & \\
\hline Fm. Nova Floresta & $1201 \pm 1 ; 1198 \pm 3$ & 6 & 25 & 165 & 7 \\
\hline Fm. Fortuna & $1.149 \pm 7$ & 10 & 60 & 156 & 8 \\
\hline Suite Rincón del Tigre* & $1.110 \pm 2$ & 13 & -30 & 29 & Este trabalho \\
\hline Suite Rincón del Tigre** & $1.110 \pm 2$ & 18 & 29 & 272 & Este trabalho \\
\hline
\end{tabular}

* - correção de ASM; ** correção tectônica; $\mathrm{A}_{95^{-}}$semi-ângulo do cone de confiança; Plat.; Plong. Paleolatitude e paleolongitude do polo paleomagnético; 1- Buchan e Halls (1990); 2- Fahrig et al. (1981); 3Ernst e Buchan (1993); 4- Irving e Naldrett (1977); 5- Halls e Pesonen (1982); 6- Davis e Sutcliffe (1985); 7Tohver et al. (2002); 8- D’Agrella-Filho et al. (2008). Estes polos foram usados nas reconstruções das Figuras 5.8 e 5.9 .

Os dados paleomagnéticos sugerem que a Laurentia e a Baltica comportaram-se como um único bloco continental até, pelo menos, 1265 Ma (Salminen e Pesonen, 2007). Se a ruptura do Columbia ocorreu após esta idade, então a configuração que prevalecia há 1265 Ma pode ter sido a do modelo SAMBA. A Figura 5.8a mostra a configuração proposta por BispoSantos et al. (2014a) utilizando o polo paleomagnético obtido para os diques MacKenzie que apresentam idade de 1267 Ma (Buchan e Halls, 1990). Provavelmente, o enxame de diques MacKenzie é o registro da ruptura inicial do Columbia (Hou et al., 2008b). 


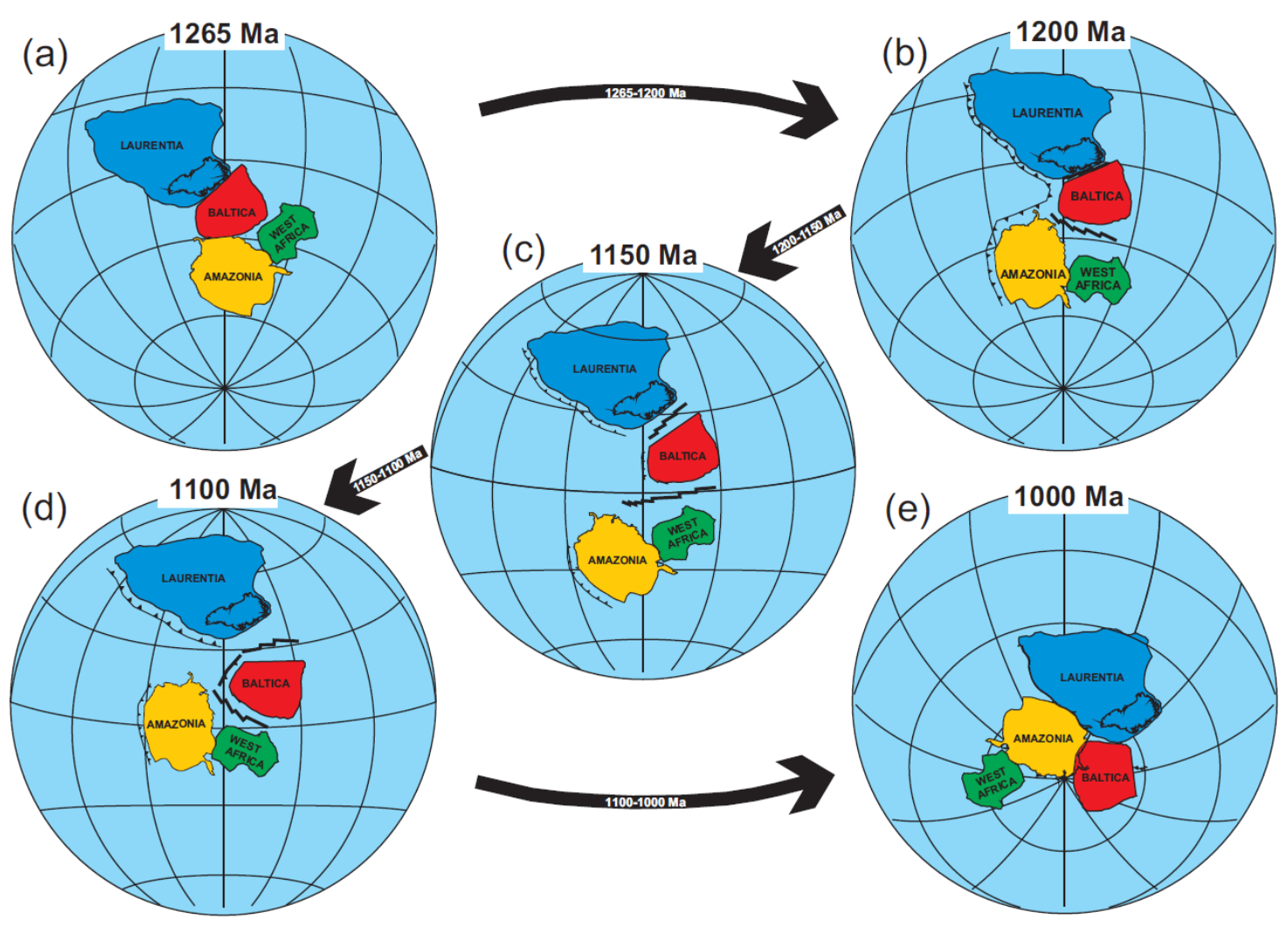

Figura 5.8. Reconstruções paleogeográficas para a Laurentia, Baltica e Cráton Amazônico/Oeste-África em $1265 \mathrm{Ma}, 1200 \mathrm{Ma}, 1150 \mathrm{Ma}, 1100 \mathrm{Ma}$ e $1000 \mathrm{Ma}$. As quatro primeiras reconstruções foram feitas utilizando os polos da Tabela 5.1. A reconstrução há 1000 Ma foi feita utilizando os polos de rotação apresentadas em Li et al. (2008). Utilizou-se o polo de Rincón del Tigre obtido após correção de ASM para posicionar o Cráton Amazônico/Oeste-África em 1100 Ma.

A Figura 5.8b mostra a configuração há 1200 Ma. As posições paleogeográficas dos Crátons Amazônico/Oeste-África e Laurentia são estabelecidos pelo polo Nova Floresta (Tohver et al., 2002) e pelo polo Upper Bylot (Fahrig et al., 1981), respectivamente. A Báltica e o Cráton Amazônico/Oeste-África romperam-se do Columbia e iniciaram sua rotação no sentido horário. A Figura 5.8c mostra a configuração há 1150 Ma, onde a Laurentia e o bloco Amazônico/Oeste-África são posicionados de acordo com o polo obtido para os diques Abitibi (Ernst e Buchan, 1993; Irving e Naldrett, 1977) e pelo polo Nova Fortuna (D’Agrella-Filho et al. 2008), respectivamente.

$\mathrm{Na}$ reconstrução em 1100 Ma (Figura 5.8d), a Laurentia foi posicionada através do polo obtido pelos sills Logan (Halls e Pesonen, 1982; Davis e Sutcliffe, 1985) e o Craton Amazônico/Oeste-África, pelo polo de Rincón del Tigre após correção de ASM. Finalmente, a Figura 5.8e mostra a configuração a $1000 \mathrm{Ma}$, tal como foi proposto por Li et al. (2008), onde o supercontinente Rodínia já estava formado. Note que para o Cráton AmazônicoOeste África passar da configuração de 1100 Ma, definida pelo polo de Rincón del Tigre 
para a posição definida por Li et al. (2008), ele teria que ter sofrido uma rotação de aproximadamente $90^{\circ}$ em $100 \mathrm{Ma}$.

A configuração há 1100 Ma apresentada na Figura 5.8d muda se considerarmos o polo de Rincón del Tigre determinado após a correção tectônica. Neste caso, uma provável configuração é apresentada na Figura 5.9, juntamente com as configurações há 1150 Ma e há 1000 Ma.

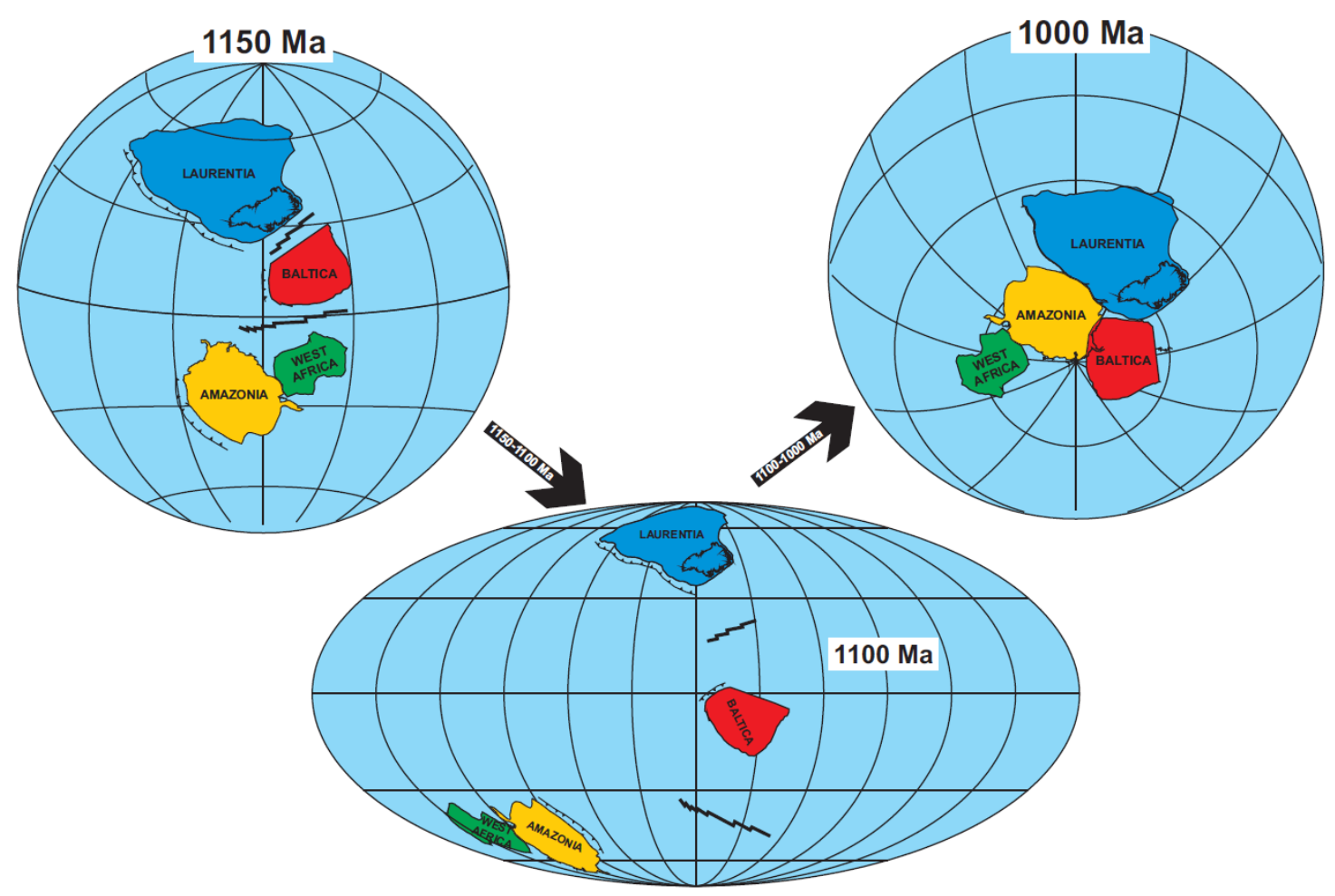

Figura 5.9. Reconstruções paleogeográficas para a Laurentia, Baltica e Cráton Amazônico/Oeste-África em $1150 \mathrm{Ma}, 1100 \mathrm{Ma}$ e $1000 \mathrm{Ma}$. As duas primeiras reconstruções foram feitas utilizando os polos da Tabela 5.1. A reconstrução há 1000 Ma foi feita utilizando os polos rotação apresentadas em Li et al. (2008). Utilizou-se o polo de Rincón del Tigre obtido após correção tectônica para posicionar o Cráton Amazônico/Oeste-África há 1100 Ma.

Neste caso, haveria uma maior separação entre o Cáton Amazônico e a Laurentia há 1100 Ma atrás. Note, entretanto, que se considerarmos uma separação de $90^{\circ}$ entre eles, e que cada grau da superfície da Terra corresponde a $111 \mathrm{~km}$, teríamos uma deriva média de 5 cm/ano para cada uma das um destes blocos continentais, o que pode ser razoável para épocas do Precambriano.

Outro fato que pode ser evidenciado é que nenhum dos dois polos determinados para Rincón del Tigre é compatível com o modelo de colisão oblíqua do Cráton Amazônico com a Laurentia seguida de movimento transcorrente, como proposto por Tohver et al. (2004b). 


\section{Capítulo 6}

\section{Conclusões}

Este trabalho apresenta o estudo paleomagnético realizado em 15 sítios no Complexo Máfico- ultramáfico Rincón del Tigre situado na região sudeste da Bolívia pertencente ao Cráton Amazônico. A análise petrográfica realizada para as amostras do Complexo mostram textura ígnea preservada (sugerindo uma mineralogía magnética primária), sendo classificados em quatro grupos litológicos: rochas ultramáficas, ortopiroxenito adcumulático, gabro noritos e serpentinitos.

Os resultados obtidos a partir da ASM indicam, para parte das amostras analisadas, trama magnética aproximadamente horizontal coerente com a colocação de sills. A lineação magnética (representada pelo eixo k1) de direção NW-SE indica que estas rochas foram influenciadas pela tectônica de deformação de direção NE-SW que as a afetou durante a orogênese Sunsás, a qual produziu uma lineação tectônica (representada pelos eixos de dobra) com a mesma direção NW-SE.

As curvas termomagnéticas mostram pico de Hopkinson bem acentuado, queda da suscetibilidade magnética próximo de $580^{\circ} \mathrm{C}$ e transição de Verwey em torno de $-153{ }^{\circ} \mathrm{C}$ para a maioria das amostras, o que indica a presença de magnetita (Dunlop \& Özdemir, 1997) como principal portador magnético destas rochas. A presença deste mineral é corroborada pelas curvas de indução magnética (MRI), pelas curvas de intensidades relativas, durante os tratamentos por campos magnéticos alternados e térmico e pelas curvas de histerese, as quais sugerem misturas de grãos de magnetita SD/MD para a maioria das amostras.

As desmagntizações por campos alternados e térmico foram eficientes para separar as componentes de magnetização das amostras, sendo possível isolar uma componente comum para boa parte dos espécimes de cada sítio analisado, embora a mesma coerência não seja observada quando calculadas as direções médias por sítio. Ainda assim, alguns sítios mostram direções noroeste (sudeste) com inclinações positivas (negativas) e outros sítios, direções leste (oeste) com inclinações baixas. 
Após a correção tectônica pode-se agrupar os sítios OL3, OL4, OL7, OL8, OL9, OL11 e OL12, cuja direção média $\mathrm{Dm}=327,9^{\circ}, \mathrm{Im}=53,5^{\circ}\left(\alpha_{95}=13,1, \mathrm{~K}=22,6, \mathrm{~N}=7\right)$ forneceu o polo paleomagnético situado em $271,7^{\circ} \mathrm{E}, 28,6^{\circ} \mathrm{N}\left(\mathrm{A}_{95}=17,6\right)$. A comparação dos parâmetros estatísticos das direções médias calculadas antes e depois da correção tectônica (vide Tabela 5.1) indica um teste de dobra positivo para este grupo de sítios.

Supondo uma trama magnética horizontal (eixo k3=90) para o complexo Rincón del Tigre, o qual é composto por sills acamadados, as direções médias dos eixos k3 obtidos para cada sítio foram utilizadas para corrigir as direções de magnetização para a situação de trama horizontal. O melhor grupo de direções após esta correção foi obtido para os sítios OL1, OL3, OL4, OL10, OL11, OL13, OL14 e OL15. Foi calculada a direção média $\mathrm{Dm}=118,6^{\circ}$, $20,7^{\circ}\left(\alpha_{95}=16,5, K=12,2, N=8\right)$, a qual forneceu o polo paleomagnético situado em $28,5^{\circ} \mathrm{E}$, $30,0^{\circ} \mathrm{S}\left(\mathrm{A}_{95}=12,8\right)$. Novamente aqui, os parâmetros estatísticos foram significativamente melhorados após a correção de ASM (vide Tabela 5.2).

Nenhum dos dois polos paleomagnéticos calculados para o Complexo Rincón del Tigre apóia o modelo proposto por Tohver et al. (2004a) de colisão obliqua do Cráton Amazônico com a Larentia (ao londo da região do Texas - Cinturão Lahano) há 1200 Ma atrás e posterior movimento transcorrente do Cráton Amazônico até a sua posição final na região de Ontario e Nova York, quando este se choca com a Baltica. Por outro lado, foi possível construir configuarações paleogeográficas que apoiam o modelo proposto por Evans (2013), o qual supõe que após a ruptura do supercontinente Columbia, por volta de 1270 Ma atrás, a Baltica e o Cráton Amazônico/Oeste-África executam um movimento de rotação horária até chocarem-se novamente com a Laurentia ao longo do cinturão Grenville (vide Figuras 5.8 e 5.9).

Embora, qualquer um dos polos determinados acima possa representar uma direção primária e, assim, a paleogeografia do Cráton Amazônico há 1100 Ma atrás, espera-se por novos dados paleomagnéticos desta idade que apoiem um dos modelos propostos neste trabalho. 


\section{Referências Bibliográficas}

Bettencourt, J.S., Leite, Jr. W., Payolla, B., Ruiz, A.S., Matos, R.S., Tosdal, R.M., 2010. The Rondonian-San Ignacio Province in the SW Amazonian Craton: an overview. Journal of South American Earth Sciences 29, 28-46.

Bispo-Santos, F., 2012. Estudo paleomagnético de unidades Paleoproterozoicas do Cráton Amazônico. Tese de Doutorado, IAG-USP, Departamento de Geofísica, São Paulo, SP, $253 p$.

Bispo-Santos, F., D’Agrella-Filho, M.S., Trindade, R.I.F., Janikian, L., Reis, N.J., 2014a. Was there SAMBA in Columbia? Paleomagnetic evidence from 1790 Ma Avanavero mafic sills (Northern Amazonian craton). Precambrian Research 244, 139-155. doi:10.1016/j.precamres. 2013.11.002

Bispo-Santos F., D’Agrella-Filho, M.S., Janikian, L., Reis, N.J., Reis, M.A.A.A., Trindade, R.I.F., 2014b. Towards Columbia: Paleomagnetism of 1980-1960 Ma Surumu volcanic rocks, Northern Amazonian Craton. Precambrian Research 244, 123-138. doi:10.1016/j.precamres.2013.08.005

Boger, S.D., Raetz, M., Giles, D., Etchart, E., Fanning, C.M., 2005. U-Pb age data from Sunsas region of Eastern Bolivia, evidence for the allochthonous origin of the Paragua Block. Precambrian Research 139, 121-146.

Borradaile G.J., 1988 Magnetic susceptibility, petrofabrics and strain. Tectonophysics 156:1-20

Buchan, K.L, Halls, H.C., 1990. Paleomagnetism of Proterozoic mafic dyke swarms of the Canadian Shiled. In: Parker, A.J., Rickwood, P.C., Tucker, D.H. Mafic Dykes and Emplacement Mechanism. A.A. Balkema, Rotterdam, pp. 209-23.

Buchan, K. L, Ernst, R. E., Hamilton, M. A., Mertanen, S., Pesonen, L. J., Elming, S. Å., 2001.Rodinia: the evidence from integrated palaeomagnetism and $\mathrm{U}-\mathrm{Pb}$ geochronology.Precambrian Research, 110, 9-32. 
Buchan, K.L., Mertanen, S., Park, R.G., Pesonen, L.J., Elming, S.-A., Abrahamsen, N., Bylund, G., 2000. Comparing the drift of Laurentia and Baltica in the Proterozoic: the importance of key palaeomagnetic poles. Tectonophysics 319, 167-198.

Butler, R. B., 1992. Paleomagnetism: Magnetic Domains to Geologic Terranes, 1992. http://geography.lancs.ac.uk/cemp/resources/Butler_book/contents.htm

Carvallo, C., Özdemir, Ö. Dunlop, D., 2004. Palaeointensity determinations, palaeodirections and magnetic properties of basalts from the Emperor seamounts. Geophysical Journal International, 156, 29-38.

Cordani, U.G., Teixeira, W., 2007. Proterozoic accretionary belts in the Amazonian Craton. Geological Society of America Mem 200, 297-320.

Cordani, U.G., Teixeira, W., D’Agrella-Filho, M.S., Trindade, R.I.F., 2009. The position of the Amazonian Craton in Supercontinents. Gondwana Research 15, 396-407. Doi: 10.1016/j.gr.2008.12.005

Cordani, U.G., Fraga. L.M., Reis, N., Tassinari, C.C.G., Brito-Neves, B.B., 2010. On the origin and tectonic significance of the intra-plate events of Grenvillian-type age in South America: A discussion. Journal of South American Earth Sciences 29, 143-159.

D’Agrella-Filho, M.S., 1984. Estudo paleomagnético dos Grupos Itajaí, Castro, Camaquã e Bom Jardim, Dissertação de Mestrado, IAG, Departamento de Geofísica, 1984, São Paulo, SP, 164 p.

D'Agrella Filho, M.S., Trindade, R.I.F., Siqueira, R., Ponte-Neto, C.F., Pacca, I.I.G., 1998. Paleomagnetic constraints on the Rodinia supercontinent: Implications for its Neoproterozoic break-up and the formation of Gondwana. International Geolology Review 40, 171-188.

D’Agrella-Filho, M.S., Tohver, E., Santos, J.O.S., Elming, S.-Á., Trindade, R.I.F., Pacca, I.G., Geraldes, M.C., 2008. Direct dating of paleomagnetic results from Precambrian sediments in the Amazon craton: Evidence for Grenvillian emplacement of exotic crust in SE Appalachians of North America. Earth and Planetary Science Letters 267, 188199. doi:10.1016/j.eps1.2007.11.030 
D’Agrella-Filho, M.S., Trindade, R.I.F., Elming, S.-Á., Teixeira, W., Yokoyama, E., Tohver, E., Geraldes, M.C., Pacca, I.I.G., Barros, M.A.S., Ruiz, A.S., 2012. The 1420 Ma Indiavaí Mafic Intrusion (SW Amazonian Craton): Paleomagnetic results and implications for the Columbia supercontinent. Gondwana Research 22, 956-973. doi:10.1016/j.gr.2012.02.022

Dalziel, I.W,D., Mosher, S., Gahagan, L.M., 2000. Laurentia-Kalahari collision and the assembly of Rodinia. Journal of Geology 108, 499-513.

David J. Dunlop, D.J., Özdemir, Ö., 1997. Rock Magnetism, Fundamentals and Frontiers, Cambridge University Press, 1997, 573 p.

Davis, D.W., Sutcliffe, R.H., 1985. U-Pb ages from the Nipigon plate and northern Lake Superior. Geolological Society of American Bulletin 96, 1572-1579.

Day, R., Fuller, M., Schmidt, V.A., 1977. Hysteresis properties of titanomagnetites: grainsize and compositional dependence. Physics of the Earth Planetary Interior 13, 260-267.

Dunlop, D.J., 2002a. Theory and application of the Day plot (Mrs/Ms versus Hcr/Hc) 1. Theoretical curves and tests using titanomagnetite data. Journal of Geophysical Research 107, B3, 10.1029/2001JB000486, 4-1 - 4-22.

Dunlop, D.J., 2002b. Theory and application of the Day plat (Mrs/Ms versus $\mathrm{Hcr} / \mathrm{Hc}) 2$. Application to data for rocks, sediments, and soils. Journal of Geophysical Research 107, B3, 10.1029/2001JB000487, 5-1 - 5-15.

Elming, S.-Á., D’Agrella-Filho, M.S., Page, L.M., Tohver, E., Trindade, R.I.F., Pacca, I.I.G., Geraldes, M.C., Teixeira, W., 2009. A palaeomagnetic and ${ }^{40} \mathrm{Ar} /{ }^{39} \mathrm{Ar}$ study of Late Precambrian sills in the SW part of the Amazonian Craton: Amazonia in the Rodinia reconstruction. Geophysical Journal International 178, 106-122. doi:10.1111/j.1365-246X.2009.04149.x

Ernst, R.E., Buchan, K.L., 1993. Paleomagnetism of the Abitibi dyke swarm, southern Superior Province and implications for the Logan Loop. Canadian Journal of Earth Sciences 30, 1886-1897.

Evans, D.A.D., 2013. Reconstructing pre-Pangean supercontinents. Geological Society of American Bulletin 125, 1735-1751. doi:10.1130/B30950.1 
Evans, D.A.D., Mitchell, R.N., 2011. Assembly and breakup of the core of Paleoproterozoic-Mesoproterozoic supercontinent Nuna. Geology 39, 443-446. doi:10.1130/G31654

Evans, D.A.D., Pisarevsky, S.A., 2008. Plate tectonics on early Earth? Weighing the paleomagnetic evidence. The Geological Society of America, Special Paper 440, 249263.

Fahrig, W.F., Christie, K.W., Jones, D.L., 1981. Paleomagnetism of the Bylot basins: evidence for MacKenzie continental tensional tectonics. Geological Survey of Canada Pap 81-10, 303-312.

Fisher, R.A., 1953. Dispersion on a sphere. Proccedings of the Royal Society of London 217, 295-305.

Font, E. 2005.: Paleomagnetismo e geoquímica do cap carbonatos do craton Amazônico: implicações para as glaciações do Neoproterozoico. Tese de Doutorado, IAG-USP, Departamento de Geofísica, São Paulo, SP, 2005.

Halls, H.C., Pesonen, L.J., 1982. Paleomagnetism of Keweenawan rocks. Geological Society of America Mem 156, 173-201.

Hoffman, P.F., 1991. Did the breakout of Laurentia turn Gondwanaland inside-out? Science 252, 1409-1412.

Hou, G., Santosh, M., Qian, X., Lister, G.S., Li, J. 2008a. Configuration of the Late Paleoproterozoic supercontinent Columbia: Insights from radiating mafic dyke swarms. Gondwana Research 14, 395-409.

Hou, G., Santosh, M., Qian, X., Lister, G.S., Li, J., 2008b. Tectonic constraints on 1.3 1.2 Ga final breakup of Columbia supercontinent from a giant radiating dyke swarm. Gondwana Research 14, 561-566.

Hrouda, F., 1982. Magnetic anisotropy of rocks and its applications in geology and geophysics. Geophysical Survey, 5, 37-82.

Ibanez-Mejia, M., Ruiz, J., Valencia, V.A., Cardona, A., Gehrels, G.E., Mora, A.R., 2011. The Putumayo Orogen of Amazonia and its implications for Rodinia reconstructions : 
New U-Pb geochronological insights into the Proterozoic tectonic evolution of northwestern South America. Precambrian Research 191, 58-77.

Irving, E., Naldrett, A.J., 1977. Paleomagnetism in Abitibi greenstone belt, and Abitibi and Matachewan diabase dykes: evidence of the Archean geomagnetic field. Journal of Geology 85, 157-176.

Jelinek, V., 1981. Characterization of the magnetic fabric of rocks. Tectonophysics, 79, T63-T67.

Johansson, А. 2009. Baltica, Amazonia and the SAMBA connection-1000 million years of neighbourhood during the Proterozoic? Precambrian Research 175, 221-234. doi:10.1016/j.precamres.2009.09.011

Johansson, Å., 2014. From Rodinia to Gondwana with the 'SAMBA' model - a distant view from Baltica towards Amazonia and beyond. Precambrian Research 244, 226-235.

Kirschvink, J. L., 1980. The least-squares line and plane and the analysis of palaeomagnetic data. Geophysical Journal of the Royal Astronomical Society 62, 699-718.

Lacerda-Filho, J.V., Abreu Filho, W., Valente, C.R., Oliveira, C.C., Albuquerque, M.C., 2004. Geologia e Recursos Minerais do Estado do Mato Grosso. Texto explicativo dos mapas geológico e de recursos minerais do Estado do Mato Grosso, Escala 1:1.000.000, Convênio CPRM e SICME-MT, p 235

Lanza, R., Meloni, A., 2006. The Earth's Magnetism: An Introduction for Geologists. Springer-Verlag, Berlin, 278 pp.

Li, Z.X., Bogdanova, S.V., Collins, A.S., Davidson, A., De Waele, B., Ernst, R.E., Fitzsimons, I.C.W., Fuck, R.A., Gladkochub, D.P., Jacobs, J., Karlstrom, K.E., Lu, S., Natapov, L.M., Pease, V., Pisarevsky, S.A., Thrane, K., Vernikovsky, V., 2008. Assembly, configuration, and break-up history of Rodinia: A synthesis. Precambrian Research 160, 179-210.

Lima, G.A., Souza, M.Z.A., Ruiz, A.S., D’Agrella-Filho, M.S., Vasconcelos, P., 2012. Sills máficos da Suíte Intrusiva Huanchaca - SW do Cráton AmazÔnico: registro de magmatismo fissural relacionado à ruptura do Supercontinente Rodinia. Revista Brasileira de Geologia 42(1), 111-129. 
Litherland, M., Annells, R.N., Appleton, J.D., Berrangé, J.P., Bloomfield, K., Burton, C.C.J., Darbyshire, D.P.F., Fletcher, C.J.N., Hawkins, M.P., Klinck, B.A., Llanos, A., Mitchell, W.I., O’Conner, E.A., Pitfield, P.E.J., Power, G., Webb, B.C., 1986. The geology and mineral resources of the Bolivian precambrian Shield, 9.British Geological Survey, Overseas Memoir, p. 153.

Litherland, M., Annells, R.N., Darbyshire, D.P.F., Fletcher, C.J.N., Hawkins, M.P., Klinck, B.A., Mitchell, W.I., O’Connor, E.A., Pitfield, P.E.J., Power, G., Webb, B.C., 1989. The Proterozoic of Eastern Bolivia and its relationship to the Andean mobile belt. Precambrian Research 43, 157-174.

Lowrie, W., 1997. Fundamentals of Geophysics, Cambridge University Press, 1997, 354 p.

McElhinny, M. W., 1973. Palaeomagnetism and Plate Tectonics, Cambridge University Press.

Luft, J.L., Rizzotto, G., Chemale Jr., F., Lima, E.F., 2000. Análise geológico-estrutural do Cinturão Sunsás na região de Brasilândia-Sudeste de Rondônia. Pesquisas em Geociências 27, 65-78.

McMenamim, M.A.S., McMenamim, D.L.S., 1990. The emergence of Animals: The Cambrian breakthrough. Columbia University Press, New York, p 217.

Meert, J.G., Torsvik, T.H., 2003. The making and unmaking of a supercontinent: Rodinia revisited. Tectonophysics 375, 261-288.

Mertanen, S., Pesonen, L.J., 2012. Paleo-Mesoproterozoic assemblages of contnents: Paleomagnetic evidence for near equatorial supercontinents. In: Haapala, I. (ed.) From the Earth's Core to Outer Space, Lecture Notes in Earth System Sciences 137, 11-35. Doi: 10.1007/978-3-642-25550-2_2.

Nomade, S., Chen, Y., Pouclet, A., Féraud, G., Théveniaut, H., Daouda, B.Y., Vidal, M., Rigolet, C., 2003. The Guiana and West African Shield Palaeoproterozoic grouping: new palaeomagnetic data for French Guiana and Ivory Coast. Geophysical Journal International 154, 677-694.

Nye, J. F., 1957. Physical Poperties of Crystals, Clarendon Press, Oxford, 322p. 
Nye, J. F., 1985 Physical Properties of Crystals, $2^{\text {nd }}$ edition, Clarendon Press, Oxford, 329 p.

Onstott, T.C., Hargraves, R.B., 1981. Proterozoic transcurrent tectonics: palaeomagnetic evidence from Venezuela and Africa. Nature 289, 131-136.

Pesonen, L.J., Elming, S-A., Mertanen, S., Pisarevsky, S., D’Agrella-Filho, M.S., Meert, J. G., Schmidt, P.W. Abrahamsen, N., Bylund, G., 2003. Palaeomagnetic configuration of continents during the Proterozoic. Tectonophysics, 375, 289-324.

Pesonen, L.J., Mertanen, S., Veikkolainen, T., 2012. Paleo-Mesoproterozoic Supercontinents - A paleomagnetic view. Geophysica 47, 5-47.

Prendergast, M.D., 2000. Layering and precious metals mineralization in the Rincón del Tigre Complex, eastern Bolivia. Economic Geology 95, 113-130.

Pinho, M.A.S.B., Chemale Jr, F., Van Schmus, W.R., Pinho, F.E.C., 2003. U-Pb and Sm-Nd evidence for 1.76-1.77 Ga magmatism in the Moriru region, Mato Grosso, Brazil: Implications for province boundaries in the SW Amazon Craton. Precambrian Research $126,1-25$.

Piper, J.D.A., 2010. Protopangea: Palaeomagnetic definition of Earth's oldest (midArchaean-Palaeoproterozoic) supercontinent. Journal of Geodynamics 50,154-165.

Pisarevsky, S.A., Bylund, G., 2010. Paleomagnetism of 1780-1770 Ma mafic and composite intrusions of Småland (Sweden): Implications for the Mesoproterozoic Supercontinent. American Journal of Science 310, 1168-1186. Doi:10.2475/09.2010.15

Pisarevsky, S.A., Wingate, M.T.D., Harris, L.B., 2003. Late Mesoproterozoic (ca 1.2 Ga) palaeomagnetism of the Albany-Fraser orogen: no pre-Rodinioa Australia-Laurentia connection. Geophysical Journal International 155, F6-F11

Reis, N.J., Teixeira, W., Hamilton, M.A., Bispo-Santos, F., Almeida, M.E., D’Agrella-Filho, M.S. 2013. The Avanavero mafic magmatism, a late Paleoproterozoic LIP in the Guiana Shield, Amazonian Craton: U-Pb TIMS baddeleyite, geochemical and paleomagnetic evidence. Lithos 174, 175-195. doi:10.1016/j.lithos.2012.10.014 
Rizzotto, G.J., Hartmann, L.A., 2012. Geological and geochemical evolution of the Trincheira Complex, a Mesoproterozoic ophiolite in the southwestern Amazon craton, Brazil. Lithos 148, 277-295. doi:10.1016/j.lithos.2012.05.027

Rizzotto, G.J., Santos, J.O.S., Hartmann, L.A., Tohver, E., Pimentel, M.M., McNaughton, N.J., 2013. The Mesoproterozoic Guaporé suture in the SW Amazonian Craton: Geotectonic implications based on field geology, zircon geochronology and $\mathrm{Nd}-\mathrm{Sr}$ isotope geochemestry. Journal of South American Earth Sciences 48, 271-295.

Sadowski, G.R., Bettencourt, J.S., 1996. Neoproterozoic tectonic correlations between east Laurentia and the western border of the Amazon Craton. Precambrian Research 76, 213 227.

Salminen, J., Pesonen, L.J., 2007. Paleomagnetic and rock magnetic study of the Mesoproterozoic sill, Valaam island, Russian Karelia. Precambrian Research 159, 212-230.

Santos, J.O.S., Hartmann, L.A., Gaudette, H.E., Groves, D.I., McNaugthon, N.J., Fletcher, I.R., 2000. A new understanding of the Provinces of Amazon Craton based on integration of field mapping and U-Pb and Sm-Nd geochronology. Gondwana Research 3, 453-488.

Santos, J.O.S., Rizzotto, G.J., Potter, P.E., McNaughton, N.J., Matos, R.S., Hartmann, L.A., Chemale Jr, F., Quadros, M.E.S., 2008. Age and autochthonous evolution of the Sunsás Orogen in West Amazon Craton based on mapping and U-Pb geochronology. Precambrian Research 165, 120-152.

Schobbenhaus, C., Brito-Neves, B.B., 2003. A geologia do Brasil no Contexto da Plataforma Sul-Americana. In: Bizzi LA, Schobbenhaus C, Vidotti RM, Gonçalves JH (eds) Geologia, tectônica e recursos minerais do Brasil: texto, mapas \& SIG, Brasília, CPRM - Serviço Geológico do Brasil, p 692

Schobbenhaus, C., Campos, D.A., Derze, G.R., Asmus, H.E., 1984. Geologia do Brasil: Texto explicativo do Mapa Geológico do Brasil e da área oceânica adjacente incluindo depósitos minerais, escala 1:2.500.000. Brasilia, DNPM, p 501

Schobbenhaus, C., Gonçalves, J.H., Santos, J.O.S., Abram, M.B., Leão Neto, R., Matos, G.M.M., Vidotti, R.M., Ramos, M.A.B., Jesus, J.D.A., 2004. Carta Geológica do Brasil 
ao Milionésimo. Sistema de Informações Geográficas. Folhas Boa Vista (NA-20) e Roraima (NB-20). Escala 1:1,000,000. CPRM

Tarling, D.H., 1983. Paleomagnetism, Chapman \& Hall, London, 379 p.

Tarling, D. H., Hrouda, F., 1993. The Magnetic Anisotropy of Rocks, Chapman and Hall, London, 217p.

Tassinari, C.C.G., Macambira, M.J.B., 1999. Geochronological provinces of the Amazonian Craton. Episodes 22, 174-182.

Tassinari, C.C.G., Macambira, M.J.B., 2004. A evolução tectônica do Cráton Amazônico. In: Mantesso-Neto V, Bartorelli A, Dal Ré Carneiro C, Brito-Neves BB (eds) Geologia do Continente Sul-Americano: Evolução da obra de Fernando Flávio Marques de Almeida. São Paulo, Ed. Beca, pp 471-485

Tassinari, C.C.G., Bettencourt, J.S., Geraldes, M.C., Macambira, M.J.B., Lafon, J.M., 2000. The Amazonian Craton. In: Cordani UG, Milani EJ, Thomaz-Filho A, Campos DA (eds), Tectonic Evolution of South America. Rio de Janeiro, 31st International Geological Congress, pp 41-95

Tauxe, L., 2002. Paleomagnetic Principles and Practice, Kluwer Academic Publishers.

Tauxe, L., 2008. Essentials of Paleomagnetism. University of California Press. 509p.

Tauxe, L., 2009. Essentials of Paleomagnetism. University of California Press. 512p.

Teixeira, W., Geraldes, M.C., Matos, R., Ruiz, A.S., Saes, G., Vargas-Mattos, G., 2010. A review of the tectonic evolution of the Sunsas belt, SW portion of the Amazonian Craton. Journal of South American Earth Sciences 29, 47-60.

Teixeira, W., Ernst, E.E., Hamilton, M., Lima, G., Ruiz, A.S., Geraldes, M.C., 2015. Widespread ca. 1.4 Ga intraplate magmatism and tectonics in a growing Amazonia. GFF - Taylor \& Francis (in press).

Teixeira, W., Hamilton, M., Lima, G.A., Ruiz, A.S., Matos, R., Ernst, R.E., 2015. Precise ID-TIMS U-Pb baddeleyite ages (1110-1112 Ma) for the Rincón del Tigre-Huanchaca 
large igneous province (LIP) of the Amazonian Craton: Implications for the Rodinia supercontinent. Precambrian Research 265, 273-285.

Tohver, E., van der Pluijm, B., Van der Voo, R., Rizzotto, G., Scandolara, J.E., 2002. Paleogeography of the Amazon craton at $1.2 \mathrm{Ga}$ : early Grenvillian collision with the Llano segment of Laurentia. Earth and Planetary Science Letters 199, 185-200.

Tohver, E., Bettencourt, J.S., Tosdal, R., Mezger, K., Leite, W.B., Payolla, B.L., 2004b. Terrane transfer during the Grenville orogeny: tracing the Amazonian ancestry of southern Appalachian basement through $\mathrm{Pb}$ and $\mathrm{Nd}$ isotopes. Earth and Planetary Science Letters 228, 161-176.

Tohver, E., van der Pluijm, B., Mezger, K., Essene, E., Scandolara, J., 2004a. Significance of the Nova Brasilândia metasedimentary belt in western Brazil: redefining the Mesoproterozoic boundary of the Amazon Craton. Tectonics 23(6), TC6004, 1-20. doi:10.1029/2003TC001563

Tohver, E., van der Pluijm, B.A., Mezger, K., Scandolara, J.E., Essene, E.J., 2005a. Two stage tectonic history of the SW Amazon craton in the late Mesoproterozoic: identifying a cryptic suture zone. Precambrian Research 137, 35-59.

Tohver, E., van der Pluijm, B.A., Scandolara, J.E., Essene, E.J., 2005b. Late Mesoproterozoic deformation of SW Amazônia (Rondônia, Brazil): Geochronological and structural evidence for collision with southern Laurentia. Journal of Geology 113, 309-323.

Tohver, E., Teixeira, W., van der Pluijm, B., Geraldes, M.C., Bettencourt, J.S., Rizzotto, G., 2006. Restored transect across the exhumed Grenville orogen of Laurentia and Amazonia, with implications for crustal architecture. Geology 34(8), 669-672. doi:10.1130/G22534.1

Van der Voo, R., 1990. The reliability of paleomagnetic data. Tectonophysics 184, 1-9.

Weil, A.B., Van der Voo, R., Niocaill, C.M., Meert, J.G., 1998. The Proterozoic supercontinent Rodinia: paleomagnetically derived reconstructions for 1100 to $800 \mathrm{Ma}$. Earth and Planetary Science Letters 154, 13-24. 
Zhang, S., Li, Z.X., Evans, D.A.D., Wu, H., Li, H., Dong, J., 2012. Pre-Rodinia supercontinent NUNA shaping up: A global synthesis with new paleomagnetic results from North China. Earth and Planetary Science Letters 353-354, 145-155.

Zijderveld, J. D. A., 1967. A. C. Demagnetization of Rocks: Analysis of Results. In: Methods in Paleomagnetism; Collinson, D. W.; Creer, K. M. Runcorn, S. K. (Eds.), pg. 254-286. 